\author{
UNIVERSIDADE DE SÃO PAULO \\ FACULDADE DE MEDICINA DE RIBEIRÃO PRETO
}

Relação entre dimensões e pressão intraluminal da transição faringoesofágica no repouso e durante a fonação e a proficiência da voz e da fala traqueoesofágica. 


\section{TELMA KIOKO TAKESHITA}

Relação entre dimensões e pressão intraluminal da transição faringoesofágica no repouso e durante a fonação e a proficiência da voz e da fala traqueoesofágica.

Dissertação apresentada a Faculdade de Medicina de Ribeirão Preto da Universidade de São Paulo para obtenção do título de Mestre em Ciências Médicas.

Área de Concentração: Morfofisiologia de estruturas faciais

Orientador: Profa. Dra. Lílian Neto Aguiar Ricz

Ribeirão Preto

2010 
Autorizo a reprodução e divulgação total ou parcial deste trabalho, por qualquer meio convencional ou eletrônico, para fins de estudo e pesquisa, desde que citada a fonte.

\section{FICHA CATALOGRÁFICA}

Takeshita, Telma Kioko

Relação entre dimensões e pressão intraluminal da transição faringoesofágica e a proficiência da voz e da fala traqueoesofágica.

Ribeirão Preto, 2010.

168p. : il. ; $30 \mathrm{~cm}$

Dissertação de Mestrado, apresentada à Faculdade de Medicina de Ribeirão Preto/USP. Área de concentração: Morfofisiologia de estruturas faciais.

Orientador: Aguiar-Ricz, Lílian Neto.

1. Fala alaríngea; 2. Fluoroscopia; 3. Manometria; 4. Prótese de voz 
TAKESHITA, T. K. Relação entre dimensões e pressão intraluminal da transição faringoesofágica no repouso e durante a fonação e a proficiência da voz e da fala traqueoesofágica. Dissertação apresentada à Faculdade de Medicina de Ribeirão Preto da Universidade de São Paulo para obtenção do título de Mestre em Ciências Médicas.

Aprovado em:

\section{Banca Examinadora}

Prof. Dr. Instituição:

Julgamento: Assinatura:

Prof. Dr. Instituição:

Julgamento: Assinatura:

Prof. Dr. Instituição:

Julgamento: Assinatura: 


\section{DEDICATÓRIA}

A Deus por tudo que sou hoje, pelo seu amor incondicional, proteção e guia constante em minha vida. A Nossa Senhora pelo seu amor e proteção divina.

Aos meus queridos pais, Koiti e Miyuko, pelo imensurável exemplo de amor, luta, compreensão e dedicação exclusiva à vida de seus quatro filhos, abdicando-se de suas vontades, desafiando e extrapolando os limites mais difíceis para concretização dos sonhos de seus filhos. Este trabalho é nosso e é um dos sonhos realizado que o papai e a mamãe me proporcionaram.

Aos meus queridos irmãos, Marcel, Fabiana e Daniela, pela união, apoio, compreensão e amor incondicional. Vocês foram essenciais para a concretização deste trabalho.

Ao meu amor, Fabricio, por todo o seu carinho, dedicação e atenção, que em todos os momentos esteve presente ao meu lado, proporcionando-me calma, segurança e motivação. Você é muito especial para mim. 


\section{AGRADECIMENTOS}

A Deus e a Nossa Senhora por estarem sempre comigo em todos os momentos da minha vida.

Aos meus queridos pais, Koiti e Miyuko, por todo amor, apoio e compreensão. Reconheço e admiro todo o esforço que fazem pelos seus filhos. Muito obrigada! Amo muito vocês!

Aos meus queridos irmãos, Marcel, Fabiana e Daniela por todo carinho, incentivo e compreensão por muitas vezes eu não conseguir estar presente em nosso lar junto a nossa família. Vocês são muito importantes para mim!

Ao meu amor, Fabricio, por ser meu companheiro de todas as horas, de me apoiar em minhas decisões, mesmo exausto após as atividades da residência ainda se dedica com carinho ao esclarecimento de minhas dúvidas. Amo muito você!

Aos meus tios e tias, Sueo, Jiro, Yoriko e Keiko, por todo carinho e incentivo aos meus estudos.

A minha cunhada-irmã Joseane pela acolhida, motivação e grande amizade.

Ao meu grande amigo Diego, por toda consideração, gentileza e disposição. Sou feliz por ter a sua amizade.

Aos meus futuros sogros, Sr. Francisco e Sra. Shirlei, pelo carinho, incentivo e compreensão. Aos meus futuros cunhados Henrique, Filipe e Ana Paula pelo apoio e grande amizade.

Aos meus queridos e grandes amigos, Nunes e Juliana, pela torcida e momentos de alegrias e descontração proporcionados a mim. 
À querida Profa. Dra. Lílian Neto Aguiar Ricz pela oportunidade ímpar em vivenciar o aprendizado científico ao seu lado desde a graduação. A cada dia, aprendo algo novo com você, como pessoa e docente. Agradeço enormemente pela confiança e pelos precisos ensinamentos. Muito obrigada por tudo que fez e faz por mim.

Ao Prof. Dr. Hilton Marcos Alves Ricz pelo aprendizado na área de cirurgia de cabeça e pescoço, dedicação e ensinamentos valiosos ao que tange o projeto de pesquisa.

Ao Prof. Dr. Roberto de Oliveira Dantas pelo aprendizado e oportunidade privilegiada de vivenciar a pesquisa ao seu lado.

À Profa. Dra. Wilma Terezinha Anselmo de Lima pelo incentivo e aprendizado contínuo dentro da pós-graduação. Agradeço pelo voto de confiança em mim depositado.

À Profa. Dra. Myriam de Lima Isaac pelo carinho, apoio e ensinamentos que foram essenciais para a minha formação. Aprendi e continuo aprendendo muito com você.

Ao Prof. Dr. Paulo Mazzoncini Marques pela oportunidade em trabalhar junto a sua equipe para o desenvolvimento deste trabalho.

À Profa. Dra. Cláudia Maria de Felício pelos ensinamentos referentes ao desenvolvimento de pesquisa científica.

À Profa. Dra. Luciana Vitaliano Vói Trawitzki pelo aprendizado, incentivo e atenção dedicada.

Ao Prof. Dr. Rui Mamede pelos valiosos ensinamentos acadêmicos e científicos. 
Ao Prof. Dr. Edson Martinez pelos ensinamentos na área da estatística que foram cruciais para o entendimento e discussão dos resultados deste trabalho.

Ao corpo docente do Curso de Fonoaudiologia da FMRP-USP pela admirada dedicação ao ensino, assistência e pesquisa, pelo meu aprendizado e formação enquanto fonoaudióloga.

À Profa. Dra. Elisabeth Carrara de Angelis pela imensa e valiosa contribuição intelectual a nossa Fonoaudiologia.

À Profa. Dra. Ingrid Gielow pelos incessantes e importantes estudos na área fonoaudiológica.

Aos pacientes que gentilmente se disponibilizaram em participar voluntariamente desta pesquisa.

À fonoaudióloga Adriana Pereira Defina-lqueda pela imensa contribuição no meu aprendizado, paciência e disposição em me ajudar no que precisei durante 0 desenvolvimento deste trabalho.

À fonoaudióloga Ariane Damasceno Pellicani pela amizade e grande consideração que tem por mim. Obrigada pelo apoio e disposição em me ajudar na concretização deste trabalho.

À fonoaudióloga Fernanda Maria de Oliveira e à psicóloga Christiane Sá pelo aprendizado, apoio e amizade.

À fonoaudióloga Nathália dos Reis pela amizade, carinho e consideração.

À equipe do CEMEQ - FMRP-USP, especialmente ao Henrique Ceretta Zozolotto pela compreensão, paciência e disposição em analisar cuidadosamente os dados deste trabalho. 
Aos já graduados do Curso de Informática Biomédica da FMRP-USP, Eduardo Alvarez e Juliano Jinzenji Duque e ao graduando Márcio Dantas pela paciência, disposição e dedicação em elaborar o instrumento de medição deste trabalho.

As fonoaudiólogas Ane Beatto, Liciane Valarelli e Taís Helena Grechi pela amizade, apoio e compreensão. As fonoaudiólogas Danielle Domenis e Paula Issa Okubo pelo apoio e aprendizado.

À Profa. Dra. Yuka Almeida Prado e à professora de canto Fernanda Onofre pelo apoio a minha pesquisa e pela disposição em colaborar no que precisei.

As fonoaudiólogas e grandes amigas Regiane Helena de Mendonça, Michele Toso e Patrícia Guedes Ribeiro pelo apoio, torcida e orações para a concretização deste trabalho.

As fonoaudiólogas e companheiras de pós-graduação pela amizade e aprendizado conjunto.

Aos amigos Yris e Fabrício, José Gabriel, Danilo, Leonardo, Rafael, Francisco e João pela consideração e grande amizade.

Ao setor de Fonoaudiologia do HCFMRP-USP pelo apoio e amizade. Às queridas secretárias desse setor, Juliana Reche e Sandra, e do Ambulatório de Cirurgia de cabeça e Pescoço, Lílian, pela atenção e disposição em me ajudar no que precisei.

Aos secretários do Departamento de Oftalmologia, Otorrinolaringologia e Cirurgia de Cabeça e Pescoço: Edson, Rogério, Rita, Amélia e especialmente a Cecília Onofre pela paciência, dedicação e surpreendente resolução dos problemas dos alunos.

À equipe de enfermagem do Ambulatório de Cirurgia de Cabeça e Pescoço: Sônia Miranda, Sônia Buozzi, Eliane, Patrícia e Luís pela atenção e assistência oferecidas quando necessárias. Aos residentes Rostan, Paulo, Ludovico, Januário, João Paulo e Fernanda pela gentileza e paciência. 
Á equipe técnica do Centro de Diagnóstico por Imagem do HCFMRP-USP pela gentileza e atenção oferecidas à realização dos exames de videofluoroscopia.

À equipe de enfermagem da Divisão de Gastroenterologia do HCFMRP - USP: Anália, Bete (in memorian) e Sônia pela cuidadosa assistência dedicada à realização dos exames manométricos. A secretária Lílian pela disposição na organização dos exames.

Ao corpo técnico do Departamento de Oftalmologia, Otorrinolaringologia e Cirurgia de Cabeça e Pescoço: Deny, Agnes, Diego, Adriana e Maria pela paciência e dedicação a análise e edição de imagens e coleta de dados. À querida Maria Helena de Andrade (Lenucha) pelo apoio, consideração e grande amizade.

À inesquecível I Turma de Fonoaudiologia da FMRP-USP pelo companheirismo e momentos maravilhosos vivenciados junto a esse grupo.

Ao Serviço de Arquivo Médico HCFMRP-USP, especialmente à Eliana, Vera e Cristina pela gentileza quanto ao fornecimento de prontuários médico para análise.

À Coordenação de Aperfeiçoamento de Pessoal de Nível Superior (CAPES) e a Fundação de Amparo à Pesquisa do Estado de São Paulo (FAPESP) pelo apoio financeiro e incentivo aos jovens pesquisadores. 
"Aqueles que contam com o Senhor renovam suas forças, ele dá-Ihes asas de águia. Correm sem se cansar, vão para a frente sem se fatigar." Isaías, 40,31 
LISTA DE ABRE VIATURAS 


\section{LISTA DE ABREVIATURAS}

$\begin{array}{ll}{ }^{\circ} \mathrm{C} & \text { Grau Celsius } \\ \text { C } & \text { Vértebra cervical } \\ \text { CLy } & \text { centi-Gray } \\ \text { cm } & \text { Comprimento longitudinal da transição faringoesofágica } \\ \text { cmH20 } & \text { centímetro } \\ \text { dB } & \text { centímetro de água } \\ \text { DP } & \text { decibel } \\ \text { E } & \text { Desvio padrão } \\ \text { EGG } & \text { Experto } \\ \text { et al. } & \text { Eletroglotografia } \\ \text { FMRP-USP } & \text { e outros (abreviatura de "et alli") } \\ & \text { Faculdade de Medicina de Ribeirão Preto da Universidade de São } \\ \text { HCFMRP- } & \text { Hospital das Clínicas da Faculdade de Medicina de Ribeirão Preto } \\ \text { USP } & \text { da Universidade de São Paulo } \\ \text { HME } & \text { Heat and Moisture Exchanger } \\ \text { HRS } & \text { Harrison-Robillard- Schultz } \\ \text { Hz } & \text { Hertz } \\ \text { ICC } & \text { Índice de concordância intraclasse } \\ \text { LT } & \text { Laringectomia total } \\ \text { Máx } & \text { Máximo } \\ \text { Mínimo }\end{array}$




$\begin{array}{ll}\mathrm{mL} & \text { mililitro } \\ \mathrm{mm} & \text { milímetro } \\ \mathrm{mmHg} & \text { milímetro de mercúrio } \\ \mathrm{n} & \text { Número de indivíduos/número de imagens } \\ \mathrm{OVQ} & \text { Qualidade vocal global } \\ \text { PTE } & \text { Prótese traqueoesofágica } \\ \text { PTFE-PAF } & \text { Distância entre a proeminência da transição faringoesofágica e a } \\ & \text { parede anterior da faringe } \\ \text { PTFE-PPF } & \text { Distância entre a proeminência da transição faringoesofágica e a } \\ & \text { parede posterior da faringe } \\ \text { QVV } & \text { Qualidade de vida e voz } \\ \mathrm{S} & \text { segundo } \\ \text { TFE } & \text { Transição faringoesofágica } \\ \text { VHI } & \text { Voice Handcap Index }\end{array}$


LISTA DE FIGURAS

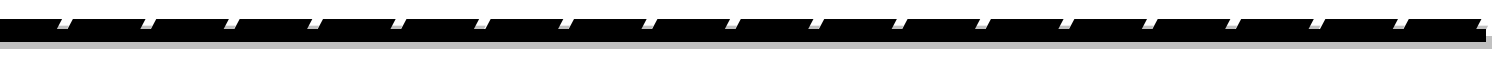




\section{LISTA DE FIGURAS}

Figura 1: Modelo do registro da extração da intensidade vocal e do ruído do ambiente no computador, pelo modo Real Time.................................90

Figura 2: Representação da amplitude da pressão intraluminal, da sua duração e da área sob a curva registrada pela onda de pressão

Figura 3: Representação manométrica do comportamento da TFE durante a fonação

Figura 4: Modelo do programa computadorizado Measures utilizado para medir as dimensões da TFE durante a fonação e repouso... 
LISTA DE TABELAS 


\section{LISTA DE TABELAS}

Tabela 1- Descrição geral da média, mínimo e máximo, e mediana, referente aos parâmetros quantitativos, pertencentes às habilidades fonatórias do protocolo de voz e da fala traqueoesofágica: tempo máximo de fonação (s), extensão dinâmica (dB) e intensidade vocal máxima (dB) 104

Tabela 2- Descrição dos parâmetros quantitativos (tempo máximo de fonação, extensão dinâmica e intensidade vocal máxima), pertencentes às habilidades fonatórias do protocolo de voz e de fala traqueoesofágica, segundo a sua categorização semântica (bom, moderado ou ruim).

Tabela 3- Descrição da média, mínimo e máximo, e mediana, referente aos parâmetros quantitativos, pertencentes às habilidades fonatórias do protocolo de voz e de fala traqueoesofágica: tempo máximo de fonação $(\mathrm{s})$, extensão dinâmica $(\mathrm{dB})$ e intensidade vocal máxima $(\mathrm{dB})$, segundo a sua categorização semântica (bom, moderado ou ruim)

Tabela 4- Descrição da média, desvio padrão, mínimo e máximo, e mediana, referente aos parâmetros quantitativos tempo máximo de fonação (s), extensão dinâmica $(\mathrm{dB})$ e intensidade vocal máxima $(\mathrm{dB})$, pertencentes às habilidades fonatórias do protocolo de avaliação da proficiência de voz e de fala traqueoesofágica, segundo o gênero dos laringectomizados totais falantes com PTE

Tabela 5- Descrição da média, desvio padrão, mínimo e máximo, e mediana, referente aos parâmetros quantitativos tempo máximo de fonação (segundos), extensão dinâmica (dB) e intensidade vocal máxima $(\mathrm{dB})$, pertencentes às habilidades fonatórias do protocolo de avaliação da proficiência de voz e de fala traqueoesofágica, segundo a realização ou não de tratamento complementar radioterápico em laringectomizados totais falantes com PTE

Tabela 6- Descrição geral do julgamento final e dos parâmetros qualitativos, pertencentes aos três aspectos globais (habilidades fonatórias, fatores adicionais e julgamento geral) do protocolo de voz e de fala traqueoesofágica, segundo a categorização semântica (bom, moderado ou ruim) avaliada pelos expertos

Tabela 7- Descrição, por gênero, do julgamento final da proficiência de voz e de fala traqueoesofágica, segundo a categorização semântica (bom, moderado ou ruim) avaliada pelos expertos

Tabela 8 - Descrição do julgamento final da proficiência de voz e de fala traqueoesofágica, segundo a categorização semântica (bom, 
moderado ou ruim) avaliada pelos expertos e considerando-se a realização ou não de tratamento complementar radioterápico pelos laringectomizados totais falantes com PTE

Tabela 9- Comparação da média, desvio padrão, mínimo e máximo, e mediana, referente às amplitudes de pressão intraluminal $(\mathrm{mmHg})$ obtidas na TFE, no repouso e durante a fonação, em laringectomizados totais falantes com PTE

Tabela 10- Descrição da média, desvio padrão, mínimo e máximo, e mediana, referente às amplitudes de pressão intraluminal $(\mathrm{mmHg})$ obtidas na TFE, no repouso e durante a fonação, segundo o gênero de laringectomizados totais falantes com PTE

Tabela 11- Descrição da média, desvio padrão, mínimo e máximo, e mediana, referente às amplitudes de pressão intraluminal $(\mathrm{mmHg})$ obtidas na TFE, no repouso e durante a fonação, segundo a realização de tratamento complementar radioterápico em laringectomizados totais falantes com PTE

Tabela 12- Descrição da média, desvio padrão, mínimo e máximo, e mediana, referente às dimensões PTFE-PAF, PTFE-PPF e CLTFE da TFE, em milímetro $(\mathrm{mm})$, no repouso e durante a fonação, segundo as análises dos três expertos

Tabela 13- Descrição, por gênero, da média, desvio padrão, mínimo e máximo, e mediana, referente às dimensões PTFE-PAF, PTFE-PPF e CLTFE da TFE, em milímetros $(\mathrm{mm})$, no repouso e durante a fonação, em laringectomizados totais falantes com PTE, segundo a avaliação dos expertos

Tabela 14- Descrição da média, desvio padrão, mínimo e máximo, e mediana, referente às dimensões PTFE-PAF, PTFE-PPF e CLTFE da TFE, em milímetros $(\mathrm{mm})$, no repouso $e$ durante a fonação, em laringectomizados totais falantes com PTE e submetidos ou não ao tratamento radioterápico complementar, segundo a avaliação dos expertos

Tabela 15- De acordo com a análise dos expertos e a amplitude de pressão intraluminal da TFE, no repouso e na fonação, coeficiente de correlação de Spearman para as dimensões (PTFE-PAF, PTFE-PPF e CLTFE)

Tabela 16- Descrição da média, desvio padrão, mínimo e máximo, e mediana, referente à amplitude de pressão intraluminal $(\mathrm{mmHg})$ da TFE, no repouso e na fonação, de acordo com a categorização semântica do parâmetro julgamento final da proficiência de voz e de fala traqueoesofágica 
Tabela 17- Descrição das dimensões PTFE-PAF, PTFE-PPF e CLTFE da TFE, em milímetros $(\mathrm{mm})$, no repouso e na fonação, de acordo com a caracterização do parâmetro julgamento final

Tabela 18- Principais coeficientes de correlação de Spearman para as dimensões e amplitude de pressão intraluminal da TFE durante o repouso e a fonação, segundo a avaliação dos expertos.

Tabela 19- Descrição das amplitudes de pressão $(\mathrm{mmHg})$ da TFE no repouso e durante a fonação, de acordo com o julgamento final da proficiência de voz e de fala traqueoesofágica

Tabela 20- Descrição das dimensões da TFE no repouso e durante a fonação, de acordo com o julgamento final da proficiência de voz e da fala traqueoesofágica 
LISTA DE QUADROS 


\section{LISTA DE QUADROS}

Quadro 1- Descrição adaptada dos parâmetros do protocolo Hilgers et al. (1997), segundo a categorização semântica em bom, moderado e ruim.

Quadro 2- Pontuação de Especialistas aplicado no modelo de Fehring (1994) e modificado por Jesus (2000). 
RESUMO

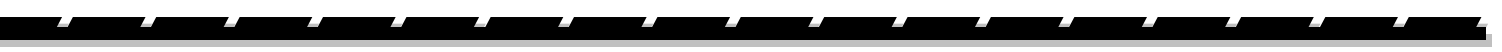




\section{RESUMO}

TAKESHITA, T. K. Relação entre dimensões e pressão intraluminal da transição faringoesofágica no repouso e durante a fonação e a proficiência da voz e da fala traqueoesofágica. 165f. [Dissertação]. Ribeirão Preto: Universidade de São Paulo, Faculdade de Medicina de Ribeirão Preto, 2010.

O propósito deste estudo foi relacionar as dimensões e a pressão intraluminal da transição faringoesofágica e a caracterização da proficiência de voz e de fala de laringectomizados totais com prótese traqueoesofágica. Participaram do estudo 20 laringectomizados totais com inserção secundária da prótese traqueoesofágica (Provox®), Atos Medical AB), sendo 17 homens e três mulheres, com idade média de 61 anos e sete meses, submetidos à laringectomia total clássica, com fechamento das camadas mucosa, submucosa e muscular para reconstrução da faringe. Todos os pacientes foram submetidos à coleta e registro do material de voz e de fala utilizando-se uma câmera de vídeo em sala silente. A avaliação da proficiência de voz e de fala foi realizada por quatro expertos, por meio de um protocolo de avaliação da comunicação traqueoesofágica. Em seguida, realizou-se a manometria esofágica para avaliação da pressão intraluminal da transição faringoesofágica no repouso e durante a emissão prolongada da vogal "a". Por fim, foi realizada a videofluoroscopia, sendo primeiramente orientado o paciente que deglutisse $20 \mathrm{ml}$ de sulfato de bário visando a identificação das estruturas anatômicas, para em seguida emitir por três vezes a vogal prolongada "a". Selecionaram-se dois quadros do exame videofluoroscópico, no repouso e durante a fonação, cujas dimensões foram avaliadas por três expertos, por meio de um programa computadorizado. Como resultados, $65 \%$ dos laringectomizados totais com prótese traqueoesofágica foram caracterizados como falantes moderados. Durante a fonação, a pressão intraluminal obtida foi de $38,1 \mathrm{mmHg}$, e de $13,83 \mathrm{mmHg}$ no repouso. Dimensões de PTFE-PAF e de PTFE-PPF foram respectivamente, $4,73 \mathrm{~mm}$ e $14,31 \mathrm{~mm}$ (repouso) e $5,22 \mathrm{~mm}$ e $18,56 \mathrm{~mm}$ (fonação). No repouso, CLTFE foi de 12,55mm e 10,46mm durante a fonação. Durante a fonação, houve correlação positiva entre PTFE-PAF e amplitude de pressão intraluminal $(0,41)$ da transição faringoesofágica. Correlações inversas foram constatadas entre CLTFE e amplitude de pressão $(-0,27)$ no repouso, e 
entre PTFE-PPF e amplitude de pressão, durante a fonação $(-0,24)$. No repouso, os bons falantes apresentaram valor de pressão de $13,1 \mathrm{mmHg}$, e durante a fonação de $25,5 \mathrm{mmHg}$. Quanto às dimensões da transição faringoesofágica, os bons falantes apresentaram maior PTFE-PAF $(5,39 \mathrm{~mm})$ e menor PTFE-PPF $(13,07 \mathrm{~mm})$ no repouso. Já na fonação, PTFE-PAF tornou-se menor $(3,86 \mathrm{~mm})$ e PTFE-PPF maior (24,3mm). CLTFE permaneceu com valor intermediário entre os moderados e ruins falantes com PTE no repouso $(16,31 \mathrm{~mm})$ e durante a fonação $(12,36 \mathrm{~mm})$. Concluiu-se que a proficiência de voz e de fala da maioria dos falantes traqueoesofágicos foi categorizada como moderada. As amplitudes de pressão e as dimensões PTFE-PPF e CLTFE da transição faringoesofágica apresentaram diferença significante, considerandose as condições de repouso e de fonação. Quando comparados aos falantes moderados e ruins, os bons falantes apresentaram valor intermediário de amplitude de pressão intraluminal na condição de repouso e menor valor durante a fonação; PTFE-PAF maior e PTFE-PPF menor, no repouso, e durante a fonação, a primeira dimensão tornou-se menor e a segunda maior. Apenas CLTFE se manteve com valores intermediários nas duas condições avaliadas para os bons falantes traqueoesofágicos.

Palavras-chave: fala alaríngea, fluoroscopia, manometria, prótese de voz 
ABSTRACT

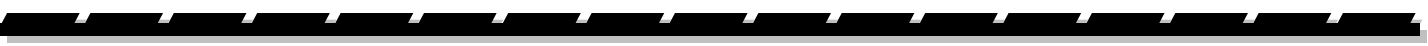




\begin{abstract}
TAKESHITA, T. K. Relation between dimensions and intraluminal pressure of pharyngoesophageal transition and vocal and speech tracheoesophageal proficiency in total laryngectomized subjects. $165 f$. 2010. Dissertação (Mestrado) - Faculdade de Medicina de Ribeirão Preto, Universidade de São Paulo, Ribeirão Preto, 2010.
\end{abstract}

The objective of this study was to relate the dimensions and the intraluminal pressure of the pharyngoesophageal transition and the voice and speech proficiency characterization of individuals with tracheoesophageal prosthesis. The participants of the study were 20 total laryngectomized people with secondary insertion of tracheoesophageal prosthesis (Provox®, Atos Medical $A B$ ), characterized by 17 men and three women, with average age of 61 years and seven months, submitted to classic total laryngectomy, with closing of layers mucous, submucous and muscular for reconstruction of pharynx. All the patients had been submitted to collection and register of the voice and speech material with the use of video camera in a silent room. The evaluation of the voice and speech proficiency was performed by four experts, by means of an evaluation protocol of the tracheoesophageal communication. After that, esophageal manometry was carried out to evaluate the intraluminal pressure of the pharyngoesophageal transition during the drawn out emission of the vowel "a" and during rest. Finally, the videofluoroscopy was performed. At first the patient was oriented to swallow $20 \mathrm{ml}$ of barium sulphate aiming the identification of the anatomical structures; afterwards the patient was oriented to emit three times the drawn out vowel "a". Two pictures of the videofluoroscopy examination during phonation and rest were selected, and their dimensions were evaluated by three experts by means of computer software. Such results, $65 \%$ of the total laryngectomized with tracheoesophageal prosthesis were characterized as moderate speakers. The intraluminal pressure obtained during the phonation was $38,1 \mathrm{mmHg}$, and $13,83 \mathrm{mmHg}$ during rest. PTFE-PAF and PTFE-PPF dimensions were respectively $4,73 \mathrm{~mm}$ and $14,31 \mathrm{~mm}$ (rest); and $5,22 \mathrm{~mm}$ and $18,56 \mathrm{~mm}$ (phonation). CLTFE was $12,55 \mathrm{~mm}$ during rest and $10,55 \mathrm{~mm}$ during phonation. During phonation, there was positive correlation between PTFE-PAF and the TFE intraluminal pressure amplitude $(0,41)$. Inverse correlations were evidenced between CLTFE and the pressure 
amplitude $(-0,27)$ during rest, and between PTFE-PPF and pressure amplitude during phonation $(-0,24)$. The good speakers presented pressure values of $13,1 \mathrm{mmHg}$ during rest and $25,5 \mathrm{mmHg}$ during phonation. Considering the pharyngoesophageal transition, good speakers presented a bigger PTFE-PAF $(5,39 \mathrm{~mm})$ and a smaller PTFE-PPF $(13,07 \mathrm{~mm})$ during rest, when compared to moderate and bad ones. However an opposite situation occurred during phonation, and PTFE-PAF was about $3,86 \mathrm{~mm}$ and PTFE-PPF about $24,3 \mathrm{~mm}$. CLTFE had an intermediate value during rest $(16,31 \mathrm{~mm})$ and during phonation $(12,36 \mathrm{~mm})$ among the moderate and bad speakers with tracheoesophageal prosthesis. A conclusion was that the voice and speech proficiency of majority of the tracheoesophageal speakers was characterized as moderate. The pressure amplitudes and the PTFE-PPF and CLTFE dimensions of pharyngoesophageal transition presented significant differences, when considering rest and phonation conditions. When compared to moderate and bad speakers with tracheoesophageal prosthesis, the good ones presented intermediate value of intraluminal pressure during rest and a smaller value during phonation. The good speakers presented a bigger PTFE-PAF and a smaller PTFE-PPF during rest, and a bigger PTFE-PPF and a smaller PTFEPPF during phonation, when compared to moderate and bad speakers. Only CLTFE had intermediate values during the two evaluated conditions for the good tracheoesophageal speakers.

Keywords: alaryngeal speech, fluoroscopy, manometry, voice prosthesis 


\section{SUMÁRIO}

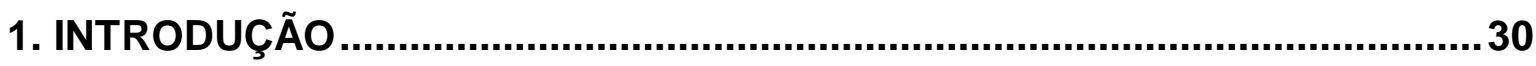

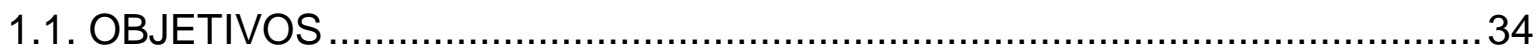

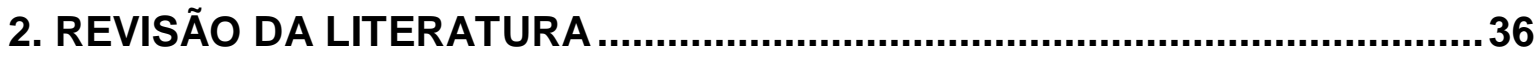

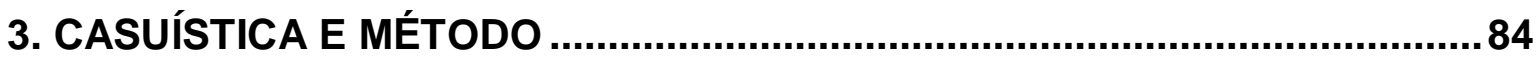

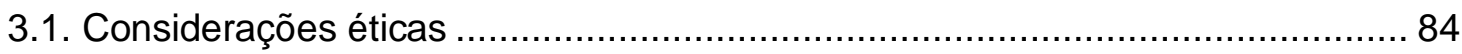

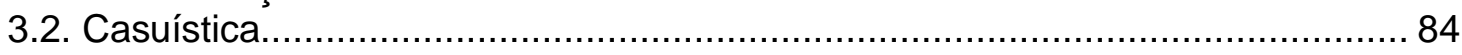

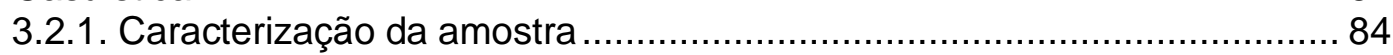

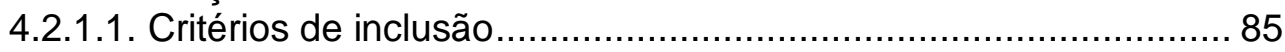

4.2.1.2. Critérios de exclusão........................................................ 85

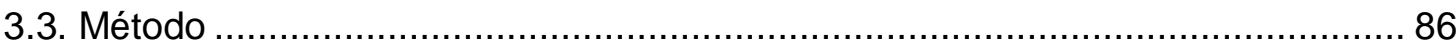

3.3.1. Proficiência de voz e fala traqueosofágica ......................................... 86

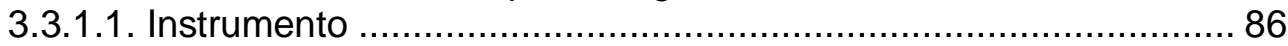

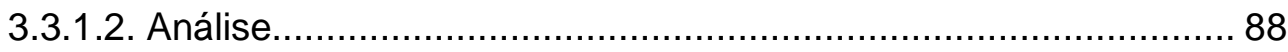

3.3.1.2.1. Seleção dos juizes........................................................... 88

3.3.1.3. Procedimento ............................................................... 89

3.3.1.3.1. Caracterização da proficiência de voz e de fala com PTE ........ 91

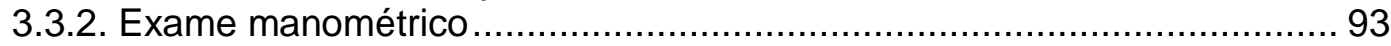

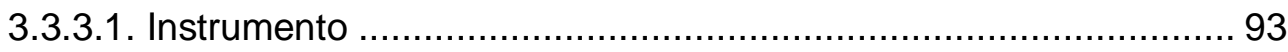

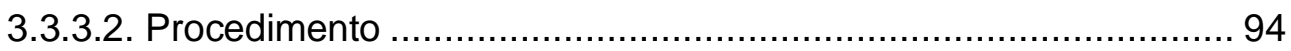

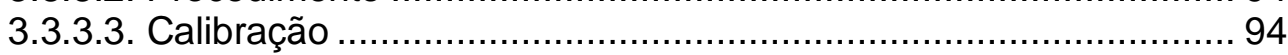

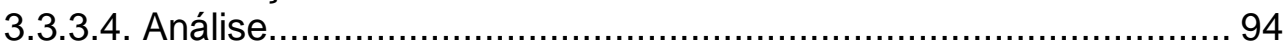

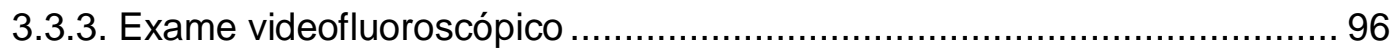

3.3.3.1. Instrumento ................................................................. 96

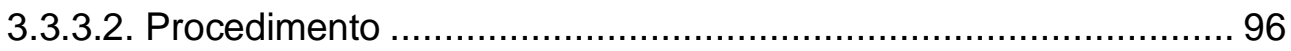

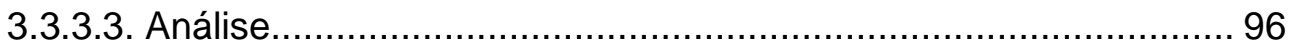

3.3.3.3.1. Instrumento e variáveis dimensionais ................................... 96

3.3.3.3.2. Mensuração das imagens................................................ 97

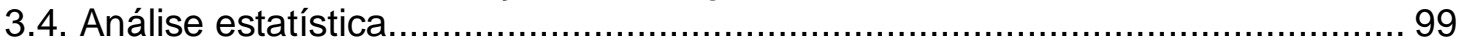

3.4.1. Proficiência da voz e da fala traqueoesofágica .................................... 99

3.4.2. Exame manométrico .................................................................. 100

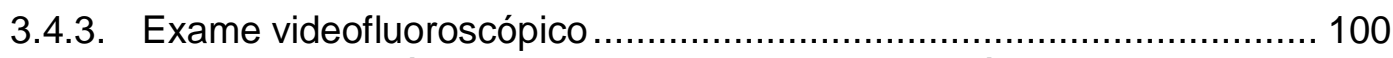

3.4.4. Exame manométrico versus exame videofluoroscópico........................ 101

3.4.5. Proficiência de voz e fala traqueoesofágica versus exame manométrico............................................................................ 101

3.4.6. Proficiência de voz e fala traqueoesofágica versus exame videofluoroscópico .................................................................. 101

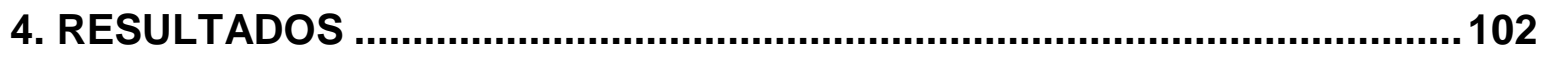

4.1. Proficiência da voz e da fala traqueoesofágica ........................................... 103

4.1.1. Parâmetros quantitativos do aspecto global habilidades fonatórias do protocolo de avaliação da proficiência de voz e de fala traqueoesofágica ........................................................................... 103

4.1.2. Parâmetros qualitativos dos três aspectos globais (habilidades fonatórias, fatores adicionais e julgamento geral) do protocolo de avaliação da proficiência de voz e de fala traqueoesofágica................ 106 
4.2. Exame manométrico

4.2.1. Amplitude de pressão intraluminal da TFE no repouso e durante a fonação

4.3. Exame videofluoroscópico

4.3.1. Dimensões da TFE no repouso e durante a fonação

4.4. Exame videofluoroscópico versus exame manométrico

4.5. Proficiência da voz e da fala traqueoesofágica versus exame manométrico 112

4.6. Proficiência da voz e da fala traqueoesofágica versus exame videofluoroscópico ............................................................................. 113

4.6.1. Exame videofluoroscópico versus exame manométrico .................... 114

4.6.2. Proficiência da voz e da fala traqueoesofágica versus exame manométrico

4.6.3. Proficiência da voz e da fala traqueoesofágica versus exame manométrico

5. DISCUSSÃO

5.1. Considerações Finais

6. CONCLUSÕES

7. REFERÊNCIAS

8. APÊNDICES

9. ANEXOS 163 
1. INTRODUC ÃO 


\section{INTRODUÇÃO}

\section{INTRODUÇÃO}

A sobrevida de indivíduos submetidos à laringectomia total (LT) é acompanhada por diversas mudanças em âmbitos físico, emocional, social e profissional com níveis de comprometimento distintos entre os sujeitos. É inegável a importância do processo de reabilitação da comunicação para o indivíduo laringectomizado total, tornando-se importante a compreensão da morfofisiologia da nova fonte sonora, incluindo-se as características de produção vocal alaríngea e os resultados de voz e de fala.

Dentre os métodos de comunicação alaríngeas disponíveis até o momento, a prótese traqueoesofágica (PTE) tem sido aceita amplamente (Most et al., 2000), promovendo uma convincente opção de reabilitação. Apesar das taxas de sucesso serem evidentes (Isman, O'Brien, 1992; Clements et al., 1997; van Weissenbrush et al., 2000) há também insucesso, cujas causas e razões não estão claramente definidas (Cantu et al., 1998; Op de Coul et al., 2003). Na tentativa de justificar essa inabilidade para a comunicação alaríngea e simultaneamente estabelecer procedimentos e critérios refinados para melhor caracterização dos indivíduos falantes com a PTE, muitos estudos têm se dedicado ao entendimento anatomofisiológico da transição faringoesofágica (TFE) visando esclarecer a sua causa e efeito para a voz e fala alaríngea, por meio de diferentes desenhos metodológicos (Winans et al., 1974; Duranceau et al., 1976; Hanks et al.,1981; Morgan et al., 1992; Dantas et al., 1999; Dantas et al., 2000; van Weissenbrush et al., 2000; Dantas et al., 2001; Nishizawa et al., 2001; van As, 2001; van As et al., 2001; Dantas et al., 2002; Op de Coul et al., 2003; Aguiar-Ricz, 2005; Schuster et al., 2005; Kazi et al., 2006; Aguiar-Ricz et al., 2007; Chone et al., 2008b; Lundström et al., 2008; Chone et al., 2009; Kazi et al., 2009a). Para tanto, destaca-se a busca preferencial por instrumentos de avaliação com caráter objetivo e mensurável, tais como a manometria e a videofluoroscopia quantitativa, associadas muitas vezes à soberana avaliação perceptivo-auditiva. 


\section{INTRODUÇÃO}

Apesar da importância da avaliação perceptual na pesquisa em voz, ainda é considerada como um instrumento subjetivo, dependente de tempo para análise e necessidade de um grupo de juízes (van As et al., 2001) para fortalecer a confiabilidade de seus achados. Especialmente no caso de vozes traqueoesofágicas, cuja produção vocal é realizada por estruturas do trato digestório de forma secundária e compensatória, recomenda-se que sua análise ocorra incluindo outros parâmetros da comunicação, não se limitando apenas a qualidade vocal. A avaliação mais abrangente da proficiência de voz e de fala traqueoesofágica contribui para o entendimento da nova fisiologia, proporcionando ao clínico a oportunidade de explorar a interface entre cada parâmetro da comunicação no processo de reabilitação, tornando-a mais produtiva e benéfica ao paciente. Atualmente, a atenção oferecida à reabilitação com a PTE extrapola o âmbito isolado de sua aquisição, enfatizando o processo terapêutico na qualidade dessa comunicação.

Quando tal investigação da comunicação traqueoesofágica ocorre associada a achados anatomofisiológicos fornecidos por instrumentos de imagem, a reabilitação vocal alaríngea torna-se mais segura e compreensível quanto às possibilidades de seu sucesso e insucesso. De acordo com van As et al. (2004), a videofluoroscopia é o método mais amplamente utilizado para avaliar a nova fonte sonora, sendo que a padronização de suas características visuais combinada com medidas quantitativas das diferentes dimensões da TFE facilitaria o estabelecimento da relação entre forma e qualidade vocal (van As et al., 2001). Apesar da obtenção de informações objetivas e quantificáveis por meio da videofluoroscopia em laringectomizados totais, poucas delas são correlacionadas entre si e com a proficiência da comunicação (Kazi et al., 2006), necessitando-se de mais pesquisas. Além disso, o fornecimento de dados quantitativos que comprovem a força empregada pela nova fonte sonora, para justificar a produção da voz traqueoesofágica, é feito apenas com base nas características morfofisiológicas da TFE e estruturas adjacentes, não assegurando sobre a verdadeira atividade da musculatura responsável.

Com o intuito de contribuir para o entendimento morfofisiológico da TFE e na elucidação dos fatores relacionados aos resultados de voz e de fala 


\section{INTRODUÇÃO}

traqueoesofágica, a manometria computadorizada tem sido empregada, estando associada ao fornecimento de informações mais precisas e reprodutíveis visando a promoção de uma avaliação quantitativa direta da pressão intraluminal (Chone et al., 2008b). É evidente a importância do seu papel para a investigação da atividade da TFE, por refletirem a força e o valor de contração ou relaxamento (Murray et al., 2003) da musculatura estriada durante a fonação alaríngea, contribuindo na compreensão de sua influência na qualidade da comunicação traqueoesofágica. Tal entendimento é fornecido comparando-se os resultados entre si ou com a literatura diversa, que por sua vez não dispõe de consenso a respeito de um valor limiar de pressão da TFE, considerando o nível de proficiência da voz e da fala de indivíduos laringectomizados totais (Murray et al., 2003; Aguiar-Ricz et al., 2007). Ressalta-se que há poucos estudos manométricos empregando a fala para análise do comportamento da TFE ((Morgan et al., 1992; Dantas et al., 2001; Aguiar-Ricz, 2005; Aguiar-Ricz et al., 2007; Chone et al., 2008b). Somente após a determinação desse valor referencial de pressão na TFE, será possível diferenciar adequadamente entre pacientes com e sem sucesso na comunicação alaríngea. Diante do exposto, mostra-se a importância do desenvolvimento de pesquisas visando a especificidade e sensibilidade das medidas pressóricas, como já demonstrada por Chone et al. (2008b).

Com base na revisão da literatura realizada até o presente momento, não há nenhum estudo relacionando a proficiência de voz e de fala traqueoesofágica com a manometria computadorizada e a videofluoroscopia quantitativa. Portanto, o desenvolvimento deste estudo torna-se importante na tentativa de melhor compreender objetivamente a função vocal alaríngea, cujos resultados poderão contribuir com novas pesquisas na área fonoaudiológica e beneficiar a população de laringectomizados totais com PTE. 
1.1. OBJETIVOS 


\section{OBJETIVOS}

\subsection{OBJETIVOS}

\subsubsection{Geral}

Relacionar as dimensões e a pressão intraluminal da TFE e a caracterização da proficiência de voz e de fala de laringectomizados totais com PTE.

\subsubsection{Específicos}

Analisar em laringectomizados totais falantes com PTE:

- Caracterização da proficiência de voz e de fala;

- Pressão intraluminal da TFE durante o repouso e a fonação;

- Dimensões da TFE durante o repouso e a fonação. 
2. RE VIS ÃO DA LITERATURA 


\section{REVISÃO DA LITERATURA}

Shames et al. (1963) estudaram as possíveis variáveis relacionadas ao aprendizado da voz alaríngea e propuseram relacionar as medidas de proficiência de fala com dados pessoais, médicos, de personalidade, social e de treinamento de fala, além de compará-las entre 118 falantes esofágicos e 35 usuários de laringe eletrônica. O grupo de laringe eletrônica realizou a leitura significativamente mais rápida do que o grupo esofágico, que por sua vez apresentou melhor articulação, inteligibilidade de palavras e escore surdosonoro. Os dois grupos mostraram fortes correlações entre as medidas de proficiência de fala, assim como entre tais medidas e outras variáveis como educação, idade na cirurgia, preservação do músculo cricofaríngeo, tempo de utilização do primeiro método de comunicação pós-operatório, tempo de treinamento de fala e variáveis de personalidade.

Damsté e Lerman (1969) estudaram as mudanças na configuração da TFE sob a produção de diversas provas de fonação em seis laringectomizados do sexo masculino, considerados bons falantes esofágicos, por meio do exame radiológico (raio-x) na visão lateral. A forma do segmento faringoesofágico variou conforme o tipo da fonação, tendendo a apresentar maior proeminência durante a fonação aguda e forte. $O$ nível da neoglote não sofreu alterações significativas pelas mudanças no pitch ou loudness. Houve maior distensão da porção superior do esôfago durante a fonação aguda e forte. Quanto aos valores quantitativos médios da TFE durante os tipos de fonação foram: fraca $(10,2 \mathrm{~mm})$, forte $(15,6 \mathrm{~mm})$, grave $(12,3 \mathrm{~mm})$ e agudo $(16,9 \mathrm{~mm})$ Quanto aos tipos de configuração em cada tipo de fonação foram: fraca (5 planas e uma circular), forte (uma plana, duas circulares e proeminentes), grave (duas planas e quatro circulares) e aguda (uma plana, duas circulares e três proeminentes).

Por meio de um eletromanômetro, Sandberg (1970) estudou em 20 laringectomizados totais, as pressões intraluminares da faringe, hipofaringe e esôfago durante o repouso, eructo esofágico e após a deglutição. Desses pacientes, foram descritos somente sobre os três casos mais típicos nesse 


\section{REVISÃO DA LITERATURA}

trabalho. Na condição pré-cirúrgica, não foram observadas alterações na função motora das estruturas avaliadas. Porém, após a cirurgia, a maioria dos pacientes apresentou alterações pressóricas bem definidas, sendo constatadas após a deglutição, pressões de contração, relaxamento e tônus de repouso mais fracos no esfíncter faringoesofágico. Na maioria dos casos, uma boa peristalse esofágica foi registrada. Destacou-se sobre a necessidade de se iniciar o treinamento para a reabilitação da voz esofágica o quanto antes, baseando-se em razões psicológicas, além da importância da função para a maturação do tecido de áreas tratadas.

Duranceau et al. (1976) estudaram o efeito da LT na motilidade do esôfago e em seus esfíncteres durante o repouso e após a deglutição em 10 laringectomizados totais e em seis indivíduos sem qualquer doença ou sintoma esofágico (grupo controle), por meio da manometria esofágica. Na comparação entre os grupos, alterações marcantes na motilidade esofágica foram observadas no esfíncter esofágico inferior e corpo do esôfago. A função do esfíncter esofágico inferior não diferiu significativamente do grupo controle. Quanto ao esfíncter esofágico superior, o grupo controle mostrou pressão de repouso de $34,3 \mathrm{mmHg}$ e de $46,4 \mathrm{mmHg}$ pós-deglutição. A coordenação do esfíncter esofágico superior do esôfago com a faringe foi normal em $98,9 \%$ das deglutições e seu relaxamento foi completo em $97 \%$ delas. Nos laringectomizados, a pressão em repouso do esfíncter superior foi de $12,9 \mathrm{mmHg}$ e o pico pós-deglutição foi de $2,5 \mathrm{mmHg}$. A coordenação foi normal em $73,9 \%$ das deglutições, enquanto o relaxamento foi completo em $65,3 \%$ delas. Os autores concluíram que os distúrbios da motilidade esofágica podem ser relativamente freqüentes após a LT e que isso pode ser clinicamente significante.

O estudo de Winans et al. (1974) envolveu 40 sujeitos, sendo 20 indivíduos normais, sem qualquer doença esofágica e 20 laringectomizados totais, os quais foram submetidos à mensuração das pressões intraluminais do estômago, do esôfago e seus esfíncteres, nas condições de repouso e pósdeglutição, além de serem avaliados quanto à proficiência de fala. Foram comparados os valores de pressão do grupo de LT com o controle e entre os 


\section{REVISÃO DA LITERATURA}

bons falantes esofágicos e piores falantes. As pressões em repouso do esfíncter cricofaríngeo foram menores $(20,6 \mathrm{mmHg})$ no grupo de $L T$ do que nos indivíduos normais $(29,4 \mathrm{mmHg})$. Quando comparado o grupo de bons e piores falantes, obtiveram-se valores de pressão menores $(13,1 \mathrm{mmHg})$ para o primeiro grupo do que para o segundo $(29,6 \mathrm{mmHg})$. A função do esfíncter esofágico inferior e corpo do esôfago foram similares em todos os grupos. Após a deglutição, o esfíncter cricofaríngeo pareceu relaxar normalmente na maioria dos laringectomizados totais.

O estudo de Welch et al. (1979) foi avaliar o papel da zona de alta pressão faringoesofágica na aquisição da voz esofágica em 31 laringectomizados totais, por meio do cálculo médio de seis medições realizadas por um instrumento manométrico nas condições pré e pós-cirurgia. Apenas 19 pacientes seguiram para a manometria esofágica pós-cirúrgica, sendo divididos após a reabilitação de voz e fala em falantes (12) e não falantes (7). Doze pacientes foram controle para avaliação da pressão préoperatória. Comparando-se as condições pré e pós LT, a média de pressão modificou-se de $130 \mathrm{mmHg}$ para $70 \mathrm{mmHg}$ no grupo de falantes e $61 \mathrm{mmHg}$ para os não falantes, cuja diferença entre os dois grupos não foram estatisticamente significantes.

Visando a reabilitação da voz alaríngea, Singer e Blom (1980) propuseram um método endoscópico para inserção traqueoesofágica da prótese fonatória unidirecional, envolvendo 60 laringectomizados totais com idade entre 42 e 78 anos, acompanhados por um período de dois anos. Todos os pacientes foram submetidos ao teste de insuflação de ar esofágico na condição pré-operatória e após a inserção da prótese, foram instruídos quanto ao seu funcionamento e aos cuidados de higiene necessários, além da orientação fonoaudiológica a respeito da comunicação como a articulação, controle respiratório e se necessário o relaxamento muscular. Do total de pacientes, $90 \%$ deles alcançaram vozes fluentes e mostraram-se satisfeitos com tal método de comunicação, sendo considerado pelos autores como uma técnica segura e efetiva para a maioria dos pacientes submetidos à LT. O intervalo máximo de uso da prótese foi de 26 meses e o mínimo de dois meses. 


\section{REVISÃO DA LITERATURA}

Hanks et al. (1981) estudaram o efeito da LT na motilidade esofágica nas condições pré e pós - operatória em 10 pacientes do sexo masculino com idade média de 54,3 anos, por meio da manometria esofágica. Todas as deglutições registradas nos esfíncteres, superior e inferior, do esôfago foram analisadas pela pressão de repouso, pico de pressão pós-deglutição, nível de relaxamento e coordenação. No caso do esfíncter esofágico superior, a pressão média de repouso diminuiu significativamente duas semanas depois da cirurgia, passando de $24,5 \mathrm{mmHg}$ para $13,5 \mathrm{mmHg}$, não se modificando estatisticamente para os seis meses seguintes e para os indivíduos que receberam radioterapia (média de $10 \mathrm{mmHg}$ ). Do mesmo modo, o pico de pressão pós-deglutição diminuiu significativamente, passando de $37,5 \mathrm{mmHg}$ para $21,7 \mathrm{mmHg}$ pós-operatório, mantendo-se também aos seis meses em ambos os grupos de pacientes. Coordenação e relaxamento também atingiram significância estatística no pós-operatório.

Richardson (1981) examinou a relação entre métodos de comunicação alaríngea, extensão cirúrgica e radioterapia, além da avaliação das expectativas de terapia de fala. Foram entrevistados 60 pacientes laringectomizados totais quanto aos métodos preferenciais de comunicação, bem como a inteligibilidade, volume e tendência a fadiga. Questionários foram encaminhados a 20 sujeitos que forneceram o treinamento de fala para obtenção de informações sobre o trabalho terapêutico desenvolvido e quanto à percepção dos determinantes para a reabilitação, sendo respondido por apenas 10 deles. Os autores constataram que não há relação entre a extensão cirúrgica e a habilidade para aprender a voz esofágica. O não fechamento das fístulas e o esvaziamento cervical não apresentaram forte relação para o aprendizado da voz esofágica, do mesmo modo que a radioterapia.

Dentre os objetivos do estudo de Daou et al. (1984), foi determinar os fatores clínicos e radiológicos que podem contribuir com a proficiência da voz esofágica. O estudo envolveu 25 laringectomizados, sendo 22 homens e três mulheres, com idade média de 60,4 anos, sendo realizada a gravação vocal e o registro da videofluoroscopia de modo simultâneo. Os fatores clínicos estudados foram: a idade do paciente no momento da cirurgia, tamanho do 


\section{REVISÃO DA LITERATURA}

tumor, esvaziamento cervical, complicações e radioterapia pós-operatórias, além do tipo de fechamento hipofaríngeo. Já os fatores radiológicos compreenderam o comprimento, forma, nível da pseudoglote e a distensão hipofaríngea. Como resultados, entre os fatores clínicos, somente o tamanho do tumor foi significativamente associado com a extensão da fala. A presença de uma pseudoglote curta, geométrica e com uma proeminência hipofaríngea bem desenvolvida foram essenciais para aquisição de uma boa voz esofágica. O nível da pseudoglote foi consistente em nossos pacientes nos níveis C5-C6 e correlacionou-se bem com o local da cirurgia.

Em 35 pacientes laringectomizados, Gatenby et al. (1985) avaliaram a hipofaringe, o esôfago cervical e o segmento faringoesofágico, por meio de uma técnica de duplo contraste. As gravações simultâneas de áudio e vídeo da voz permitiram a correlação do comportamento do segmento faringoesofágico com a produção sonora. Dentre os resultados, nove pacientes foram julgados como excelentes falantes esofágicos e serviram como grupo controle ("normal"). Nove tiveram adequada fonação esofágica que foi limitada pelo volume ou fluxo de palavras diminuído. Em cinco deles, uma coluna de ar estreitada ou distorcida foi observada. Um deles teve estenose de hipofaringe que pode ter contribuído com a redução da qualidade de fala. Quatro apresentaram um segmento faringoesofágico flácido, sendo associado com a formação de pseudovalécula em três deles. Dezessete pacientes tiveram fala esofágica inadequada relacionando-se à severa disfunção do segmento faringoesofágico que não permitiu a injeção ou ejeção de ar para a vocalização.

Wetmore et al. (1985) estudaram a localização e o formato do segmento vibratório em 16 falantes traqueoesofágicos, com idade média de 63 anos que foram submetidos, simultaneamente, ao exame de videofluoroscopia e gravação da voz, durante a emissão da vogal sustentada /a/, sendo que a análise do segmento necessitou de fotografias das imagens de interesse. Como resultados, todos os pacientes apresentaram uma área contraída, 0 segmento vibratório, no esôfago ou hipofaringe durante a fonação, estando localizado mais comumente no terço inferior do pescoço correspondente as vértebras cervicais C5 a C7. O outro local comum foi o terço médio do pescoço 


\section{REVISÃO DA LITERATURA}

que correspondeu à vértebra cervical C4. Cinco dos sujeitos apresentaram dois segmentos vibratórios e dois outros tiveram segmento vibratório longo. Os segmentos vibratórios observados em falantes traqueoesofágicos foram caracterizados como sendo similares aos dos falantes esofágicos.

Williams e Watson (1985) examinaram os níveis de experiência de três grupos de juízes (Grupo I: leigos, II: informados e III: experientes) em relação aos parâmetros de comunicação de 10 falantes traqueoesofágicos, 12 esofágicos e 11 usuários de eletrolaringe e constataram que as percepções dos ouvintes dependeram do nível de experiência dos mesmos. Para o grupo I, os fatores que diferiram entre os falantes foram: velocidade de fala, loudness, inteligibilidade e efetividade geral da comunicação. Quanto ao segundo grupo de juízes, houve diferença na apresentação visual durante a fala, velocidade de fala, ruído acentuado, inteligibilidade e efetividade geral da comunicação, sendo estes melhores para os falantes com PTE, com exceção do parâmetro velocidade de fala. Finalmente, quanto aos juízes experientes, os parâmetros que se diferenciaram foram: apresentação visual durante a fala, velocidade de fala, ruído acentuado, inteligibilidade e efetividade geral da comunicação, sendo que todas as variáveis foram melhores para os usuários de PTE.

Perry et al. (1987) apresentaram os resultados da restauração cirúrgica da voz em 50 pacientes (49 laringectomizados totais e um faringolaringectomizado), sendo 43 homens e sete mulheres com idade média de 62,8 anos e analisaram as razões de insucesso. Todos os pacientes foram submetidos à videofluoroscopia, por meio da qual foram agrupados de acordo com a categorização vocal, e orientados quanto aos procedimentos necessários para restauração com sucesso da comunicação alaríngea, como a miotomia, uso de pressão digital adicional durante a oclusão e cirurgia para aumentar o lúmen faríngeo. Além disso, a proficiência da fala foi avaliada e utilizada na comparação em duas semanas e em três meses pós-restauração vocal. Em duas semanas pós-cirurgia, constataram-se $94 \%$ de sucesso na restauração vocal. Nos três meses pós-inserção da PTE, o sucesso diminuiu para $73 \%$, cujos problemas evidenciados não se relacionaram a questões 


\section{REVISÃO DA LITERATURA}

anatômicas/físicas, sendo apresentados pelos pacientes baixa aptidão mental para manutenção da prótese e insatisfação pessoal.

Williams e Watson (1987) estudaram 33 laringectomizados totais que foram divididos em três grupos: 12 esofágicos, 11 com eletrolaringe e 10 falantes com PTE, além de 10 falantes laríngeos como grupo controle, cujos objetivos foram determinar se tais métodos de comunicação alaríngea eram significativamente diferentes em relação aos diversos parâmetros de fala caracterizados por juizes inexperientes na área e quais os parâmetros mais fortes para tal discriminação. Para todos os parâmetros avaliados, os falantes com PTE foram melhores do que os esofágicos. Quando comparado os falantes com PTE e os usuários de eletrolaringe, exceto a loudness, todos os outros aspectos foram melhores também para os primeiros. Quanto aos falantes esofágicos e eletrolaringe, os parâmetros que se diferiram entre esses grupos foram qualidade/ruído e inteligibilidade/efetividade geral da comunicação, sendo tais variáveis melhores para os esofágicos. O grupo laríngeo foi melhor que os demais grupos em todos os parâmetros avaliados.

Com a finalidade de se avaliar e classificar a anatomia e a função da faringe reconstruída durante a deglutição e fonação com insuflação de ar, Mclvor et al. (1990) realizaram a combinação de videofluoroscopia, gravações de vídeo e radiografias estáticas em 134 falantes esofágicos ruins ou sem sucesso, dos quais $14 \%$ foram classificados radiologicamente como hipotônicos, 30\% como hipertônicos, $46 \%$ espásticos e 10\% casos de estenose.

St. Guily et al. (1992) estudaram prospectivamente a restauração da voz alaríngea em 83 laringectomizados totais, sendo 79 homens e quatro mulheres, com idade média de 59,7 anos. Caracterizou-se o método de comunicação utilizado, de acordo com a sua qualidade vocal e uso, avaliando-se os resultados imediatos após restauração vocal e a longo-prazo. Quanto aos métodos de comunicação, 19 pacientes utilizaram a voz esofágica, 41 a traqueoesofágica (primária, secundária ou shunt miomucoso) e a eletrolaringe nunca foi utilizada como reabilitação primária exclusiva; enquanto 21 pacientes não foram reabilitados. Os resultados imediatos da restauração vocal foram 


\section{REVISÃO DA LITERATURA}

melhores para o procedimento traqueoesofágico (73\%) do que para a voz esofágica (5\%), enquanto que a taxa de falhas para ambos os grupos não apresentou diferença. Após um ano, 21 dos 28 sobreviventes ainda utilizavam somente a voz traqueoesofágica como forma de comunicação.

O estudo de Isman e O'Brien (1992) objetivou identificar a localização e o comprimento do segmento faringoesofágico durante a fala esofágica e com PTE entre quatro laringectomizados proficientes em ambos os métodos de comunicação. Tais pacientes foram submetidos à coleta de material de fala para análise perceptual e à videofluoroscopia para medições dos segmentos vibratórios. Os resultados revelaram que a voz com PTE foi mais efetiva do que a esofágica nos quatro pacientes. Dois pontos de estreitamento na neofaringe durante a produção esofágica como na voz com PTE foram observados em três dos pacientes. Os segmentos faringoesofágicos localizaram-se entre as vértebras cervicais C3-C6 durante a voz esofágica e entre C4-C6 na voz com PTE. O comprimento do segmento faringoesofágico estendeu-se de 12 a $50 \mathrm{~mm}$ no falante com PTE e de 8 a $48 \mathrm{~mm}$ para a fala esofágica. A configuração do segmento faringoesofágico em ambas as formas de comunicação foram similares, sugerindo que sua localização e comprimento na voz esofágica e com PTE são no mínimo comparáveis.

Morgan et al. (1992) avaliaram o uso da manometria do segmento faringoesofágico como um meio para predizer eventual resultado de fala esofágica. Dois grupos de pacientes foram estudados, sendo que no grupo I, composto por 18 laringectomizados totais, as pressões do segmento foram comparadas com os achados da videofluoroscopia, e no grupo II, composto por 12 pacientes, as pressões foram registradas no período pós-operatório imediato e comparadas com seu eventual resultado de fala. A manomentria classificou os pacientes em: hipotônico (três indivíduos, média de pressão de $11,3 \mathrm{mmHg}$ ), tônico (três indivíduos, média de pressão de 18,3mmHg), hipertônico (quatro indivíduos, média de pressão de $45 \mathrm{mmHg}$ ) e espasmo (três indivíduos, média de pressão de $66,2 \mathrm{mmHg}$ ), sendo que pressão acima de $20 \mathrm{mmHg}$ associou-se a falhas na voz. No grupo II, todos os casos predisseram o eventual resultado de fala, de acordo com a pressão. 


\section{REVISÃO DA LITERATURA}

Por meio da eletromiografia do músculo cricofaríngeo durante a deglutição e a fonação, Pruszewicz et al. (1992) avaliaram 30 laringectomizados totais e falantes esofágicos, com idade entre 43 e 74 anos, cujos parâmetros analisados foram amplitudes máxima e mínima, freqüência das descargas e tempo de duração da atividade elétrica muscular. De acordo com o domínio da voz e fala alaríngea, os pacientes foram divididos em cinco grupos (muito bom, bom, voz esofágica suficiente, voz faríngea e pseudo sussurro bucofaríngeo). Como resultado, constatou-se dependência entre atividade do cricofaríngeo e o domínio da voz esofágica, ou seja, os melhores falantes apresentaram especialmente maiores valores de amplitude e duração. A atividade do músculo cricofaríngeo durante a fonação foi maior quando comparada a deglutição, considerando falantes esofágicos bons e muito bons.

Em 21 pacientes, Clevens et al. (1993) examinaram a segurança e a eficácia da LT e punção traqueoesofágica associadas ao não fechamento da musculatura faríngea para prevenir o faringoespasmo como uma alternativa ao fechamento de três camadas com a neurectomia do plexo faríngeo e/ou miotomia do constritor faríngeo. De forma prospectiva, tais pacientes receberam seguimento especializado de pelo menos uma vez por mês durante o primeiro ano pós-operatório e de duas vezes por mês após esse período, sendo avaliada a produção vocal traqueoesofágica, segundo a sua fluência e as complicações cirúrgicas. Quanto as complicações gerais, observou-se uma taxa de $28,5 \%$, sendo que três pacientes apresentaram estenose do estoma, dois desenvolveram fístula salivar faringocutânea e um paciente apresentou um ponto de abcesso no estoma. Dos 20 pacientes disponíveis para seguimento, 15 deles atingiram a reabilitação vocal fluente. Os autores concluíram que o procedimento cirúrgico estudado é relativamente seguro e evita a ocorrência de espasmos faringoesofágicos, já que estes não foram constatados.

O objetivo de Horowitz e Sasaki (1993) foi determinar, por meio da manometria, o efeito da miotomia cricofaríngea nas pressões de contração faríngea durante a deglutição seca em oito laringectomizados totais, sendo que quatro deles foram submetidos à miotomia e quatro serviram como grupo controle. Os picos de pressão faríngea obtidos em pacientes sem miotomia 


\section{REVISÃO DA LITERATURA}

foram maiores que $60 \mathrm{mmHg}$, já para o grupo com miotomia, a média dos picos de pressão apresentada foi de $37,8 \mathrm{mmHg}$. Os autores referiram que a miotomia do cricofaríngeo realizada no momento da LT pode diminuir o pico de pressão faríngea gerada durante a deglutição e assim reduzir a possibilidade de formação de fístula faringocutânea, principalmente naqueles casos envolvendo reconstrução faríngea complexa.

Foi o propósito do estudo de Omori et al. (1994) avaliar o mecanismo vibratório e a origem da neoglote em 25 laringectomizados totais falantes com shunt traqueoesofágico, submetidos aos exames de videofluoroscopia, estrobofibroscopia e eletromiografia. Pela videofluoroscopia, observaram-se duas proeminências no segmento faringoesofágico durante a fonação em 23 pacientes, sendo que a superior localizou-se entre C4-C6, com comprimento vertical médio de $22 \mathrm{~mm}$ e horizontal de $13 \mathrm{~mm}$. Já a inferior localizou-se entre C5-C7, com comprimento vertical de $8 \mathrm{~mm}$ e horizontal de $6 \mathrm{~mm}$. Na estroboscopia, observou-se que a proeminência superior era uma protrusão da parede posterior faríngea e a inferior era uma constrição circular. Em todos os pacientes, a superior foi a parte vibratória na fonação, com movimentos regulares em 18 deles. A eletromiografia elucidou a contribuição da contração muscular das duas proeminências, sendo a superior formada pelo tireofaríngeo e a inferior pelo cricofaríngeo.

Blitzer et al. (1995) verificaram os efeitos da toxina botulínica no cricofaríngeo sobre a falha vocal após a inserção de PTE em seis pacientes, todos do gênero masculino e com idade entre 55 e 75 anos. Todos os pacientes se beneficiaram das injeções de toxina, incluindo-se dois deles submetidos a prévia miotomia do cricofaríngeo, sendo que os efeitos positivos foram observados dentro de uma semana após a aplicação, com duração média de 12 semanas. Quanto à habilidade de fala, a melhora foi observada em todos os pacientes, estendendo-se de $20 \%$ a $60 \%$, com média de $40 \%$. Os autores concluíram que a toxina botulínica no esfíncter esofágico superior parece ser diagnosticamente e terapeuticamente efetiva no manejo de falhas vocais após a inserção da PTE. 


\section{REVISÃO DA LITERATURA}

Blom et al. (1995) compararam as medidas objetivas da voz traqueoesofágica em 29 laringectomizados totais submetidos à inserção primária da PTE e que receberam a neurectomia do plexo faríngeo e/ou a miotomia seletiva para prevenção do faringoespasmo. Todos os pacientes foram submetidos a uma entrevista, a gravações vocais e a videofluoroscopia. Não houve diferença significante quanto à incidência de faringoespasmos entre os três grupos cirúrgicos, assim como para a percepção da fluência. Apenas os pacientes submetidos à neurectomia apresentaram redução no comprimento do segmento faringoesofágico dentro de 12 meses. Nesse mesmo período de tempo, o grupo de neurectomia e miotomia combinado mostrou aumento do tempo máximo de fonação de 12,5 s para 21,9s. Para o grupo de neurectomia, a freqüência fundamental aumentou significativamente $(89,9 \mathrm{~Hz}-96,4 \mathrm{~Hz}-$ $111,1 \mathrm{~Hz}$ ) quando comparada aos outros grupos. O tempo de pausa durante a leitura diminuiu entre três e seis meses, não se modificando entre 6-12 meses, assim como a taxa de palavras que aumentou entre 3-6 meses e se manteve.

O estudo de Culton e Gerwin (1996) determinou as percepções de 151 fonoaudiólogos a respeito das práticas atuais e de mudanças na reabilitação da comunicação de pacientes laringectomizados durante a década de 80 , por meio da aplicação de um questionário contendo 15 questões a respeito. Como resultados, a PTE foi selecionada por $69 \%$ dos fonoaudiólogos como o método preferencial, enquanto somente $7 \%$ julgaram-na como menos preferida. Já a eletrolaringe foi julgada por $68 \%$ como menos preferencial e a voz esofágica apresentou resultados intermediários. Os autores destacaram que no início dos anos 90, o uso da PTE aumentou de $21 \%$ para $31 \%$. Quanto à possibilidade de escolha do método de comunicação pelo próprio paciente, $65 \%$ dos fonoaudiólogos revelaram que mais da metade dos pacientes participaram dessa seleção. Dentre os problemas relacionados à PTE, o mais citado foi o vazamento ao redor/por meio desta (43\%) e casos de hipertonia e espasmos do cricofaríngeo ocorreram em $10 \%$ das respostas.

De forma retrospectiva, Geraghty et al. (1996) examinaram o sucesso a longo-prazo e a taxa de sobrevivência, além dos possíveis efeitos dos fatores sociais e econômicos em 40 laringectomizados totais submetidos a inserção da 


\section{REVISÃO DA LITERATURA}

PTE (18 colocações primárias e 22 secundárias). Como resultados, a taxa de sobrevivência foi de aproximadamente $75 \%$ e a taxa de sucesso inicial de $70 \%$. Vinte e nove dos 40 pacientes continuaram em seguimento, apresentando taxa de sucesso de $66 \%$. Níveis educacionais e consumo continuado de álcool no período pós-operatório não afetaram o sucesso da PTE.

Max et al. (1996) compararam 10 falantes esofágicos e 10 traqueoesofágicos, com média de idade de 60 anos, em relação as suas capacidades vocais. Os parâmetros comparados foram: tempo máximo de fonação, número máximo de sílabas emitidas em uma única ingestão de ar, extensões dinâmica e de freqüência, e nível de intensidade máxima. Quanto aos resultados, observou-se relação significante entre os grupos quanto aos parâmetros de tempo máximo de fonação (esofágicos: 1,33s e traqueoesofágicos: 8,19s), número máximo de sílabas (esofágicos: 7,10 e traqueoesofágicos: 24,93 ) e nível de intensidade máxima (esofágicos: 61,90dB e traqueoesofágicos: $70,70 \mathrm{~dB}$ ). Os autores destacaram que o tempo máximo de fonação foi o fator que melhor se correlacionou com as outras variáveis, sendo sugerido que fatores aerodinâmicos e pseudo-fonação interagem por meios diferentes dentro dos dois grupos de falantes alaríngeos.

Artazkoz Del Toro e Martínez (1997) caracterizaram o segmento faringoesofágico em 220 indivíduos submetidos à LT fonatória que incluiu a miotomia do constritor inferior e inserção da PTE, por meio da correlação das imagens dinâmicas radiológicas com a manometria esofágica. Daqueles pacientes que realizaram a videofluoroscopia, a maioria deles apresentou segmento faringoesofágico com forma trapezoidal em repouso, com facilidade na passagem de contraste na deglutição, com uma distância ântero-posterior do segmento a altura de $\mathrm{C} 5-\mathrm{C} 6$ maior que $1 \mathrm{~cm}$, com pouca ou nula proeminência do constritor inferior a este nível, tempo máximo de fonação maior que 12 segundos, voz fluida e ausência de contato da prótese com a parede posterior do esôfago durante a fonação. Tal caracterização radiológica foi apresentada por todos os indivíduos considerados como hipotônicos na manometria esofágica, que por sua vez foram a maioria. Nenhum caso de espasmo foi observado. 


\section{REVISÃO DA LITERATURA}

O estudo de Clements et al. (1997) objetivou determinar a satisfação de quatro grupos de pacientes laringectomizados com o seu método específico de comunicação alaríngea, por meio de um questionário contendo aspectos relacionados à satisfação do indivíduo com a comunicação, com a qualidade vocal, habilidade para se comunicar ao telefone, limitação na interação social e qualidade de vida. Dentre as respostas dos 31 participantes, os usuários de PTE demonstraram serem mais satisfeitos com o seu método de comunicação, ficando a escrita como o menos satisfatório. Com base nesses achados, a inserção da PTE foi recomendada como o procedimento de eleição para a restauração da comunicação alaríngea.

Hilgers et al. (1997) descreveram a respeito do processo terapêutico para aquisição da voz traqueoesofágica e enfatizaram a importância de realização da avaliação pré-operatória fonoaudiológica. Dentre os fatores relacionados a uma adequada produção vocal, os autores citaram a oclusão completa do estoma, respiração abdominal, coordenação fonorrespiratória, postura e relaxamento corporal. Por outro lado, problemas com a tonicidade do segmento faringoesofágico, prótese vocal e estoma foram relacionados a resultados insatisfatórios de fala, cujas soluções foram descritas pelos autores. Além disso, ressaltaram a necessidade de instruir os pacientes quanto aos cuidados com a prótese e apresentaram uma forma de avaliação da voz traqueoesofágica, por meio da utilização de um protocolo composto por três categorias, cujo julgamento final é caracterizado em bom, moderado ou falante ruim. Segundo os autores, o processo terapêutico deve ser flexível e adaptado a cada paciente, não existindo desse modo um método correto para a terapia traqueoesofágica.

Em um artigo de revisão, Brok et al. (1998) descreveram a respeito dos métodos existentes para tratamento da hipertonicidade do segmento faringoesofágico, relatando inicialmente sobre o procedimento cirúrgico da LT que inclui as remoções do osso hióide, do conteúdo do espaço pré-epiglótico, da cartilagem tireóidea, do anel cricóide e de um a quatro anéis traqueais, além dos músculos constritores que são seccionados da linha oblíqua da cartilagem tireóidea e cricóide, cujas mudanças pós-cirúrgicas alteram o esfíncter 


\section{REVISÃO DA LITERATURA}

esofágico superior e a sua tonicidade. Tanto a hipotonicidade como a hipertonicidade influenciam o desenvolvimento da voz alaríngea negativamente, além de outras causas como escaras, fibroses, persistência do tumor ou fibrose de radiação dos músculos do segmento faringoesofágico. Dentre os tratamentos para a tonicidade, foram destacadas a miotomia, o não fechamento da musculatura faríngea, a neurectomia do plexo faríngeo e a aplicação da toxina botulínica, não existindo consenso quanto à superioridade de uma dessas técnicas. Considerando a influência de fatores neurofisiológicos no sucesso da reabilitação alaríngea, os autores referiram que há diferentes opiniões a respeito do suprimento nervoso do esfíncter esofágico superior, cuja exata influência da neurectomia unilateral do plexo faríngeo ainda não está clara, exigindo-se uma investigação mais precisa da inervação motora do cricofaríngeo. Destacaram que se o cricofaríngeo recebe inervação motora de ramos do nervo recorrente ou de ramos contralaterais do plexo faríngeo ou recorrente, a neurectomia isoladamente não seria suficiente, considerando que a realização do procedimento ocorre unilateralmente no plexo faríngeo.

Cantu et al. (1998) examinaram a extensão de sucesso a longo prazo e os seus fatores de predição para 36 laringectomizados totais submetidos à colocação da PTE. Além disso, compararam os julgamentos da comunicação alaríngea realizados por fonoaudiólogos e pelo próprio paciente ou responsável. Após caracterização dos indivíduos com sucesso e insucesso com a PTE, comparou-se ao tempo de cirurgia e aos parâmetros categóricos relacionados à falha ou sucesso da comunicação. Como resultados, 23 pacientes apresentaram sucesso com a comunicação traqueoesofágica, enquanto o restante falhou, apresentando como fatores relacionados a tal condição: visão reduzida, movimentação limitada de braço/mão e história de radioterapia. Quanto à comparação do perfil de comunicação julgado pelo fonoaudiólogo e pelo paciente ou responsável, os valores foram idênticos em $67 \%$ dos casos, apesar de quase $1 / 3$ das comparações terem apresentado discrepância, sendo atribuídos valores mais elevados pelo clínico, na maioria das vezes. 


\section{REVISÃO DA LITERATURA}

Ceccon et al. (1998) analisaram as características temporais, perceptivas e acústicas da voz traqueoesofágica, cuja população estudada consistiu de 15 laringectomizados totais falantes com a PTE, sendo 13 do sexo masculino e dois do feminino, com idade média de 62,5 anos. Quanto ao tempo máximo de fonação, a média encontrada para a emissão prolongada da vogal /a/ foi de $12,36 \mathrm{~s}$, as médias da intensidade habitual, máxima e variação da mesma foram respectivamente, $66,29 \mathrm{~dB}, 76,55 \mathrm{~dB}$ e $21,66 \mathrm{~dB}$. A média da freqüência fundamental foi de $137,69 \mathrm{~Hz}$. Quanto à avaliação global da qualidade vocal, $66,7 \%$ apresentaram qualidade vocal boa e $33,3 \%$ foram julgados como moderado.

Por meio do exame manométrico, Dantas et al. (1998) estudaram a motilidade esofágica em 20 homens e 20 mulheres saudáveis, por meio da alternância de 10 deglutições secas e 10 deglutições líquidas, não sendo observada diferença na amplitude de contração esofágica entre os gêneros, porém os homens apresentaram aumento na velocidade da peristalse esofágica na parte média do corpo esofágico e uma diminuição na duração das contrações $5 \mathrm{~cm}$ acima do esfíncter esofágico superior, em comparação as mulheres.

Mohri et al. (1998) exploraram o papel do lúmen subneoglótico na fonação traqueoesofágica em 13 laringectomizados totais falantes e submetidos a fístula traqueoesofágica, sendo 12 homens e uma mulher, com idade média de 62 anos. Tal estudo consistiu de observações fibroscópicas e fluoroscópicas da hipofaringe e esôfago realizadas durante a fonação. Como resultados, a fibroscopia mostrou um fechamento concêntrico do esôfago com a formação de uma câmara no lúmen subneoglótico durante a fonação, seguido pela abertura do esôfago durante a inspiração. A videofluoroscopia revelou uma dilatação do lúmen subneoglótico com fechamento do esôfago distal durante a fonação.

Dantas et al. (1999) estudaram a motilidade esofágica em 17 pacientes laringectomizados totais ( 11 reabilitados com a voz esofágica e 6 incapazes de falar) e em 40 indivíduos saudáveis, por meio da manometria esofágica durante a deglutição líquida. Comparando-se os resultados de ambos os grupos, 


\section{REVISÃO DA LITERATURA}

observou-se menor amplitude de contrações, menor duração do relaxamento do esfíncter inferior do esôfago, além de uma menor pressão do esfíncter esofágico superior $(34,9 \mathrm{mmHg})$. Não houve diferença entre os grupos quanto a duração e a velocidade das contrações, número de contrações com picos múltiplos ou falhas, pressão do esfíncter esofágico inferior e no número de deglutições seguidas pelo relaxamento completo deste.

Deschler et al. (1999) estudaram os efeitos dos níveis de pressão sonora na freqüência fundamental e a sua modulação em 11 laringectomizados totais falantes com PTE, sendo 10 homens e uma mulher. Tais indivíduos foram orientados a produzir a vogal sustentada "a" em intensidade fraca e forte, variando-se o pitch em agudo e grave para cada nível de intensidade. A média da freqüência fundamental para a tarefa de pitch agudo com voz fraca foi de $82 \mathrm{~Hz}$, enquanto que para o pitch agudo com voz forte foi de $116,4 \mathrm{~Hz}$. O nível de pressão sonora foi $57,7 \mathrm{~dB}$ para pitch agudo com voz fraca e $64,6 \mathrm{~dB}$ para pitch agudo com voz forte. Os autores constataram que o nível de pressão sonora foi um fator significante na predição da freqüência fundamental, entretanto, outros fatores podem estar relacionados a sua modulação em falantes traqueoesofágicos.

Finizia et al. (1999) compararam achados acústicos, perceptuais e autojulgamento da voz entre 12 laringectomizados totais com PTE, 12 indivíduos tratados exclusivamente com radioterapia e 10 indivíduos laríngeos normais, sendo todos do gênero masculino. Constataram que a análise perceptual pôde indicar diferenças significantes entre os grupos de LT e irradiados, já a análise acústica foi mais eficiente em vozes sem disfunção severa. Quanto à freqüência fundamental, não houve diferença significante entre os grupos, porém o de LT mostrou os menores valores, com média de $103,1 \mathrm{~Hz}$. Os valores médios de tempo máximo de fonação para os grupos de LT, radioterapia e normal foram respectivamente, $14,7 \mathrm{~s}, 15,6 \mathrm{~s}$ e $21,7 \mathrm{~s}$. Na autoavaliação dos LT, a inteligibilidade foi menor entre os grupos e os juízes também os caracterizaram como mais desviantes que os tratados com radioterapia quanto à qualidade vocal, aceitabilidade e inteligibilidade de fala. 


\section{REVISÃO DA LITERATURA}

Hirano et al. (1999) examinaram o efeito da miotomia do cricofaríngeo e implante da cartilagem traqueal na parede anterior do esôfago para fonação esofágica e com shunt traqueoesofágico em 13 pacientes alaríngeos, além de oito representando o grupo controle, cujos procedimentos cirúrgicos anteriormente citados não foram realizados. Todos os participantes foram submetidos à fibroscopia com câmera de alta velocidade para análise da neoglote, sendo observada melhor regularidade de vibração para os pacientes submetidos ao implante de cartilagem e para a maioria destes observou-se fechamento completo da neoglote. Em função da facilidade de fonação ter sido induzida pelos efeitos vibratórios, os autores recomendaram a miotomia do cricofaríngeo para evitar o espasmo esofágico reconstruído e o implante do anel traqueal cartilaginoso para formação de um espaço subneoglótico amplo.

Omori e Kojima (1999) examinaram em 30 laringectomizados totais e usuários de prótese vocal, os tipos viratórios da neoglote e certificaram sobre as possíveis condições relacionadas à falha na fonação com shunt traqueoesofágico. Foram realizadas a avaliação perceptual das vozes e a videoestroboscopia do segmento faringoesofágico. Apenas um paciente submeteu-se à fluoroscopia para identificação do gap neoglótico entre as paredes, anterior e posterior, do segmento faringoesofágico. Em 28 pacientes, a neoglote abriu e fechou ântero-posteriormente, e médio-lateralmente em apenas dois. A vibração neoglótica foi consistentemente regular em oito pacientes, e irregular em nove. Em 23 pacientes, observou-se o fechamento completo, incompleto em três e excessivamente ocluído em quatro, sendo que nestes últimos, as vozes foram severas ou moderadamente tensas. O contato das paredes mucosas no segmento faringoesofágico foi único em 26 pacientes e múltiplos em quatro; com qualidade vocal severamente rouca para este último grupo. Segundo os autores, a regularidade de vibração da neoglote pode ser o achado mais importante e a estroboscopia pode contribuir no entendimento das causas de falhas de vozes com shunt traqueoesofágico.

Zormeier et al. (1999) avaliaram os efeitos da toxina botulínica na qualidade de voz traqueoesofágica ruim apresentada por oito laringectomizados totais com disfunção do segmento faringoesofágico, cuja 


\section{REVISÃO DA LITERATURA}

hipertonicidade/espasmos foram julgados de acordo com as pressões de insuflação pré-punção traqueoesofágica, sintomas clínicos, medidas pressóricas de ar traqueal e avaliação da deglutição de bário antes e após a injeção de toxina botulínica. Como resultados, sete dos oito pacientes apresentaram significante melhora da qualidade vocal e as pressões aéreas traqueal normalizaram em seis dos oito pacientes após a injeção da toxina botulínica, sendo assim considerada pelos autores como a primeira linha de tratamento à laringectomizados com qualidade vocal traqueoesofágica ruim, causada por disfunção do segmento faringoesofágico.

MCAuliffe et al. (2000) compararam os resultados de fala funcional traqueoesofágica de 30 laringectomizados totais e 13 faringolaringectomizados totais, por meio de medidas de inteligibilidade, qualidade vocal, uso da voz traqueoesofágica, satisfação vocal, níveis de percepção de incapacidade vocal, handcap e bem-estar. Foi constatado que o grupo de faringolaringectomia apresentou aumento do esforço para produção vocal, redução da agradabilidade e naturalidade vocal, além de maior aumento no ruído da fala. A inteligibilidade ao nível de sentença foi melhor para o grupo de laringectomizados totais. Não houve diferença significante entre os grupos quanto a proporção de falantes traqueoesofágicos com sucesso. Baixo nível de handcap e altos níveis de bem-estar foram encontrados em ambos os grupos.

Dantas et al. (2000) avaliaram as alterações motoras do esôfago em oito pacientes laringectomizados totais, sendo todos do sexo masculino e com idade entre 40 e 66 anos. Tais indivíduos foram submetidos a dois exames manométricos do esôfago com perfusão contínua durante a deglutição líquida, com intervalo de seis a 12 meses, não sendo observada diferença entre eles quanto a amplitude, duração e velocidade das contrações nas pressões dos esfíncteres superior e inferior do esôfago e quanto aos números de contrações falhas e síncronas. Segundo os autores, uma vez comprometida a motilidade esofágica, ela permanece sem mais alterações, sugerindo que não há progressão das alterações motoras esofágicas em pacientes laringectomizados. 


\section{REVISÃO DA LITERATURA}

Most et al. (2000) compararam a fala de indivíduos laríngeos, traqueoesofágicos e esofágicos (bons e moderados) a fim de determinar as conseqüências da reabilitação traqueoesofágica versus esofágica. Participaram do estudo 20 falantes (cinco de cada grupo), cujas vozes foram registradas e analisadas acusticamente e perceptualmente. Os principais resultados acústicos mostraram que falantes laríngeos diferem significativamente dos falantes alaríngeos em freqüência fundamental e entonação. Falantes esofágicos moderados diferiram de todos os outros grupos nas medidas de duração. Resultados perceptuais revelaram que falantes moderados esofágicos foram os menos aceitáveis, enquanto que os traqueoesofágicos foram mais aceitáveis do que bons falantes esofágicos, mas não mais inteligível. Houve correlações significantes entre freqüência fundamental, medidas de duração e aceitabilidade, entre freqüência fundamental e inteligibilidade, e entre esta última e aceitabilidade.

van Weissenbrush et al. (2000) avaliaram os achados cinerradiográficos em 60 laringectomizados totais e falantes traqueoesofágicos e também esofágicos durante a fonação, os quais foram divididos em três grupos para avaliação da proficiência de fala alaríngea, de acordo com o procedimento cirúrgico adicional (miotomia unilateral dos músculos cricofaríngeo e constritor faríngeo inferior e neurectomia adicional unilateral do plexo faríngeo combinada com a miotomia) a que foram submetidos ou não. Foram determinadas características visuais relacionadas ao segmento faringoesofágico, sendo constatado que a voz traqueoesofágica foi melhor em todos os grupos, quando comparada à esofágica. Os laringectomizados submetidos à miotomia primária e neurectomia tiveram mais sucesso em obter uma boa voz traqueoesofágica (81\%). Espasmos, hipertonicidade e estenose hipofaríngea foram associadas com falhas da voz esofágica e traqueoesofágica. A maioria das desordens estruturais e funcionais foi observada no grupo sem procedimento cirúrgico adicional. Bons falantes esofágicos e traqueoesofágicos mostraram um reservatório de ar proeminente durante a fonação. Propulsão abundante de ar em direção ao esôfago distal foi evidente somente nos piores falantes traqueoesofágicos. Diante disso, os autores concluíram que a aquisição da voz 


\section{REVISÃO DA LITERATURA}

alaríngea não diferiu significativamente entre os dois grupos submetidos a procedimento cirúrgico adicional.

A proposição do estudo de Dantas et al. (2001) foi avaliar e comparar a pressão intra-esofágica durante a produção da voz esofágica de 10 laringectomizados totais reabilitados com a voz esofágica e 15 incapazes de produzi-la, com idade variando entre 40 e 70 anos, por meio do exame manométrico com sonda aberta e perfusão contínua, obtendo-se como resultados que a pressão intra-esofágica durante a produção da voz esofágica foi maior nos pacientes reabilitados com tal forma de comunicação $(26,4 \mathrm{mmHg})$ do que nos pacientes inabilitados para a comunicação oral $(13,7 \mathrm{mmHg})$, que segundo os autores deve refletir a presença de ar no esôfago.

De forma retrospectiva, Ferrer Ramírez et al. (2001) examinaram o sucesso fonatório a longo-prazo e as complicações pós-operatórias de 350 laringectomizados totais com PTE. A fala traqueoesofágica foi alcançada a longo-prazo por aproximadamente $70 \%$ dos pacientes e em $30 \%$, as fístulas foram fechadas, sendo as causas desse fechamento: falhas na produção vocal; recorrência ou persistência de vazamento salivar; deslocamento acidental da PTE sem substituição e fechamento espontâneo; falta de motivação, condições socioculturais ou aquisição de uma boa voz esofágica pelo paciente, além das complicações médicas, tais como, tecido de granulação (15\%) bloqueando o fluxo aéreo e a inserção da PTE; ampliação da punção traqueoesofágica (7\%) e estenose do estoma (6\%). Aproximadamente $80 \%$ dos pacientes apresentaram uma boa voz com PTE e $8,6 \%$ não falaram. Somente $15 \%$ apresentaram boa comunicação esofágica, enquanto $64,5 \%$ não apresentaram qualquer comunicação ou foram considerados piores.

O propósito de Lewin et al. (2001) foi determinar em 23 laringectomizados totais que falharam em adquirir o nível conversacional da produção vocal traqueoesofágica os resultados vocais alcançados após a injeção de Botox; a duração do seu efeito e a taxa de reinjeção para manter a sua produção vocal bem sucedida. Cada paciente recebeu uma injeção de Botox® guiada pela eletromiografia, sendo oferecida uma segunda aplicação somente àqueles que falharam em alcançar a produção traqueoesofágica 


\section{REVISÃO DA LITERATURA}

fluente. Como resultados, $87 \%$ apresentaram sucesso na produção da voz traqueoesofágica após a injeção de Botox®, constatando-se que tal procedimento é efetivo para aliviar a hipertonicidade do constritor faríngeo na maioria dos casos. Somente um indivíduo falhou em adquirir a voz traqueoesofágica com sucesso após três injeções da neurotoxina, sendo que a duração média do efeito foi de 20,4 meses.

Nishizawa et al. (2001) apresentaram os achados dos mecanismos de abertura e fechamento da neoglote e os discutiram com a literatura. Participaram do estudo quatro laringectomizados totais e falantes esofágicos, sendo que dois deles submeteram-se à videofluoroscopia do faringoesôfago durante a deglutição e à injeção de ar prévia à fala esofágica, e os outros dois foram submetidos ao registro da largura da neoglote e à pressão de ar intraoral simultaneamente com a eletromiografia dos músculos gêniohioideo e constritor faríngeo inferior. No repouso, a neoglote foi fechada pela protrusão mucosa da parede posterior do faringoesôfago e durante a deglutição foi amplamente aberta, por meio da tração anterior da parede faríngea anterior, realizada pelo geniohióideo e supressão recíproca da atividade do constritor faríngeo inferior. No entanto, tal reciprocidade não foi observada durante a injeção de ar, apesar da abertura transiente da neoglote ter sido observada. Segundo os autores, o geniohioideo foi o responsável pela abertura da neoglote e o constritor faríngeo inferior pelo seu fechamento.

van As (2001) investigou as relações entre os resultados da avaliação visual e quantitativa da neoglote, e as análises perceptual e acústica da qualidade vocal, assim como descreveu as influências de fatores sociodemográficos e clínicos nas características da neoglote de pacientes laringectomizados totais. A avaliação perceptual consistiu de um julgamento geral da qualidade vocal e de uma escala de sete pontos composta por 19 pares de parâmetros semânticos. A análise acústica se baseou no tipo de sinal, medidas acústicas de peridiocidade e harmonia, além da medida do tempo máximo de fonação. A avaliação da videofluoroscopia foi feita por meio de um protocolo contendo características visuais e medidas quantitativas da neoglote. Dentre os resultados, observou-se que tanto a análise perceptual como a 


\section{REVISÃO DA LITERATURA}

acústica apresentou relação com as características da neoglote, por meio da videofluoroscopia. Em relação à avaliação perceptual, a análise visual durante a fonação quanto a presença da barra neoglote, regurgitação de bário e tonicidade da neoglote foram consideradas importantes características junto às medidas quantitativas em repouso e durante a fonação relacionadas à neoglote: distância mínima, índice de distância máxima e área superficial da barra, sendo que esta foi considerada importante em relação a frequência fundamental.

O objetivo do estudo de van As et al. (2001) foi desenvolver um protocolo de videofluoroscopia quantitativa, utilizando-se de parâmetros visuais bem definidos e medidas quantitativas para avaliação das características morfológicas e anatômicas da neoglote em relação a avaliação perceptual da qualidade vocal traqueoesofágica. Para a realização do estudo, participaram 39 laringectomizados, sendo 30 submetidos a LT convencional e nove a reconstrução parcial ou total da faringe, com idade média de 67 anos. Os autores constataram que as medidas quantitativas da videofluoroscopia foram significativamente relacionadas aos achados de avaliação visual. Tonicidade e presença da barra neoglote durante a fonação foram relacionadas à qualidade vocal, bem como outras medidas quantitativas, especialmente a distância mínima entre a barra neoglote e a parede anterior do esôfago no repouso e na fonação, e o índice de aumento relativo da distância subneoglótica máxima. De acordo com os achados, concluiu-se que é possível analisar a videofluoroscopia de uma maneira mais quantitativa e que algumas medidas objetivas podem substituir parâmetros subjetivos antigamente utilizados para avaliar a neoglote.

Karlen e Maisel (2001) avaliaram o benefício da punção traqueoesofágica primária, por meio da revisão de arquivos de 96 pacientes submetidos à $L T$, os quais foram divididos naqueles que se submeteram (33 pacientes) a inserção primária ou não (63 pacientes), sendo ainda subdivididos quanto ao tratamento radioterápico pré - cirurgia. Quanto aos resultados, não houve diferença entre os grupos, primário e secundário ou com e sem radiação, quanto às taxas de estenose esofágica ou de estoma, e à 


\section{REVISÃO DA LITERATURA}

cicatrização sem fístula. Nenhum paciente com inserção primária apresentou fístula e $52 \%$ deles mantiveram e utilizaram sua prótese de fala a longo-prazo. Diante disso, os autores reforçaram o valor de tal procedimento, concluindo que não há aumento da morbidade ou da incidência de complicações após a laringectomia quando realizada a punção traqueoesofágica primária.

Definir as características perceptuais e aerodinâmicas da voz esofágica em relação as diferentes modalidades de reabilitação alaríngea foi a proposta de Motta et al. (2001), a qual envolveu 19 laringectomizados totais, sendo 13 falantes esofágicos (A1: 8 bons falantes e A2: cinco falantes moderados) e seis falantes com PTE (B). Após o período de reabilitação da comunicação, cada participante foi submetido ao teste de inteligibilidade, estudo perceptivoacústico e aerodinâmico. Os resultados mostraram que os sujeitos do grupo A1 apresentaram uma proporção positiva entre volume e fluxo fonatórios, os quais se mantiveram com um adequado tempo de fonação. No A2, o reduzido volume fonatório associou-se com uma dispersão mais rápida do fluxo fonatório, menor duração da fonação e necessidade de pausas freqüentes; ruído do estoma e a hiperarticulação consonantal prejudicou o comportamento vocal nesse grupo. Finalmente, no grupo B, uma positiva proporção entre volume e fluxo fonatório representou o pré-requisito da fala sem pausas freqüentes.

Dentre os objetivos propostos, Barros (2002) verificou a efetividade da comunicação oral e a qualidade de vida, além da sua relação com a depressão após a faringolaringectomia e LT. Tal estudo envolveu 82 pacientes (52 $\begin{array}{lllll}\text { laringectomizados totais, } 17 \text { faringolaringectomizados, } & 10\end{array}$ faringolaringectomizados totais e três faringoesofagogectomizados totais) que foram submetidos à avaliação perceptivo-auditiva, temporal e global da voz, responderam aos questionários de qualidade de vida e realizaram exames laboratoriais para investigação da dosagem hormonal. Destes, 41 eram falantes alaríngeos, sendo 18 traqueoesofágicos, 12 esofágicos e 11 usuários de vibrador laríngeo. Focando-se na comunicação oral, a voz traqueoesofágica apresentou a melhor efetividade da comunicação, assim como o grupo submetido à colocação primária da PTE. A fonoterapia foi essencial para o 


\section{REVISÃO DA LITERATURA}

desenvolvimento, adaptação e maximização da comunicação alaríngea. A pior caracterização da qualidade de vida ocorreu em relação aos aspectos emocionais, a alteração do olfato e paladar, a dificuldade financeira e de fala e a sexualidade.

Dantas et al. (2002) avaliaram a motilidade esofágica de 10 pacientes laringectomizados que desenvolveram a voz esofágica e 15 pacientes incapazes em adquiri-la, além de 40 voluntários saudáveis. Todos foram submetidos à manometria esofágica com perfusão contínua, durante a deglutição, para análise das variáveis de amplitude das contrações, duração e velocidade, sendo constatado que a motilidade esofágica estava prejudicada em laringectomizados totais, mas somente a diminuição da contração esofágica mostrou associação com a aquisição da voz esofágica.

Por meio de uma análise retrospectiva de arquivos de 97 laringectomizados totais, Fagan et al. (2002) observaram que os resultados da voz trqueoesofágica na prática médica do 3 mundo são comparáveis com centros de excelência de $1^{\circ}$ mundo e não são afetados pelos fatores emprego ou proximidade aos serviços especializados. Apesar do grau de instrução e qualidade da moradia pudessem influenciar os resultados da fala, vários pacientes analfabetos e aqueles que viviam em precárias condições conseguiram adquirir também boa voz traqueoesofágica.

Dentre os objetivos do estudo, Mendenhall et al. (2002) analisaram o tipo e a extensão de sucesso das técnicas de reabilitação de voz em 173 pacientes tratados com a LT e irradiação pós-operatória, sendo 158 homens e 15 mulheres, com idade média de 60 anos. De modo geral, a reabilitação vocal envolveu as categorias de voz traqueoesofágica, laringe artificial, voz esofágica, ausência de voz e ausência de informações a respeito. Quanto ao método de reabilitação vocal, as informações pertinentes estavam disponíveis de dois a três anos ou mais para 118 pacientes e cinco anos ou mais para 69 pacientes. A extensão de sucesso dos métodos de reabilitação para os dois períodos citados anteriormente foram, respectivamente: voz traqueoesofágica, $27 \%$ e $19 \%$; laringe artificial, $50 \%$ e $57 \%$; voz esofágica, $1 \%$ e 3\%; ausência de voz, $17 \%$ e $14 \%$ e nenhuma informação a respeito, $5 \%$ e $7 \%$. A forma de 


\section{REVISÃO DA LITERATURA}

reabilitação vocal mais comum após a LT e irradiação pós-operatória foi a laringe artificial e daqueles que se submeteram a punção traqueoesofágica, aproximadamente metade deles utilizará tal método em longo prazo.

Brown et al. (2003) forneceram informações históricas quanto as formas de comunicação alaríngea, abrangendo desde a fala faríngea e bucal até a reabilitação cirúrgica da voz. Referiram que apesar da remoção laríngea resultar na perda da voz, tal situação não elimina inteiramente as suas possibilidades de produção, já que o movimento de ar pulmonar ainda está presente, assim como os mecanismos de ressonância da voz. Limitando-se à PTE, os autores incentivaram a sua inserção de forma primária e destacaram sobre a importância de controle da tonicidade do segmento faringoesofágico, sendo relatada a efetividade da miotomia dos constritores faríngeos, médio e inferior, além do cricofaríngeo para casos de hipertonicidade ou espasticidade pós-operatória. Quanto à principal causa para substituição da PTE, citaram o vazamento de fluidos pelo seu interior, cuja incompetência valvular é geralmente causada por depósitos de cândida no material de silicone. Ressaltaram também sobre a utilização do HME (Heat and Moisture Exchanger) visando a melhora da condição pulmonar e da qualidade de vida dos pacientes, contribuindo também com a reabilitação vocal. Dentre as vantagens com o uso da PTE, destacaram a produção vocal imediata, altas taxas de sucesso e baixas taxas relativas de complicações, já as desvantagens mencionadas foram a obstrução e vazamento pelo interior da prótese, além da necessidade de utilização da mão para oclusão do traqueostoma, apesar deste poder ser solucionado com válvulas de fala em determinados pacientes.

Num total de 24 peças obtidas de cadáveres de adultos de ambos os sexos fixados em formaldeído a 10\%, Costa (2003) estudou as características morfológicas da laringofaringe e suas relações. Nos cortes sagitais, evidenciou a convexidade da lordose cervical em nível de C5 e C6, intimamente aposta a laringe, definindo ação de pinça que mantém aproximadas as paredes anterior e posterior da laringofaringe por toda a extensão longitudinal da cartilagem cricóide. As paredes laterais e posterior musculares da laringofaringe mostraram-se constituídas pela inter-relação de fascículos musculares pares, 
aplanados e de pequena espessura, que constituíram o constritor inferior da faringe. A parede anterior da laringofaringe em nível da projeção da cartilagem cricóide não apresentou musculatura faríngea e sendo conjuntivo-mucosa, cobria o contorno posterior da cartilagem cricóide. O músculo cricofaríngeo apresentou suas inserções ântero-laterais nas bordas póstero-laterais da cartilagem cricóide, configurando morfologia em meia calha, cuja contração não permitiu a geração de pressão com predomínio anterior e posterior, como a encontrada na TFE.

Koybasioglu et al. (2003) compararam os valores de pressão do segmento faringoesofágico no décimo dia pós-operatório em 20 laringectomizados totais com neurectomia faríngea e $25 \mathrm{sem}$ tal procedimento, sendo todos usuários de PTE. Quanto aos valores pressóricos obtidos, os grupos de pacientes com e sem neurectomia apresentaram médias de $12,82 \mathrm{mmHg}$ e $17,4 \mathrm{mmHg}$, respectivamente. Considerando-se o ponto crítico de $20 \mathrm{mmHg}$, entre os pacientes sem neurectomia faríngea, 10 deles apresentaram níveis de pressão maiores que tal valor pré-estabelecido, enquanto que no outro grupo, somente um. Em suma, os autores constataram que a neurectomia faríngea resultou em uma diminuição pressórica significante do segmento faringoesofágico em indivíduos submetidos à LT.

Fouquet et al. (2009) relacionou a avaliação videofluoroscópica do esôfago com a qualidade da voz esofágica em 30 laringectomizados totais que foram divididos em grupos de bons, moderados e ruins falantes. De acordo com os resultados obtidos, o grupo de falantes esofágicos ruins foi caracterizado pela ausência de um segmento faringoesofágico observável e de um reservatório de ar pequeno ou ausente, e os grupos de falantes bons e moderados apresentaram presença de um reservatório de ar e um segmento faringoesofágico vibrante, sendo este mais curto no grupo bom do que no moderado. A barra cricofaríngea foi observada com maior freqüência nos grupos de bons e moderados falantes. $\mathrm{Na}$ análise perceptivo-auditiva, o grupo de falantes ruins foi caracterizado pela ausência de voz esofágica e presença de fala articulada, fala bucal, ou faríngea, o grupo de falantes esofágicos bons 


\section{REVISÃO DA LITERATURA}

apresentou qualidade vocal predominantemente rouca e o moderado, voz rouco-tensa e rouco-áspera.

Para avaliar a efetividade da neurotoxina botulínica (BOTOX®) na eliminação do espasmo muscular do constritor faríngeo quanto à restauração da voz traqueoesofágica, Hamaker e Blom (2003) realizaram uma revisão de 62 pacientes submetidos a tal procedimento, os quais foram divididos em três grupos, de acordo com a resposta a toxina, ou seja, grupo I (41 indivíduos) apresentou completo relaxamento dos constritores faríngeos, resultando em fala fluente; grupo II (oito) apresentou hipertonia ou relaxamento incompleto dos constritores faríngeos e finalmente, o grupo III (13) que não atingiu resposta a neurotoxina e permaneceram afônicos. Após a primeira injeção de BOTOX $\circledast$, 34 pacientes do grupo I (28) e II (seis) responderam à neurotoxina por mais que seis meses e com a segunda aplicação, seis dos 13 que falharam seguiram para o grupo I, demonstrando a efetividade desse procedimento que tem substituído a miotomia secundária em seu tratamento inicial, oferecendo resultados fonatórios máximos.

Por meio de uma revisão bibliográfica, Murray et al. (2003) descreveram sobre a anatomofisiologia do corpo do esôfago e de seus esfíncteres, sendo que o esfíncter esofágico superior foi definido como uma zona de alta pressão de $2-4 \mathrm{~cm}$ interposta entre a faringe e o esôfago, composto pelo músculo cricofaríngeo e a porção inferior do constritor faríngeo. As pressões manométricas obtidas nesse local apresentam duas origens, ou seja, contração do músculo do próprio esfíncter e forças viscoelásticas passivas produzidas pelos tecidos ao seu redor. A complexa sequência neuromuscular observada durante a deglutição, cujos mecanismos atuantes nessa função incluem a tração da parede anterior do esfíncter pela contração dos músculos supra e infrahioideos durante a elevação da laringe, relaxamento do cricofaríngeo e pressão do bolo deglutido pode ser constatada manometricamente. Os autores discorreram também a respeito dos componentes da manometria, forma de realização do exame e suas indicações, sendo destacado que valores normais de pressão em repouso no esfíncter esofágico superior e ondas de pressão peristáltica na faringe não estão bem estabelecidos na literatura, cuja avaliação 


\section{REVISÃO DA LITERATURA}

dos mesmos é dificultada por problemas técnicos relacionados a própria anatomia e fisiologia dessas regiões. Porém, tal exame pode ser utilizado como um teste adjuvante em pacientes que apresentem uma maior probabilidade de desordens afetando a musculatura estriada.

Op de Coul et al. (2003) utilizaram a videofluroscopia visual e quantitativa para avaliar a influência da miotomia primária nas características da neoglote em 19 laringectomizados totais e usuários de PTE, sendo que 12 deles foram submetidos a miotomia lateral primária do esfíncter esofágico superior e sete não requiseram tal procedimento. Dentre os resultados, durante a fonação, todos os pacientes apresentaram uma única barra neoglote. Não houve relação entre presença de uma barra neoglote durante o repouso e realização da miotomia, assim como entre miotomia e qualidade vocal. Do mesmo modo, nenhuma das medidas quantitativas da neoglote se relacionou com os grupos com e sem miotomia.

Os objetivos propostos por van As et al. (2003) foi investigar a qualidade vocal traqueoesofágica conduzida por juízes leigos e experientes e desenvolver um protocolo de escalas perceptuais suficiente para sua avaliação perceptual. Participaram do estudo 40 laringectomizados totais, sendo 30 homens e 10 mulheres. O material de fala foi apresentado aos dois grupos de juízes, sendo composto um deles por 20 juízes leigos e outro por quatro expertos. Foi utilizado um conjunto de escalas de sete pontos semânticos, consistindo de três escalas de avaliação, e 16 escalas descritivas para os juízes leigos e 17 escalas descritivas para os expertos. Ambos os grupos utilizaram a mesma escala para avaliação, exceto o parâmetro relacionado à tonicidade foi modificado para cada grupo. A parte desse julgamento das escalas, os expertos foram orientados a caracterizarem a qualidade vocal geral dos indivíduos. A confiabilidade inter-juízes foi alta para ambos os grupos, sendo a menor observada para a escala rugosa e não rugosa. Quanto à confiabilidade intra-juízes, esta foi maior no grupo de expertos, porém a escala rugosidade continuou sendo a que apresentava o menor coeficiente de confiabilidade. Foi elaborado um protocolo com quatro escalas e duas dimensões (pitch e qualidade vocal) para os juízes leigos e sete escalas e quatro dimensões 


\section{REVISÃO DA LITERATURA}

(qualidade vocal. tonicidade, pitch e tempo) para os juízes expertos. Para os juízes leigos, apenas as escalas alto e baixo, e profundo e agudo não foram diferentes para os grupos de falantes bom, moderado e ruim, do mesmo modo que para os expertos, porém acrescidas pelas escalas: hipertônica e não hipertônica, lenta e rápida. Quanto a radioterapia, a voz foi julgada como menos expressiva, monótona no grupo de paciente submetido a radioterapia pós-operatória. Além disso, o grupo que não necessitou de esvaziamento cervical, apresentou uma fala mais rápida.

No estudo de Bayles e Deschler (2004), uma atenção especial foi destinada à hipertonicidade do constritor faríngeo após o desenvolvimento da voz traqueoesofágica e as crescentes experiências na área possibilitaram mostrar que a sua restauração pode ser limitada por espasmos induzidos pela insuflação de ar no interior do esôfago e neofaringe. Tal espasmo faringoesofágico, também referido como hipertonicidade, geralmente manifesta-se como um aumento abrupto no pitch e conseqüente interrupção completa da fala. Destacaram que modificações em técnicas cirúrgicas e manejo dos constritores faríngeos são necessários para reverter ou prevenir o espasmo de tal musculatura em indivíduos que optaram pela comunicação traqueoesofágica. Em relação aos procedimentos realizados intra ou póscirurgico para prevenção e melhora dos espasmos, foram citadas: a miotomia do constritor faríngeo, a injeção de toxina botulínica e a neurectomia do plexo faríngeo. Quanto as técnicas de fechamento faríngeo na cirurgia de LT e seus resultados alcançados, discorreram sobre o fechamento tradicional de três camadas que compreende a mucosa, submucosa e músculos constritores, fornecendo tecido vascularizado sobre a linha de fechamento e limitando 0 risco de formação de fístulas, e o tipo de fechamento não muscular, envolvendo a mucosa e a submucosa, a fim de se evitar o espasmo faringoesofágico, já que este evita a formação do anel circunferencial. Seguindo a proposta de se evitar o completo fechamento circunferencial e mantendo o benefício da vascularização muscular, referiram sobre a possibilidade de fechamento da metade muscular (half-muscle closure), a qual oferece uma oportunidade primária para controle do espasmo e do tônus, além 


\section{REVISÃO DA LITERATURA}

de parecer ter a possível vantagem de fornecer frequências fundamentais mais aceitáveis.

Bunting (2004) discutiu sobre os problemas mais comuns encontrados em pacientes submetidos à inserção de PTE, cujo processo de identificação e solução do problema requer uma avaliação sistemática pelo clínico, especialmente nos casos de dificuldade de fonação alaríngea. Tal atenção deve ser criteriosa a fim de determinar se a falha está relacionada com a PTE, segmento faringoesofágico ou a outros aspectos, tal como a forma de oclusão do traqueostoma. De acordo com o autor, problemas relacionados ao segmento faringoesofágico devem ser considerados quando os pacientes ocluem corretamente o traqueostoma, mas continuam a apresentar esforço ao vocalizar ou afonia, sendo necessária a realização de exames para avaliação do segmento, como a nasofibroendoscopia, videoestroboscopia ou videofluoroscopia para contribuir com a elucidação do caso. Além disso, discutiu a respeito dos problemas de granulação, microestoma, local incorreto da punção, entre outros, fornecendo as possíveis causas e soluções.

Por meio da avaliação acústica e da pronúncia, Globlek et al. (2004) compararam a voz e a fala entre três grupos de falantes alaríngeos, composto cada um por cinco laringectomizados totais: esofágicos, usuários de dispositivo eletro-acústico e traqueoesofágicos. Quanto à análise acústica, os valores médios de frequência fudamental para os grupos de voz esofágica, dispositivo eletro-acústico e voz traqueoesofágica foram, respectivamente: $56,97 \mathrm{~Hz}, 71,96 \mathrm{~Hz}$ e $70,75 \mathrm{~Hz}$. Seguindo a mesma ordem apresentada, o tempo máximo de fonação foi de $0,95 \mathrm{~s}, 0,81$ s e $6,85 \mathrm{~s}$. Os esofágicos apresentaram os maiores valores de jitter $(3,19 \%)$ e shimmer $(2,66 \mathrm{~dB})$. Os falantes com dispositivo eletro-acústico apresentaram a maior intensidade vocal (74,81dB), seguidos pelos usuários de PTE $(70,75 \mathrm{~dB})$ e esofágicos $(63,72 \mathrm{~dB})$. Quanto à pronúncia, a duração do bloco fonético foi menor nos falantes esofágicos $(0,71 \mathrm{~s})$, assim como o número de sílabas no bloco $(2,63)$ e a taxa de fala $(1,39$ sílabas/s). A taxa de articulação no bloco fonético máximo foi maior para os traqueoesofágicos (481 sílabas/s). Diante dos achados, os autores concluíram que apesar da voz e a pronúncia traqueosofágica serem mais próximas da voz 


\section{REVISÃO DA LITERATURA}

normal em vários aspectos, a maioria utilizou a voz esofágica, que associada ao dispositivo de fala transcervical, promoveram a oportunidade de estabelecimento de adequada comunicação.

De acordo com Gress (2004), quatro critérios são utilizados para caracterizar sucesso da reabilitação traqueoesofágica, ou seja, a fala deve satisfazer consistentemente as necessidades diárias de comunicação do falante; a prótese deve estar posicionada adequadamente no local da punção; a prótese deve prevenir o vazamento de saliva, alimentos e líquidos para dentro do traqueostoma e o paciente ou o seu cuidador deve ser capaz de realizar a manutenção do dispositivo. O princípio básico para a decisão clínica é sempre o sacrifício da voz em consideração a saúde do paciente. Em função de um grande número de pacientes serem incapazes de adquirir uma voz adequada, os autores referiram que uma avaliação criteriosa prévia à inserção secundária pode contribuir na identificação de casos potenciais de afonia, sendo que a intervenção deve ser iniciada o quanto antes, excluindo um longo período de frustração, destacando que muitas vezes, tal falha está relacionada à integridade estrutural e funcional do segmento faringoesofágico. Exames como a videofluorografia, manometria, endoscopia de alta velocidade, além de estudos acústicos e aerodinâmicos têm elucidado algumas características gerais do faringoesôfago e mecanismo de vibração da neoglote. Testes preditivos incluídos na avaliação pré-operatória para restauração secundária da voz podem identificar os pacientes com anormalidades estruturais ou fisiológicas que irão comprometer o desenvolvimento satisfatório da voz traqueoesofágica. O precoce reconhecimento e manejo dos obstáculos à aquisição da voz traqueoesofágica diminui o tempo de recuperação até que a comunicação seja alcançada, permitindo a um maior número de indivíduos se beneficiarem da restauração da voz traqueoesofágica.

No artigo de Lewin (2004) foram discutidos os problemas relacionados à forma, tamanho e posição do traqueostoma em laringectomizados em relação à aquisição da voz traqueoesofágica, sendo realizada uma revisão de técnicas não cirúrgicas para manejo de tais problemas. Primeiramente, foi exposto sobre o tamanho do estoma como determinante para a oclusão adequada 


\section{REVISÃO DA LITERATURA}

durante a produção da voz com PTE, tanto manualmente (digital) quanto por meio de uma válvula, referindo que o tamanho ideal é aquele grande o bastante para acomodar a PTE sem comprometer o fluxo aéreo e pequeno o suficiente para permitir uma oclusão adequada para a produção da voz traqueoesofagica. Descreveu sobre técnicas como próteses manufaturadas (como bolas de ping-pong) utilizadas para ocluir estomas grandes que não possam ser ocluídas digitalmente, além de cânulas fenestradas de laringectomia para diminuir o diâmetro do estoma e permitir a oclusão digital, com variáveis níveis de sucesso e aceitação pelos pacientes. O estoma pequeno foi apresentado como mais freqüente em pacientes submetidos à radioterapia, dificultando a colocação da PTE e os cuidados com ela, sendo a solução mais comum para este caso a dilatação seriada do estoma com tubos de laringectomia de silicone progressivamente mais largos. $O$ artigo explicou que a posição e o formato do estoma são dependentes de cada laringectomizado total, tamanho e localização do tumor laríngeo e da técnica cirúrgica utilizada.

De acordo com Pou (2004), a LT altera profundamente a fala, a respiração e a sensação de olfato e paladar, considerando a perda da voz como principal responsável pelas conseqüências econômicas e psicossociais. Descreveu sobre as formas de comunicação alaríngea, destacando sobre a evolução da PTE ao longo dos anos e sua ampla aceitabilidade entre os usuários. Relatou que o objetivo da reabilitação alaríngea é promover uma fala fluente, inteligível e sem esforço, relacionando a fluência traqueoesofágica com a necessidade de relaxamento faríngeo, já que $20-40 \%$ dos usuários de PTE apresentam fala hipertônica na tentativa de fonação, indicando espasmo do cricofaríngeo e músculos constritores médios e inferiores da faringe.

Schuster et al. (2004) utilizaram o questionário VHI (Voice Handcap Index) para analisar o handcap vocal em 20 laringectomizados reabilitados com a PTE, 15 pacientes sem desordens de voz, $15 \mathrm{com}$ desordens funcionais e 29 com desordens orgânicas. Considerando a extensão de valores de avaliação do questionário como zero representando ausência de handcap vocal a 120 (máximo de handcap vocal), o valor médio obtido neste estudo foi 45,5 , com 


\section{REVISÃO DA LITERATURA}

amplas diferenças individuais (13-101), podendo ser utilizado como um guia para o manejo terapêutico individual do laringectomizado total. $\mathrm{O}$ VHI dos laringectomizados foi significativamente maior do que aqueles apresentados por pacientes com desordens de voz funcional e ao grupo normal. Quanto ao grupo de desordens orgânicas e LT, houve diferença significante apenas na escala funcional.

Singer (2004) discorreu a respeito do desenvolvimento da voz traqueoesofágica abordando desde a primeira cirurgia de LT até o transplante de laringe já realizado. Dentre as possibilidades de reabilitação vocal, foi descrito a respeito da voz esofágica, cujo sucesso é alcançado para menos que $1 / 3$ dos laringectomizados, e ainda poucos são considerados falantes excepcionais. Quanto à evolução da PTE, destacou a importância do shunt traqueoesofágico como um favorecedor do entendimento do mecanismo de fala alaríngea, demonstrando o papel da pseudoglote e revelando a sua simplicidade, porém não deixou de citar os possíveis problemas de estenose e aspiração junto à traquéia que podem limitar o uso desse procedimento. Referiu que os bons resultados atingidos com a comunicação com PTE ultrapassaram qualquer outra forma de fala alaríngea, e em função de sua melhor inteligibilidade tem se tornado o método de escolha para a reabilitação vocal. O autor concluiu que a qualidade da fala tem sido o principal aspecto para as cirurgias de câncer de laringe, afetando o desenvolvimento dos tratamentos e motivando cirurgiões a experienciarem pesquisas inovadoras a respeito.

O propósito do estudo de van As et al. (2004) foi obter conhecimento em relação ao valor clínico da utilização da endoscopia digital de alta velocidade em adição a videofluoroscopia a respeito da neoglote em falantes traqueoesofágicos. Desse modo, foram estudadas as características anatômicas e morfológicas da neoglote em 37 laringectomizados totais usuários de PTE, por meio da utilização de medidas visuais da endoscopia digital de alta velocidade e avaliação quantitativa e visual da videofluoroscopia. De forma geral, a endoscopia digital de alta velocidade complementou a videofluoroscopia quanto aos parâmetros de localização da vibração, presença 


\section{REVISÃO DA LITERATURA}

de onda mucosa, regularidade de vibração e fechamento da neoglote. A quantidade de saliva mostrou relação com a presença da barra neoglote no repouso, regurgitação de bário e tonicidade da barra durante a fonação. $A$ forma da neoglote se relacionou com a presença da barra neoglote no repouso. No caso da onda mucosa, a distância subneoglótica durante a fonação foi maior quando a onda mucosa foi observada. No grupo de pacientes que se submeteram a reconstrução, observou-se maior quantidade de saliva comparando-se àqueles submetidos à LT clássica.

Por meio da manometria, Aguiar-Ricz (2005) comparou as pressões intraluminares do esôfago durante a deglutição líquida, da TFE em repouso e do esôfago, da TFE e da faringe durante a emissão da voz e da fala, em 11 laringectomizados falantes com PTE e 14 não falantes sem prótese. Quanto a TFE, a média de pressão observada durante o repouso para os falantes traqueoesofágicos foi de $17,2 \mathrm{mmHg}$ e para os não falantes de $25,1 \mathrm{mmHg}$. Não houve diferença entre os dois grupos em todas as variáveis de pressão durante as provas de voz e fala, exceto a duração da pressão na emissão do monossílabo que foi menor no grupo de falantes. Na faringe, não houve diferença entre as variáveis de pressão para ambos os grupos durante as provas de voz e de fala. Quanto ao esôfago distal, a amplitude de pressão foi maior nos falantes durante a emissão sonora; no medial, a pressão foi maior durante a emissão de frase em todas as variáveis nos falantes também, ao contrário da deglutição, cuja duração foi maior nos não falantes e no proximal, os falantes foram os que apresentaram menor duração e área sob a curva durante a deglutição.

O estudo prospectivo de Chone et al. (2005) envolveu 71 pacientes laringectomizados totais e reabilitados com a prótese vocal, sendo 62 com prótese primária e nove com secundária, cuja qualidade vocal e utilidade da prótese vocal foram avaliadas continuamente em um mês, a cada três meses até um ano de seguimento, e a cada seis meses após um ano. A taxa geral de sucesso da voz traqueoesofágica foi de $94 \%$, com $97 \%$ para a primária e $78 \%$ a secundária. Após dois anos de seguimento, a taxa de sucesso diminuiu para $96 \%$ para a primária e $75 \%$ para a secundária. O uso da radioterapia não 


\section{REVISÃO DA LITERATURA}

influenciou a taxa de sucesso no uso da prótese vocal, independente do momento de sua inserção, assim como o fator idade. De forma geral, houve tendência de maior sucesso para os pacientes com inserção primária da prótese vocal.

Por meio da manometria esofágica durante a deglutição, Dantas et al. (2005) avaliaram as contrações no corpo do esôfago proximal em 12 indivíduos controle e 20 laringectomizados totais, dos quais 12 foram reabilitados com a voz esofágica. Como resultados, os valores médios de amplitude e duração das contrações durante a deglutição foram menores em pacientes laringectomizados $(37,3 \mathrm{mmHg}$, com duração de $2,2 \mathrm{~s})$ do que no controle $(81,1$ $\mathrm{mmHg}$, com duração de 2,6s), sugerindo que a laringectomia pode afetar as contrações do esôfago proximal. A amplitude média de contração em pacientes habilitados com a voz esofágica não se diferenciou dos pacientes incapazes de produzi-la. Do mesmo modo, os pacientes submetidos a radioterapia $(36,7 \mathrm{mmHg})$ tiveram a mesma amplitude daqueles que não foram submetidos a tal procedimento $(34,7 \mathrm{mmHg})$.

Gerwin e Culton (2005) mensuraram a eficácia da voz com PTE em 16 laringectomizados totais em relação aos parâmetros de qualidade de vida, por meio da aplicação combinada de dois protocolos validados (University of Washington Quality of life scale e Functional Assesmentof câncer therapy head and neck scale) e um questionário contendo informações demográficas. Como resultados, os indivíduos referiram que são capazes de se comunicar com outras pessoas, julgando sua voz pós-cirurgica como sendo bastante ou quase similar à qualidade e força da voz pré-cirúrgica. Dois terços dos pacientes consideraram sua fala como sendo inteligível, com necessidade ocasional de repetição, enquanto o 1/3 restante revelaram ser sua fala sempre inteligível. Todos os pacientes responderam ser entendidos ao telefone e $87 \%$ deles mostraram-se tanto satisfeitos como muito satisfeitos com a sua forma de comunicação. Diante disso, concluiu-se que a restauração com a PTE atingiu as expectativas, satisfação com a fala e boa qualidade de vida, mensurada por meio dos parâmetros de bem-estar físico, funcional, social e emocional. 


\section{REVISÃO DA LITERATURA}

Kazi et al. (2005) entrevistaram 25 pacientes laringectomizados totais e usuários de PTE, sendo 16 homens e nove mulheres, por meio de um questionário auto-administrado com o objetivo de se obter informações a respeito das suas experiências com a PTE. Analisando-se os resultados, foi relatado melhora da qualidade de vida com a PTE e as mulheres mostraram-se menos satisfeitas com a qualidade vocal alaríngea do que os homens. Quatorze pacientes (60\%) revelaram vazamento ao redor ou pelo meio da prótese recentemente, sendo o tempo de vida útil da mesma de três meses. Diante dos dados obtidos, os autores concluíram que o questionário serviu como um valioso instrumento para monitorar a reabilitação vocal em pacientes submetidos a LT.

Oliveira et al. (2005) compararam a qualidade da comunicação oral pré e pós-treinamento fonoaudiológico em 17 pacientes laringectomizados, com idade entre 40 e 81 anos, usuários de PTE, obtendo-se como resultados que $11(64,7 \%)$ deles apresentaram melhora na sua comunicação, dois tiveram as suas avaliações inalteradas e quatro apresentaram notas piores no período de pós-treinamento. Os itens melodia frasal e canto apresentaram o maior número de sujeitos com melhora. A qualidade vocal foi considerada como rouca em $100 \%$ dos casos, havendo indicação de rouco-áspera para sete $(41,1 \%)$.

Schuster et al. (2005) avaliaram o tipo de vibração da pseudoglote e quantificaram automaticamente as oscilações do segmento faringoesofágico em 10 laringectomizados totais do sexo masculino com idade média de 61, 5 anos, por meio da endoscopia de alta velocidade e de um algorítimo desenvolvido para processamento das imagens. Dentre os formatos da neoglote, três indivíduos a apresentaram mais circular e em um deles foi triangular. Em todas as gravações, observou-se abertura e fechamento quaseperiódico da pseudoglote, não sendo constatado movimento caótico do segmento faringoesofágico. A identificação automática da pseudoglote foi realizada, independentemente de sua localização, formato e deformação durante a oscilação. As freqüências das oscilações extraídas da pseudoglote assemelharam-se as freqüências dos sinais acústicos. 


\section{REVISÃO DA LITERATURA}

Albirmawy et al. (2006) apresentaram a experiência de seu serviço com a PTE, oferecendo atenção a incidência e manejo dos eventos adversos encontrados com esse método de reabilitação vocal. Por meio da revisão de arquivos de pacientes usuários de PTE, foram selecionados 75 indivíduos, os quais foram divididos em dois grupos: inserção primária ou secundária da PTE. De modo geral, no grupo de inserção primária, os resultados foram inicialmente favoráveis em $91 \%$ dos pacientes e ainda positivo em $81,4 \%$ após três anos. No grupo de inserção secundária, resultados imediatos foram favoráveis em todos os pacientes, e somente dois deles foram informados para fechamento tardio eletivo da punção traqueoesofágica. A maioria dos problemas pôde ser resolvida adequadamente, minimizando o desconforto dos pacientes.

Carmo et al. (2006) investigaram os indicativos da qualidade de vida em seis indivíduos laringectomizados totais, falantes esofágicos ou traqueoesofágicos, e a sua relação com os aspectos perceptivo-auditivos da qualidade vocal. Foi aplicado um protocolo de qualidade de vida e de voz (QVV) e um roteiro de escala de fluência para avaliação dos juízes; além de um roteiro de auto-percepção vocal para os laringectomizados totais. Quanto aos resultados, os sujeitos que apresentaram um escore global baixo no protocolo de QVV foram àqueles que sentiram maior desconforto na voz, referindo tensão e rouquidão, além dos juízes os classificarem como limitantes para se comunicar. Os sujeitos com escore global alto apresentaram uma melhor percepção de sua voz e realizaram fonoterapia, tendo sido classificados pelos juízes como bons falantes, capazes de emitir sentenças ou falar fluentemente, sem hesitação. Desse modo, o maior desconforto apresentou-se no domínio físico e os julgamentos efetuados pelos profissionais e pelos laringectomizados totais correlacionaram-se entre si e com o QVV.

Hilgers et al. (2006) relataram a experiência de sucesso com o caso de um paciente submetido à radioterapia e posteriormente a LT, sendo reabilitado com a voz traqueoesofágica, porém apresentando-a de forma soprosa e sussurrada, cuja melhora foi atingida após realização de um procedimento cirúrgico específico, o qual se baseou no funcionamento de pressão externa do traqueostoma, por meio da distensão do músculo esternocleidomastoideo ao 


\section{REVISÃO DA LITERATURA}

longo da parede faríngea no nível do ponto de pressão estabelecido anteriormente sobre a pele, através da videofluoroscopia, e suturado junto à parede faríngea sob determinada tensão. Como resultados, houve melhora dos momentos de afonia e de aerofagia, sendo constatada uma voz mais forte com pitch discretamente grave e menos soprosa, melhora na extensão dinâmica e no tempo máximo de fonação. Diante disso, os autores consideraram que tal procedimento cirúrgico pôde melhorar a voz hipotônica em pacientes motivados a se submeterem a uma cirurgia adicional.

Iwai et al. (2006) examinaram a aquisição imediata da fonação esofágica seguindo a fonação traqueoesofágica, além dos mecanismos subjacentes e métodos fonatórios preferenciais por falantes que dominavam ambos os métodos de comunicação alaríngea. Os 44 participantes foram divididos em três grupos: A: 13 falantes esofágicos apenas, B: 21 falantes traqueoesofágicos apenas e C: 10 indivíduos que adquiriram a fonação esofágica após aprenderem a fonação traqueoesofágica. Constatou-se que a aquisição da fonação traqueoesofágica acelerou significativamente a aquisição da voz esofágica, passando de 184,6 dias para 59,3 dias, sendo que os pacientes no grupo C passaram a utilizar predominantemente a fonação esofágica. Não houve diferenças entre os grupos, considerando a relação entre aquisição de cada método de fonação e as características do paciente, incluindo idade, tempo de cirurgia, irradiação e esvaziamento cervical. Os autores concluíram que a fonação traqueoesofágica participa na aquisição mais imediata da voz esofágica.

Kazi et al. (2006) avaliaram o segmento faringoesofágico em 42 pacientes laringectomizados totais, por meio da videofluoroscopia, cujas medidas objetivas e visuais foram comparadas com a qualidade vocal e tratamentos variados. Dentre os resultados, o grau geral da voz mostrou-se como o mais confiável e consistente entre os juízes, sendo observada apenas correlação entre voz com grau geral discreto da escala GRBAS e menor distância mínima da neoglote na fonação. A maioria dos pacientes apresentou uma única barra neoglote no repouso e na fonação $(n=27$ e $n=35$, respectivamente) e somente três apresentaram dupla barra. Neoglote regular, 


\section{REVISÃO DA LITERATURA}

normotônica com fechamento durante a fonação foi observada em $64,2 \%$ dos pacientes. Não houve nenhuma relação entre os parâmetros visuais e os vários tratamentos. Comparações dos parâmetros da videofluoroscopia revelaram uma diferença entre a barra neoglote no repouso (média=23mm) e na fonação (média=22mm) e a máxima distância subneoglótica no repouso (média=7mm) e na fonação (média=8mm). Os resultados sugeriram que apesar da videofluoroscopia ser atrativa em laringectomizados, ainda apresenta limitações.

Stajner-Katusic et al. (2006) compararam achados acústicos, temporais e de inteligibilidade produzidos por diferentes formas de comunicação alaríngea, sendo avaliados 10 falantes esofágicos, seis com eletrolaringe e três com PTE. Os valores de freqüência fundamental e intensidade vocal obtidos para os grupos foram de $70,2 \mathrm{~Hz}$ e $63,72 \mathrm{~dB}$ (voz esofágica), $81,4 \mathrm{~Hz}$ e 74,81dB (eletrolaringe) e, $59,9 \mathrm{~Hz}$ e 70,75dB (PTE). Quanto as características temporais e limitando-se a voz com PTE, o tempo total de leitura foi de 31,40s, taxa de fala de 2,77 silabas/s e duração do bloqueio fonético de 2,07s. As categorias nasais, sonoras e africadas apresentaram maior porcentagem de reconhecimento $(51,2 \%)$, assim como as consoantes surdas $(49,5 \%)$. Desse modo, os autores destacaram a vantagem da prótese vocal sobre os outros tipos de comunicação, baseando-se no fluxo pulmonar e então sua proximidade com a voz e fala normal, considerando a inteligibilidade e as características temporais.

Com a utilização da manometria esofágica, Aguiar-Ricz et al. (2007) avaliaram a pressão do esfíncter esofágico superior, durante o repouso e a fonação, em 20 laringectomizados totais, dos quais 12 eram falantes com sucesso e oito sem sucesso. Durante o repouso, a média de pressão do esfíncter foi de $11,83 \mathrm{mmHg}$ para falantes com sucesso e 9,92mmHg para os sem sucesso, com média para os dois grupos de 11,06mmHg. Assim como para o repouso, não foi observada diferença significante durante a emissão de voz e fala, concluindo-se que a pressão do segmento cricofaríngeo não é um fator preponderante para a aquisição da voz e da fala esofágica. 


\section{REVISÃO DA LITERATURA}

Comparando-se os resultados da inserção primária e secundária da prótese de voz indwelling, Boscolo-Rizzo et al. (2008) avaliaram os resultados vocais e as complicações pós-operatórias, por meio da escala HarrisonRobillard- Schultz (HRS). Um total de 93 laringectomizados totais com idade média de 63 anos e com seguimento maior do que dois anos foram considerados para avaliação, sendo que 75 deles foram submetidos à inserção primária da prótese e 18 à secundária. A taxa de sucesso geral obtida de acordo com HRS foi de $81,7 \%$, com $80 \%$ na forma primária e $88,9 \%$ na condição secundária. O uso da radioterapia pós-operatória não influenciou significativamente a taxa de sucesso no uso da prótese. A maior taxa de complicações observadas na forma primária não foi significante. A prótese vocal indwelling foi considerada segura e efetiva, independente do momento de sua inserção, porém os autores demonstraram preferência pela forma primária.

A proposta de Casso et al. (2008) foi determinar o efeito da radioterapia pré (47 pacientes) ou pós-operatória (48 pacientes) na deglutição e função vocal em 121 pacientes submetidos à $L T$, cujas informações necessárias foram obtidas pela revisão de pastas clínicas e informações da terapia vocal. Quanto à produção vocal, os pacientes foram divididos em boa voz e naqueles incapazes de produzi-la, assim como de se comunicar verbalmente livremente e/ou apresentar qualidade vocal insuficiente, necessitando então de uma eletrolaringe em adição. A respeito da deglutição, tais pacientes foram divididos naqueles capazes de deglutir sólidos sem restrição, deglutir pastosos, somente líquidos e/ou que necessitaram de dieta enteral. Quanto à deglutição, 48\% foram capazes de deglutir sólidos, 19\% puderam deglutir alimentos pastosos e 40 (33\%) apresentaram sérias dificuldades, 21\% foram capazes de ingerir apenas líquidos e 17 (14\%) necessitaram de dieta suplementar ou como medida primária de alimentação. Após a LT, a radioterapia afetou os resultados da deglutição, mas não o desenvolvimento da fala, quando realizada tanto como tratamento inicial como na situação pós-operatória.

Chone et al. (2008a) avaliaram a eficácia da toxina botulínica em oito laringectomizados totais, reabilitados com a PTE, cuja voz apresentava-se com esforço devido ao espasmo do segmento faringoesofágico. A avaliação 


\section{REVISÃO DA LITERATURA}

constituiu-se da análise perceptivo-auditiva e acústica da voz, videofluoroscopia e manometria computadorizada, todos realizados antes e após a aplicação da toxina botulínica. Quanto aos resultados, todos os pacientes apresentaram melhora vocal após a aplicação da neurotoxina no segmento faringoesofágico, evidenciada pela diminuição na pressão local, emissão de voz sem esforço, melhora do espasmo e da qualidade dos harmônicos após o tratamento.

Chone et al. (2008b) avaliaram a utilidade da manometria computadorizada para identificação de espasmo do segmento faringoesofágico durante a fonação traqueoesofágica, determinando o valor limiar para o seu diagnóstico. O estudo envolveu 20 falantes traqueoesofágicos, sendo que oito deles apresentavam espasmos do segmento e foram avaliados antes e após o tratamento com toxina botulínica. Além da manometria, foram realizadas a avaliação do tempo máximo de fonação e a videofluoroscopia do segmento faringoesofágico. A média de pressão obtida para os pacientes com e sem espasmos foi de $25,36 \mathrm{mmHg}$ e $11,76 \mathrm{mmHg}$, respectivamente. Após a aplicação da toxina botulínica, $86 \%$ dos pacientes apresentaram pressões menores que $16 \mathrm{mmHg}$. A sensibilidade e a especificidade para o diagnóstico de espasmo com valor limiar de $16 \mathrm{mmHg}$ foram de $100 \%$ e $90 \%$, respectivamente, com acurácia de $93 \%$.

O estudo de Grolman et al. (2008) envolveu um grupo de oito laringectomizados totais, cujos objetivos foram descrever a eficiência da voz traqueoesofágica e compará-la com a eficiência vocal laríngea. Além disso, foi mensurada a força aerodinâmica perdida na PTE. Para tais mensurações, foi utilizado um sistema computadorizado de transdutores de fluxo aéreo, de pressão e medição da intensidade sonora, dentre outros transdutores. Os autores observaram que a força aerodinâmica foi uma indicação da necessidade de esforço para produção vocal e a eficiência da voz traqueoesofágica foi menor quando comparada com a produção laríngea, além de sua força aerodinâmica efetiva ter sido reduzida pela prótese vocal durante a fonação. 
O objetivo do estudo de Lundström et al. (2008) foi relacionar, entre falantes esofágicos e traqueoesofágicos, os achados da função vocal com a avaliação perceptual e acústica da voz, além das possíveis diferenças na aparência e localização da nova fonte sonora. Nove laringectomizados totais, sendo cinco falantes traqueoesofágicos e quatro esofágicos, foram submetidos a registros videorradiográficos durante a fonação e repouso e o material de fala registrado foi analisado perceptualmente e acusticamente. Não foi observada relação entre medidas fisiológicas e resultados acústicos e perceptuais. Resultados significantes foram observados entre todas as medidas fisiológicas do segmento faringoesofágico. Não houve diferenças específicas no segmento faringoesofágico entre falantes esofágicos e traqueoesofágicos, porém observaram grandes diferenças individuais dentro de cada grupo. Todos os participantes apresentaram um bom fechamento ao nível do segmento faringoesofágico durante a fonação.

Masson et al. (2008) avaliaram a influência do uso HME no controle da secreção em pacientes pós-LT e a possível melhora da qualidade vocal esofágica e traqueoesofágica. O estudo envolveu nove laringectomizados totais falantes esofágicos (seis) e traqueoesofágicos (três), os quais responderam a um protocolo com questões relacionadas à secreção pulmonar em três momentos distintos de pré e pós-uso do HME, e suas vozes foram registradas e avaliadas perceptualmente em cada encontro. Os parâmetros da qualidade vocal não apresentaram diferença entre os momentos de avaliação, porém o uso do HME durante seis semanas diminuiu a tosse e a expectoração desses pacientes.

Foram objetivos de Perera et al. (2008) determinar e caracterizar o efeito da fonação na pressão intraluminal do trato gastrointestinal superior em 17 indivíduos saudáveis, sendo sete homens e 10 mulheres, por meio da associação da manometria esofágica de alta resolução e gravação vocal. Em oito dos 17 pacientes, foi realizada também a videofluoroscopia para análise do movimento laríngeo durante a fonação. Para confirmação dos achados pressóricos, seis pacientes foram ainda submetidos a outro exame manométrico. Constatou-se que todas as provas de fonação induziram a um 


\section{REVISÃO DA LITERATURA}

aumento significativo na pressão do esfíncter esofágico superior, sendo maior que os valores encontrados no esôfago, esfíncter esofágico inferior e estômago, sugerindo a existência de uma contração reflexa do esfíncter superior induzida pela fonação. Quanto aos achados da videofluoroscopia, não houve movimentação laríngea posterior durante a fonação, eliminando a causa exclusivamente mecânica para o aumento pressórico.

Allan et al. (2009) examinaram o efeito da alta pressão esofágica na motilidade do corpo do esôfago, na função do esfíncter esofágico inferior e nos sintomas de disfagia em 16 laringectomizados totais falantes com a fístula traqueoesofágica. Tais participantes responderam a um questionário sobre deglutição e foram submetidos à manometria esofágica, à videofluoroscopia e a medidas de pressão traqueal. Quanto ao questionário, 69\% dos pacientes referiram disfagia para a consistência sólida. Na manometria, seis pacientes apresentaram baixa pressão do esfíncter esofágico inferior $(<6 \mathrm{mmHg})$ e dois não mostraram relaxamento na deglutição. A função motora do corpo do esôfago foi anormal em nove pacientes. Quanto a videofluoroscopia, o diâmetro médio do esôfago superior na fonação foi de $16 \mathrm{~mm}$ e a motilidade esofágica alterada foi observada em sete pacientes, sendo que em seis deles já fora constatada pela manometria. A média de pressão traqueal na fonação foi de $36 \mathrm{cmH} 20$ para todos os pacientes. Os autores concluíram que não há contra-indicação para continuar com a fístula traqueoesofágica mesmo em pacientes com história de disfunção esofágica.

Bellandese (2009) investigou a relação entre freqüência fundamental e a correta identificação do gênero de 43 falantes alaríngeos, sendo 23 homens e 20 mulheres com idade média de 58 anos e que utilizavam a voz traqueoesofágica ou esofágica como o seu método primário de comunicação. $A$ amostra de voz foi avaliada por 48 indivíduos que tinham pouca ou nenhuma experiência com a voz alaríngea e a freqüência fundamental foi determinada por um programa específico computadorizado. A média da freqüência fundamental para falantes esofágicos foi de $123,6 \mathrm{~Hz}$ e traqueoeofágicos de 131,6 Hz. Dos pacientes avaliados, 79\% foram identificados corretamente quanto ao gênero. Correlação significante entre freqüência fundamental e 


\section{REVISÃO DA LITERATURA}

identificação correta do gênero foi observada apenas para o sexo feminino. Mulheres com freqüência fundamental abaixo de $90 \mathrm{~Hz}$ apresentaram maior risco de serem percebidas como homens quando comparada àquelas com valores mais elevados. Entretanto, isso não foi regra, sugerindo que outros fatores devem estar relacionados também.

Bozec et al. (2009) avaliaram de forma retrospectiva a restauração da voz traqueoesofágica e identificaram fatores correlacionados aos resultados funcionais de fala e de dieta oral após seis meses pós-cirurgia em 103 laringectomizados totais com idade média de 65,4 anos, sendo que a inserção da PTE ocorreu em apenas 87 deles. Quanto aos resultados funcionais, a dieta oral foi normal ou discretamente prejudicada em 70 pacientes, e severamente alterada ou impossível em 14. A faringolaringectomia circular, tumor hipofaríngeo e uso de retalho miocutâneo peitoral maior (pectoralis major myocutaneous flap) foram identificados como fatores preditivos à dieta oral desfavorável. Reabilitação vocal com sucesso foi obtida por 67 dos 82 pacientes capazes de se comunicar, sendo que o alto nível de comorbidades foi o único parâmetro clínico identificado como preditivo para a inteligibilidade de fala prejudicada. Complicações imediatas com a punção traqueoesofágica ocorreram em apenas três casos e as tardias em 14, incluindo-se neste último o alargamento severo da fístula, deslocamento da PTE e formação de tecido de granulação. Diante dos achados, concluiu-se que os benefícios obtidos em termos de comunicação com a PTE compensaram os seus riscos.

Chone et al. (2009) analisaram o relaxamento do segmento faringoesofágico em laringectomizados totais espásticos após a aplicação de toxina botulínica e a sua relação com a qualidade vocal. Oito laringectomizados totais, usuários de PTE, sem emissão vocal foram submetidos à injeção de toxina botulínica no segmento faringoesofágico para tratamento dos espasmos. Foram realizados: avaliação do tempo médio de fonação, análise acústica, videofluoroscopia da fala e da deglutição, e manometria esofágica. Em todos os pacientes, houve melhora no espasmo e redução na pressão do segmento faringoesofágico após a injeção da toxina botulínica, passando de $25,36 \mathrm{mmHg}$ 
para 14,31 mmHg. Constatou-se presença de harmônicos após a injeção da toxina, com produção vocal sem esforço e aumento do tempo de fonação.

Gravesen et al. (2009) referiram que a função esofágica é complexa e dependente de músculos circulares e longitudinais, cujas informações fornecidas pela tradicional manometria são restritas apenas as forças radiais no interior esofágico, não sendo suficiente para descrever e quantificar a motilidade esofágica. Desse modo, citaram outros métodos de avaliação, tais como a fluoroscopia e a ultrasonografia, que podem ajudar na avaliação da função esofágica, porém fornecem apenas informações qualitativas. Foi apresentada a medida de força axial no interior esofágico como o parâmetro mais fidedigno de avaliação da função esofágica em conduzir o bolo alimentar ao esôfago. Os autores revisaram métodos apresentados em estudos prévios para a mensuração da força axial esofágica, além de apresentar uma técnica própria desenvolvida por seu grupo de pesquisa, baseada em plarimetria de impedância. Apresentaram também dados próprios que revelaram que as medidas de força axial aumentam mais com o aumento do volume do corpo intraluminal do que a amplitude da manometria, o que pode fornecer uma avaliação dinâmica da função esofágica. Os autores concluíram que as medidas de força axial podem fornecer informações adicionais e mais fisiológicas em relação à função de deglutição, podendo até ser utilizadas para predizer pacientes que irão ou não desenvolver disfagia pós-operatória em cirurgias de fundoplicatura para a doença do refluxo gastroesofágico, função que estudos prévios não mostram ser desempenhada com sucesso pela manometria.

Foram objetivos do estudo de Kazi et al. (2009a) analisar e validar a eletroglotografia (EGG) como um instrumento de avaliação da voz traqueoesofágica. Participaram do estudo 47 laringectomizados totais e usuários de PTE, sendo que em sete deles foi associada à faringectomia parcial com reconstrução e em três uma faringectomia circunferencial. O grupo controle compreendeu 31 sujeitos com pregas vocais sem alterações. Todos foram submetidos à avaliação perceptual da voz e à EGG. Para a vogal sustentada, o valor da freqüência fundamental foi menor (Homens: $98,2 \mathrm{~Hz}$ e 


\section{REVISÃO DA LITERATURA}

Mulheres: $120,6 \mathrm{~Hz}$ ) e as medidas acústicas foram piores para falantes traqueoesofágicos, comparadas ao grupo controle, sendo ainda mais grave para aqueles submetidos à reconstrução faríngea. Quanto à fala encadeada, os resultados foram piores em todas as medidas quantitativas com maior variabilidade nos falantes traqueoesofágicos quando comparados ao controle. $\mathrm{Na}$ avaliação perceptual, somente o grau geral $(\mathrm{G})$ da escala GRBAS e a qualidade vocal global (OVQ) pareceram reprodutíveis e confiáveis. Diante de seus resultados, os autores estabeleceram que a EGG utilizando tanto a fala encadeada como a vogal sustentada é um método forte, válido e confiável.

Kazi et al. (2009b) exploraram a possível utilização da videoestroboscopia baseada na eletroglotografia em 52 laringectomizados totais usuários de válvulas de fala. Além disso, correlacionaram os achados estroboscópicos com a avaliação perceptivo-auditiva, a qual foi avaliada por meio da escala GRBAS e OVQ. Dos 52 pacientes, a videoestroboscopia pode ser realizada em 46 deles, sendo observada a neoglote em apenas 26 pacientes. Forte segmento vibratório, vibrações regulares e presença de onda mucosa foram observados em nove pacientes. Houve relação significante entre e qualidade vocal geral, assim como para G1/OVQ e pouca ou nenhuma saliva, entre G1 e localização visível da vibração e entre este e boa OVQ.

Kotby et al. (2009) estudaram as mudanças de pressão e de fluxo aéreo na pseudo-glote para ressaltar o mecanismo de produção vocal e elucidar a possível implicação na reabilitação final da voz traqueoesofágica. Participaram do estudo 18 laringectomizados totais falantes com PTE para avaliação do nível de fluxo aéreo, da pressão subpseudo-glótica, da eficiência e da resistência, bem como nível da pressão sonora, cujos resultados foram comparados com os de indivíduos sem alteração de pregas vocais. A pressão e a resistência da pseudoglote foram maiores do que os valores correspondentes encontrados em pregas vocais verdadeiras. O nível de pressão sonora, bem como os valores de eficiência obtidos pela pseudoglote não foram diferentes daqueles obtidos pelo grupo controle. Observou-se correlação positiva entre a pressão subpseudoglótica e o fluxo aéreo. 
3. CASUÍSTICA $\mathcal{E}$ MÉTODO 


\section{CASUÍSTICA E MÉTODO}

\subsection{CONSIDERAÇÕES ÉTICAS}

Este estudo foi realizado de acordo com a declaração de Helsinque para a pesquisa em seres humanos, com obtenção de consentimento por escrito de cada participante, expresso em termos específicos para os diferentes procedimentos, após serem devidamente informados (APÊNDICE A). A pesquisa foi aprovada pelo Comitê de Ética em Pesquisa do Hospital das Clínicas da Faculdade de Medicina de Ribeirão Preto da Universidade de São Paulo, Processo HCRP oo 11444/2007 (ANEXO A).

\subsection{CASUÍSTICA}

\subsubsection{CARACTERIZAÇÃO DA AMOSTRA}

Participaram deste estudo pacientes da Divisão de Cirurgia de Cabeça e Pescoço do Hospital das Clínicas da Faculdade de Medicina de Ribeirão Preto da Universidade de São Paulo (HCFMRP-USP) que se submeteram a LT por carcinoma de laringe.

A amostra constou de 20 laringectomizados, sendo 17 do gênero masculino e três do gênero feminino, com idade mínima de 47 anos e seis meses e máxima de 74 anos e cinco meses, média de idade de 61 anos e sete meses. Os indivíduos apresentaram no mínimo 11 meses de seguimento pósoperatório e no máximo 12 anos, com média de cinco anos e 10 meses. Dezessete pacientes foram submetidos a radioterapia, cuja dose média de radiação foi de 6105,3cGy, com mínima de 4000cGy e máxima de 11600cGy. Todos os participantes foram submetidos a punção secundária para colocação da prótese de fala da marca Provox®, fabricada pela indústria sueca Atos Medical $A B$ e fornecida pela Fundação de Apoio ao Ensino, Pesquisa e Assistência do HCFMRP-USP. A vida útil da PTE nos laringectomizados totais atingiu a média de um ano e dois meses, sendo que cada participante se 


\section{CASUÍSTICA E MÉTODO}

submeteu em média a quatro trocas da prótese. Todos os indivíduos foram submetidos a terapia fonoaudiológica para a reabilitação da comunicação oral, com média de cinco atendimentos.

Os laringectomizados selecionados foram convidados a participar do estudo por telefone, correspondência impressa ou pessoalmente após a consulta médica. Após aceitação e consentimento por escrito, o participante foi encaminhado para a coleta dos dados da pesquisa.

\subsubsection{CRITÉRIOS DE INCLUSÃO}

Para a composição da amostra, realizou-se revisão dos prontuários médicos de laringectomizados totais operados no período de 1995 a 2008, no HCFMRP-USP, totalizando 258 prontuários. Destes, foram selecionados apenas os indivíduos submetidos a LT clássica, com fechamento das camadas mucosa, submucosa e muscular para reconstrução da faringe. Aceitaram-se para constituição do grupo do estudo os laringectomizados totais que foram submetidos ao esvaziamento cervical e radioterapia complementar, falantes com inserção secundária da prótese fonatória traqueoesofágica com oclusão digital, independente da qualidade da fonação, do tipo de esvaziamento cervical, ou da dosagem radioterápica. Para registro e análise dos dados da amostra criou-se um protocolo para verificar dados de identificação, cirurgia, tratamento de radioterapia, tratamento fonoaudiológico e aspectos relacionados à PTE (APÊNDICE B).

\subsubsection{CRITÉRIOS DE EXCLUSÃO}

Com base na análise dos prontuários médicos, foram excluídos deste estudo os laringectomizados submetidos a faringectomia, LT associada a glossectomia ou pelveglossectomia, laringectomia com uso de retalhos para reconstrução da faringe e a tratamentos preventivos ou curativos de espasmos e hipertonicidade faríngea, ou seja, a neurectomia do plexo faríngeo, a miotomia do cricofaríngeo, a denervação química da musculatura constritora da faringe ou a reconstrução da faringe sem o fechamento da camada muscular. Também foram excluídos os laringectomizados totais que apresentaram 
recidivas ou metástases de carcinoma de laringe no momento do presente estudo, novo tumor primário de cabeça e pescoço, patologias esofágicas ou do trato gastrointestinal. Não foram aceitos para a composição da amostra os indivíduos que apresentaram manifestação de disfagia, diminuição da acuidade auditiva e/ou algum tipo de comprometimento cognitivo. Para a identificação dos critérios de exclusão, realizou-se questionamento verbal e análise da evolução clínica do prontuário médico do laringectomizado total (APÊNDICE B).

\subsection{MÉTODO}

\subsubsection{PROFICIÊNCIA DE VOZ E DE FALA TRAQUEOESOFÁGICA}

\subsubsection{Instrumento}

Para a qualificação da proficiência de voz e de fala com PTE, realizou-se uma adaptação do Protocolo validado de Hilgers et al. (1997) (ANEXO B), que considera três aspectos globais para caracterização do julgamento final da proficiência de voz e de fala traqueoesofágica: habilidades fonatórias, fatores adicionais e julgamento geral (Quadro 1). 
Quadro 1 - Descrição adaptada dos parâmetros do protocolo Hilgers et al. (1997), segundo a categorização semântica em bom, moderado e ruim.

\begin{tabular}{|c|c|c|c|}
\hline Parâmetro Classificação & BOM & MODERADO & RUIM \\
\hline \multicolumn{4}{|l|}{$\begin{array}{r}\text { Habilidades } \\
\text { fonatórias }\end{array}$} \\
\hline 1. Fluência & $\begin{array}{c}\text { Fala fluente, sem hesitação } \\
\text { ou Sentenças emitidas } \\
\text { consistentemente }\end{array}$ & $\begin{array}{c}\text { Emite algumas } \\
\text { sentenças ou é } \\
\text { capaz de combinar } 2 \\
\text { ou } 3 \text { palavras ou } \\
\text { ainda produz } \\
\text { palavras } \\
\text { simples } \\
\star \star \star \star *\end{array}$ & $\begin{array}{c}\text { Emite sons } \\
\text { isolados com } \\
\text { pouco controle }\end{array}$ \\
\hline $\begin{array}{l}\text { 2. Tempo máximo de } \\
\text { fonação }\end{array}$ & 10 segundos ou mais & $\begin{array}{l}\text { De quatro a nove } \\
\text { segundos }\end{array}$ & Até três segundos \\
\hline 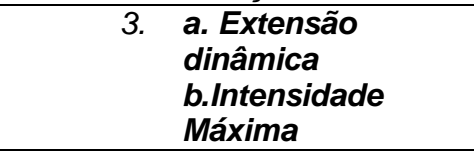 & $\begin{array}{l}25 \mathrm{~dB} \text { ou mais } \\
\text { Acima de } 75 \mathrm{~dB}\end{array}$ & $\begin{array}{c}\text { De } 16 \text { a } 24 d B \\
65 \text { a } 75 d B\end{array}$ & $\begin{array}{l}15 \mathrm{~dB} \text { ou menos } \\
\text { Abaixo de } 65 \mathrm{~dB}\end{array}$ \\
\hline $\begin{array}{l}\text { 4. Facilidade para } \\
\text { iniciar fonação }\end{array}$ & $\begin{array}{c}\text { Se vocalizar imediatamente } \\
\text { ao ocluir o estoma * }\end{array}$ & $\begin{array}{c}\text { Se após a oclusão } \\
\text { apresentar } \\
\text { dificuldade discreta } \\
\text { para realizar a } \\
\text { fonação** }\end{array}$ & $\begin{array}{l}\text { Se após a oclusão } \\
\text { apresentar } \\
\text { dificuldade } \\
\text { moderada a severa } \\
\text { para realizar a } \\
\text { fonação** }\end{array}$ \\
\hline 5. Articulação & Articulação precisa*** & $\begin{array}{l}\text { Dificuldade } \\
\text { discreta }\end{array}$ & $\begin{array}{c}\text { Dificuldade } \\
\text { moderada a severa }\end{array}$ \\
\hline 6. Modulação da voz & Adequada* $^{*}$ & Dificuldade discreta & Monótona* \\
\hline 7. Velocidade de fala & $\begin{array}{l}\text { Fala rápida*** } \\
\text { (adequada) }\end{array}$ & $\begin{array}{l}\text { Redução discreta da } \\
\text { fluência }\end{array}$ & Fala lenta* (rápida) \\
\hline \multicolumn{4}{|l|}{$\begin{array}{r}\text { II. Fatores } \\
\text { adicionais }\end{array}$} \\
\hline 1. Ruído do estoma & Ausência de ruído* & $\begin{array}{l}\text { Ruído do estoma } \\
\text { discreto*** }\end{array}$ & $\begin{array}{l}\text { Ruído do estoma } \\
\text { moderado a } \\
\text { severo*** }\end{array}$ \\
\hline $\begin{array}{l}\text { 2. Audibilidade da } \\
\text { inspiração }\end{array}$ & $\begin{array}{l}\text { Ausência de audibilidade da } \\
\text { inspiração* }\end{array}$ & $\begin{array}{l}\text { Audibilidade da } \\
\text { inspiração } \\
\text { discreta }\end{array}$ & $\begin{array}{l}\text { Audibilidade da } \\
\text { inspiração } \\
\text { moderada a } \\
\text { severa }^{\star * *}\end{array}$ \\
\hline $\begin{array}{ll}\text { 3. } & \text { Movimentos } \\
\text { associados de } \\
\text { cabeça, pescoço } \\
\text { ou ombros }\end{array}$ & $\begin{array}{l}\text { Ausência de movimentos } \\
\text { associados a fonação* }\end{array}$ & $\begin{array}{l}\text { Movimentos } \\
\text { associados } \\
\text { discretos }^{\star \star \star}\end{array}$ & $\begin{array}{l}\text { Movimentos } \\
\text { associados } \\
\text { moderados a } \\
\text { severos }^{* * *}\end{array}$ \\
\hline \multicolumn{4}{|l|}{$\begin{array}{c}\text { III. Julgamento } \\
\text { Geral }\end{array}$} \\
\hline 1. Qualidade vocal & Adequada $^{\star * *}$ & Voz fraca $^{* * *}$ & Voz insuficiente \\
\hline $\begin{array}{ll}\text { 2. } & \text { Inteligibilidade de } \\
\text { fala }\end{array}$ & Inteligível & $\begin{array}{l}\text { Inteligível com } \\
\text { atenção }\end{array}$ & Ininteligível \\
\hline Julgamento final & $\begin{array}{l}\text { No máximo três aspectos } \\
\text { são julgados como } \\
\text { moderado e todos os outros } \\
\text { como bons }\end{array}$ & $\begin{array}{l}\text { Somente um } \\
\text { aspecto é julgado } \\
\text { como ruim }\end{array}$ & $\begin{array}{l}\text { Dois ou mais } \\
\text { aspectos são } \\
\text { julgados como } \\
\text { ruins } \\
\end{array}$ \\
\hline
\end{tabular}

*Hilgers et al. (1997); **Ceccon et al. (1998); ${ }^{* \star \star}$ Barros (2002);

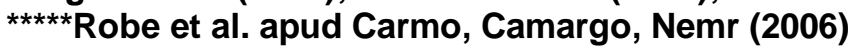


Convém ressaltar que, exceto os parâmetros quantitativos (tempo máximo de fonação, extensão dinâmica e intensidade máxima) pertencentes as habilidades fonatórias, que foram mensurados de forma quantitativa, via equipamentos, todos os outros foram julgados auditivamente e/ou visualmente pelos expertos.

\subsubsection{Análise}

\subsection{Seleção dos expertos}

A seleção dos expertos foi realizada por meio da adaptação de um Sistema de Pontuação de Especialistas aplicado no modelo de Fehring (1994) e modificado por Jesus (2000) (Quadro 2).

Quadro 2 - Sistema de Pontuação de Especialistas aplicado no modelo de Fehring (1994) e modificado por Jesus (2000).

\begin{tabular}{|l|c|}
\hline Critério & Pontuação \\
\hline - Mestre em Fonoaudiologia/Cirurgia de Cabeça e Pescoço & 4 \\
\hline - Mestre em Fonoaudiologia//Cirurgia de Cabeça e Pescoço - Dissertação com & 1 \\
\hline conteúdo relevante dentro da área & 2 \\
\hline - Pesquisa na área de avaliação de interesse (com publicação) & 2 \\
\hline - Prática clínica de pelo menos 1 ano de duração na área de Fonoaudiologia em & 1 \\
\hline Cabeça e Pescoço//Cirurgia de Cabeça e Pescoço & 2 \\
\hline - Certificado (Especialização) em área de Cabeça e Pescoço com comprovada & 2 \\
\hline prática clínica & \\
\hline - Doutorado em avaliação de interesse & \\
\hline
\end{tabular}


Baseando-se em tais critérios, os expertos selecionados deveriam apresentar no mínimo uma pontuação igual a cinco, sendo que suas atribuições foram investigadas e confirmadas pelo sistema Plataforma Lattes, disponível no site www.cnpq.br. Atendendo a tais requisitos, foram selecionados quatro expertos fonoaudiólogos para a avaliação da proficiência de voz e de fala, com tempo médio de três anos e cinco meses de experiência em atendimento a laringectomizados totais com PTE, sendo todos do gênero feminino, sem queixa auditiva e com experiência na análise auditiva perceptual. A pontuação atingida para cada um dos expertos, segundo os critérios de seleção previamente estabelecidos, foi de 14,13 e nove para dois deles, com média de 11,3 pontos. A cada experto selecionado foi entregue um Termo de Consentimento Livre e Esclarecido (APÊNDICE C) e pormenorizadas as características de sua participação no estudo, após o que houve concordância em aderir ao mesmo.

\subsubsection{Procedimento}

As gravações foram feitas individualmente em sala com tratamento acústico e monitorada para que o registro do sinal sonoro ocorresse com ruído abaixo de $50 \mathrm{~dB}$ (média de 43,34dB, máximo de 49,7dB e mínimo de 38,5dB). Para tanto, utilizou-se um decibelímetro digital Impac® IP-900DL data logger Tipo II, calibrado (calibrador ND9 Impac®) e programado no nível automático, considerando um intervalo de captação da intensidade de 30 - 130dB (slow) no modo Real time, cujos registros foram feitos em computador PC com processador Intel ${ }^{\circledR}$ Core $^{\text {TM }} 2$ duo (Figura 1). Monitorou-se também a temperatura e umidade do ar da sala acústica, cujas médias foram respectivamente de $26,2^{\circ} \mathrm{C}$ (máximo de $27,43^{\circ} \mathrm{C}$ e mínimo de $25,54^{\circ} \mathrm{C}$ ) e de $45 \%$ (máximo de $51,2 \%$ e mínimo de $43 \%$ ), e que foram mensuradas e registradas por meio de um termohigrômetro portátil digital Impac® TH02, ajustado na posição out. 


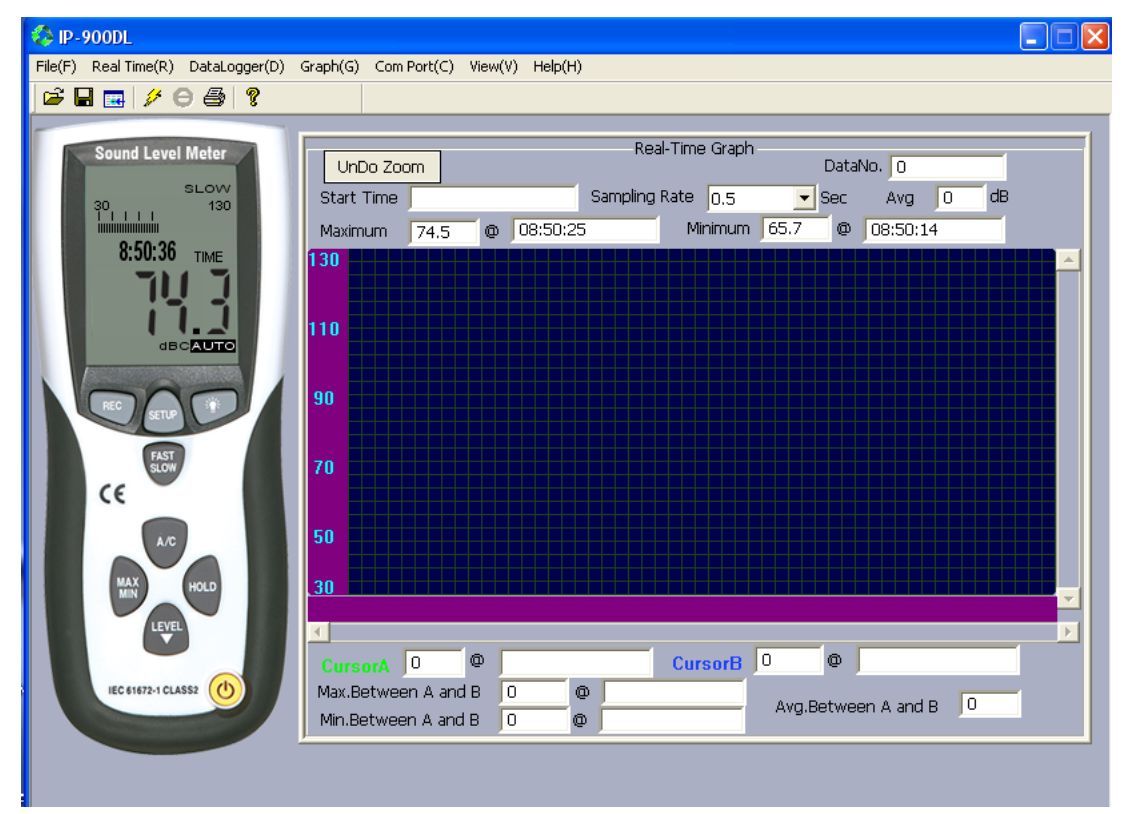

Figura 1 - Modelo do registro de extração da intensidade vocal e do ruído do ambiente no computador, pelo modo Real time.

A coleta e registro do material de voz e de fala foram realizados por meio de uma câmera de vídeo digital Sony® handycam - DCR-SR85 adaptada a um tripé. Os indivíduos permaneceram sentados a um metro de distância da câmera filmadora, para que a produção sonora fosse registrada de forma padronizada, sem perda de qualidade e intensidade do sinal sonoro. As filmagens foram realizadas delimitando-se a imagem da região da cabeça e tórax de cada participante, a fim de padronizar o registro para avaliação posterior pelos expertos. Os pacientes foram instruídos para que as provas da seqüência da voz e da fala ocorressem com intensidade, velocidade, qualidade e freqüência vocais habituais, visando a condição existencial da comunicação do laringectomizado. O tempo de registro da gravação não foi pré-determinado devido a variação da duração das provas vocais inter-indivíduos.

Os participantes realizaram as seguintes provas:

1- emissão prolongada das vogais "a", “i”, “u”, após a inspiração: selecionadas como prova de voz devido à natureza articulatória, pois as vogais permitem a 
análise da habilidade em controlar as forças aerodinâmicas da corrente pulmonar e as forças mioelásticas; é um teste de eficiência glótica (Behlau et al., 2001), que também pode ser utilizado para julgar o tipo de voz traqueoesofágica.

2- emissão da contagem de números de um a vinte, após a inspiração: avalia a eficiência de controlar e coordenar a respiração e a fonação no processo da fala encadeada (Behlau et al., 2001).

3- emissão do canto "Parabéns a você!": utilizado para a avaliação dos aspectos de modulação e entonação da voz;

4- emissão da fala espontânea a partir do questionamento: "Quais as vantagens e desvantagens do uso da prótese vocal?": utilizada para analisar a fala encadeada, fluência e a inteligibilidade.

Foram registrados e mensurados os seguintes parâmetros:

1-Extensão dinâmica da fonação traqueoesofágica: utilizou-se a prova da emissão sustentada da vogal "a", com a colocação do decibelímetro a um metro de distância da cavidade oral do participante. Para o registro do sinal sonoro, a gravação da intensidade vocal foi programada a cada 0,5 segundo (s), sendo então calculada uma média final de acordo com o tempo máximo de fonação. $O$ cálculo da extensão dinâmica também utilizou os dados capturados pelo decibelímetro, considerando a intensidade máxima e mínima.

2-Tempo máximo de fonação: "a", "i", "u" foram mensurados duas vezes, por meio do uso do cronômetro digital Timex $\operatorname{Triathlon}^{\circledR}$, medida em segundos, sendo calculada a média final para as emissões prolongadas.

Após o registro de voz e de fala, os participantes selecionados foram encaminhados para o exame manométrico.

\subsection{Caracterização da proficiência de voz e de fala com PTE}

A qualificação da proficiência da voz e da fala foi realizada por meio do julgamento de quatro expertos durante três encontros que ocorreram em uma sala de aula do Departamento de Oftalmologia, Otorrinolaringologia e Cirurgia de Cabeça e Pescoço da Faculdade de Medicina de Ribeirão Preto da Universidade de São Paulo (FMRP-USP) com duração média de três horas 


\section{CASUÍSTICA E MÉTODO}

cada um, previamente agendados com cada experto participante. Os encontros ocorreram com um intervalo mínimo de uma semana, a fim de evitar qualquer memorização perceptivo-auditiva das respostas.

Apresentou-se 0 protocolo, e 0 procedimento de avaliação da proficiência de voz e fala foi explicado a cada experto. Orientou-se que cada um faria a análise individualmente, não tendo acesso a qualquer resposta dos demais, como forma de garantir a fidedignidade das respostas.

Assim, a avaliação da proficiência comunicativa com PTE compreendeu as seguintes etapas:

- Exposição dos objetivos do presente estudo e apresentação do Protocolo adaptado de Hilgers et al. (1997): o primeiro encontro com os expertos teve como objetivo explicar-Ihes os conceitos de cada parâmetro vocal, atribuindoIhe significados capazes de serem estimados de forma a assegurar a uniformização entre os avaliadores. Com relação à apresentação gráfica dos parâmetros descritos no protocolo, foi solicitada a apreciação dos expertos a respeito dos aspectos de clareza, de representatividade e de abrangência do que se deseja atingir. Foi verificado se os expertos consideraram os dados suficientes para a análise dos parâmetros propostos, e foram aceitas sugestões pertinentes com a proposta da pesquisa.

- Treinamento dos expertos: ofereceu-se aos expertos uma amostra de dez imagens de laringectomizados falantes com PTE, previamente à análise efetiva da pesquisa, com a finalidade de equalizar os conceitos de caracterização da qualidade da proficiência comunicativa com PTE;

- Julgamento pelos expertos: a cada experto, distribuíram-se 20 protocolos com a descrição dos possíveis resultados a serem assinalados, e uma ficha com a definição conceitual dos parâmetros a serem avaliados, para favorecer a confiabilidade da mensuração da comunicação oral. Para o julgamento pelos expertos, providenciou-se uma sala silente com poltronas confortáveis e localizadas de fronte a tela (distância de um metro) que transmitiu as imagens registradas e gravadas da voz e da fala dos laringectomizados em formato Movie clip, por meio de data show e computador PC, com processador Pentium®. As imagens foram apresentadas a todos os expertos de forma 
randomizada, com a intensidade das vozes dos participantes ajustada em um nível confortável aos ouvintes, mantendo-se a mesma para todo o restante do arquivo. O número de apresentações da imagem de cada participante não foi limitado, ocorrendo a sua repetição de acordo com a necessidade dos expertos, sendo que o número máximo não ultrapassou quatro vezes. Do mesmo modo, o tempo entre uma apresentação de um participante e de outro foi variável, dependendo do término de preenchimento do protocolo por todos os expertos.

\subsubsection{EXAME MANOMÉTRICO}

Todos os testes manométricos foram realizados por um médico gastroenterologista e acompanhados por um fonoaudiólogo, no laboratório de provas funcionais da Divisão de Gastroenterologia do HCFMRP - USP.

\subsubsection{Instrumento}

No exame manométrico foi utilizada uma sonda de polivinil, dotada de oito canais com quatro milímetros de diâmetro externo e 0,8 mm de diâmetro interno em cada canal (Menfis Biomedica( ${ }^{\circledR}$ ). Os quatro canais proximais tinham cinco centímetros de distância entre si e eram conectados a transdutores de pressão - Dtp-6100, PVB Medizintechnik Gmbh® (Germany) com saída para o fisiógrafo PC Polygraf HR - Synectics Medical® (Estocolmo, Suécia). O catéter de manometria foi perfundido continuamente com água filtrada a um fluxo de $0,5 \mathrm{ml} /$ minuto, por um sistema de perfusão de baixa complacência (J. S. Biomedicals, Inc®, Califórnia - USA).

\subsubsection{Procedimento}

Os participantes foram submetidos ao exame manométrico para avaliação da pressão intraluminal da TFE em repouso e durante a fonação. Com o indivíduo sentado confortavelmente, iniciou-se o exame, anestesiandose a cavidade nasal com lidocaína gel a $2 \%$. A sonda foi introduzida pela narina e posicionada no esôfago de forma a manter aberto um canal a dois centímetros da TFE, considerado como esôfago proximal, outro canal a $12 \mathrm{~cm}$ 
da TFE, chamado de esôfago médio e por fim, um terceiro canal a $17 \mathrm{~cm}$ da TFE, esôfago distal. Definiu-se a TFE como a área de alta pressão observada no traçado manométrico.

Após período de 10 minutos para adaptação à sonda, foi solicitada ao indivíduo a produção da vogal prolongada "a" por duas vezes, com intervalo entre cada emissão de 30 segundos.

Em seguida, a sonda foi tracionada lentamente por dois centímetros, com o canal proximal localizando-se na região da TFE, caracterizada pelo aumento da pressão, mantendo-se um único canal aberto na sonda. Então, foi solicitado ao laringectomizado que repetisse a emissão da vogal sustentada "a" em intensidade e freqüência vocais habituais por duas vezes, com intervalo entre elas de 30 segundos. Após o término deste registro, a sonda foi novamente tracionada lentamente até localizar o canal proximal na faringe, posicionando-se a abertura da sonda a dois centímetros acima da TFE, com reprodução da prova sonora.

\subsubsection{Calibração}

Após a conexão da sonda aos transdutores de pressão, acionamento do sistema de perfusão e retirada de todo o ar do sistema, foi realizada a calibração do equipamento com o indivíduo sentado, tendo como registro zero a pressão obtida na altura do ombro direito do participante. A sonda foi nivelada para que os transdutores registrassem a pressão de $37 \mathrm{mmHg}$. Para tal procedimento, foi utilizada uma régua de calibração com indicação do local de pressão zero e de $37 \mathrm{mmHg}$.

\subsubsection{Análise}

Para análise da coleta dos dados, os resultados foram registrados e armazenados em computador PC, processador Pentium $\AA^{\circledR}$, sendo consideradas para este estudo apenas as medidas da amplitude da pressão intraluminal da TFE em repouso e durante a fonação, durante a produção da vogal "a" (Figuras 2 e 3). Para a medida da pressão em repouso da TFE, foi considerada como referência a linha de base do esôfago. 


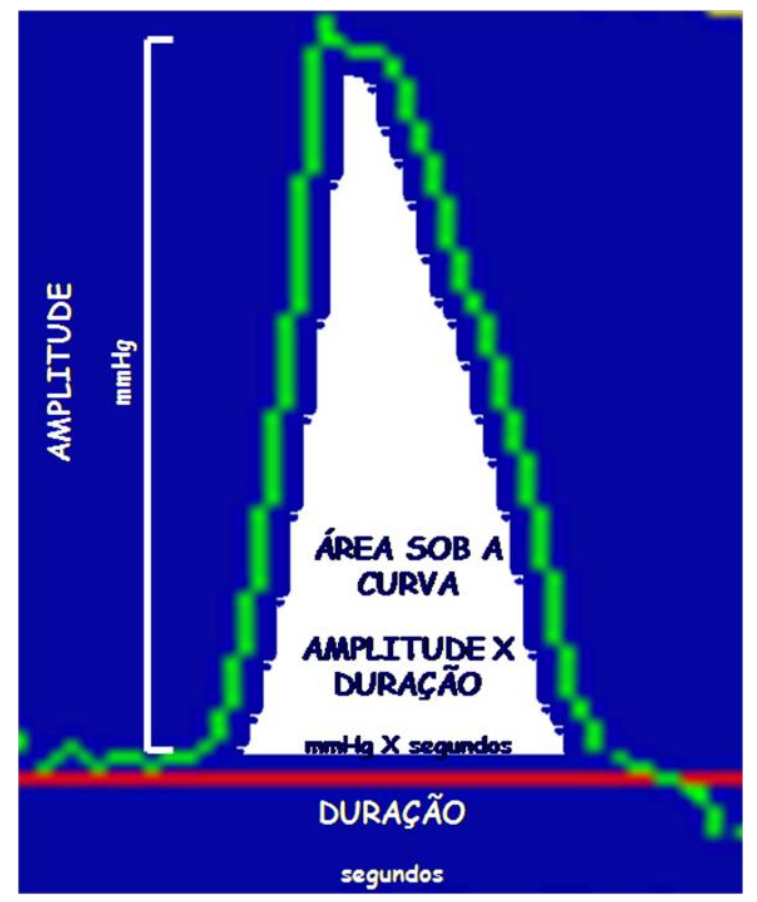

Figura 2 - Representação da amplitude da pressão intraluminal, da sua duração e da área sob a curva registrada pela onda de pressão (Arquivo Aguiar-Ricz, 2005).

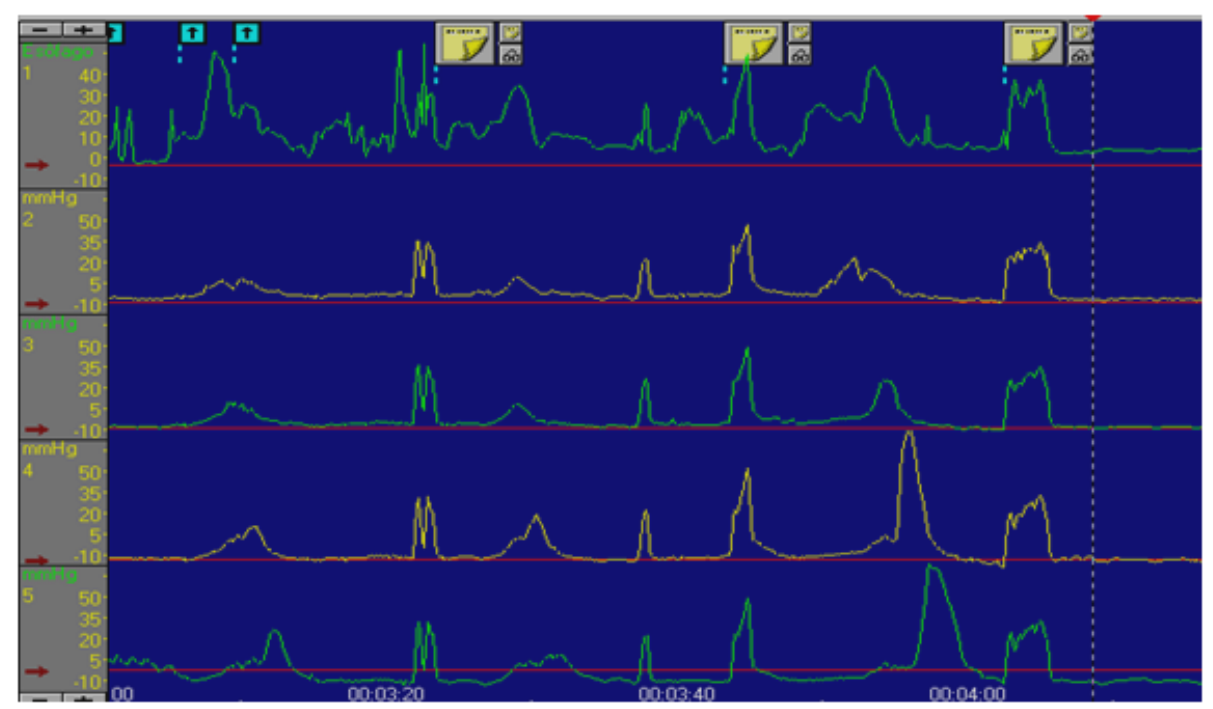

Figura 3 - Representação manométrica do comportamento da TFE durante a fonação (Arquivo Aguiar-Ricz, 2005). 


\subsubsection{EXAME VIDEOFLUOROSCÓPICO}

Todos os exames foram realizados por um técnico em Radiologia da Divisão de Diagnóstico por Imagem do HCFMRP-USP e acompanhados pela pesquisadora responsável.

\subsubsection{Instrumento}

No exame de videofluoroscopia foi utilizado o equipamento Philips ${ }^{\circledR}$ - $B V$ Pulsera (Netherlands-Amsterdam) associado ao aparelho de gravação das imagens Philips ${ }^{\circledR}$ MDVDR-100-Medical DVD Recorder (Holanda).

\subsubsection{Procedimento}

O laringectomizado total foi orientado a sentar-se confortavelmente na cadeira em posição de perfil em relação à ampola de radiação. Colocou-se uma moeda de cinco centavos abaixo da mastóide direita do participante para servir como parâmetro anatômico para as medições. Selecionou-se no equipamento, o zoom de $23 \mathrm{~cm}$ por possibilitar melhor visualização e registro da imagem, além de favorecer a uniformidade para as medições que foram realizadas. No primeiro momento, orientou-se ao indivíduo que deglutisse $20 \mathrm{~mL}$ de sulfato de bário (Bariogel® 100\% radiológico, sabor maçã, suspensão oral indicado para uso pediátrico e adulto) com a finalidade de identificar as estruturas anatômicas. Em seguida, o laringectomizado foi instruído a emitir por três vezes a vogal prolongada "a", com intervalo entre elas de cinco segundos. As imagens do comportamento da TFE foram identificadas por meio do computador e registradas pelo gravador contido no equipamento. Os participantes não utilizaram protetores contra radiação, por estes impedirem a visualização das estruturas anatômicas. Porém, o tempo total de exposição a radiação não excedeu o tempo máximo de 8 minutos, período efetivo para 0 exame, mas sem causar dano à saúde (Wright et al., 1998).

\subsubsection{Análise}

\subsection{Instrumento e variáveis dimensionais}


Para medir as dimensões da TFE durante o repouso e a fonação, utilizou-se a imagem videofluoroscópica, cujas dimensões foram analisadas por meio de um programa computadorizado de medição semi-automática, desenvolvido pelo Centro de Ciências das Imagens e Física Medica do HCFMRP-USP em conjunto com alunos do curso de Informática Biomédica da FMRP-USP, caracterizado como Measures (Figura 4).

O programa foi desenvolvido em linguagem de programação Java sobre um pacote utilizado no tratamento de imagens médicas conhecido como ImageJ, o qual é de domínio público e desenvolvido pelo National Institute of Health, fornecendo extensibilidade por meio da criação de plugins. Criou-se também um banco de dados para inserção automática das medidas obtidas, por meio da utilização de chave de acesso para cada experto, a fim de assegurar a confiabilidade dos achados, sendo possível acessá-los apenas pela senha de administrador, cujo domínio era exclusivo dos responsáveis pelo presente estudo.

Os exames videofluoroscópicos dos laringectomizados totais foram registrados pela pesquisadora responsável, que selecionou e editou os quadros durante os momentos de repouso e fonação, sendo que as variáveis dimensionais da TFE foram mensuradas por meio de um plugin do ImageJ.:

- Distância ântero-posterior entre a proeminência da transição faringoesofágica e a parede anterior da faringe em repouso e durante a fonação (PTFE-PAF);

- Distância ântero-posterior entre a proeminência da transição faringoesofágica e a parede posterior da faringe (PTFE-PPF);

- Comprimento longitudinal da transição faringoesofágica no repouso e durante a fonação (CLTFE).

\subsection{Mensuração das imagens}

A medida das imagens videofluoroscópicas selecionadas foi realizada de acordo com as seguintes etapas:

- Seleção dos expertos: foi realizada de acordo com o que foi proposto anteriormente para a caracterização da proficiência do falante com PTE. Desse 
modo, atendendo a tais requisitos, foram selecionados três expertos, dois fonoaudiólogos e um médico cirurgião de cabeça e pescoço, com média de nove anos e seis meses de experiência em atendimento a laringectomizados totais com PTE. A pontuação atingida para cada um dos expertos, segundo os critérios de seleção previamente estabelecidos, foi de 14 e 13 para dois deles, com média de 10 pontos. A cada experto selecionado, foi entregue um Termo de Consentimento Livre e Esclarecido (APÊNDICE D) e pormenorizadas as características de sua participação no estudo, após o que houve concordância em aderir ao mesmo.

- Treinamento dos expertos: primeiramente, a pesquisadora fez um treinamento técnico com o grupo responsável pela elaboração do programa de medição, utilizando imagens videofluoroscópicas não inseridas neste estudo. $O$ instrumento de medida desenvolvido foi instalado em um computador tipo lap top da marca $H p \AA$, juntamente com o arquivo das 40 imagens (20 em repouso e 20 durante a fonação) dos 20 indivíduos laringectomizados deste estudo que foram apresentadas a cada experto. $O$ treinamento ocorreu individualmente, respeitando suas disponibilidades de datas e horários. A duração do treinamento não ultrapassou três horas para cada experto.

- Mensuração pelos expertos: cada experto realizou individualmente as medidas no lap top com o programa instalado, a qual ocorreu duas vezes para cada um deles, em momentos diferentes, com intervalo mínimo de uma semana entre cada análise, com a finalidade de adquirir o máximo de confiabilidade possível. A sequência de apresentação das imagens nas duas análises foi a mesma para os três expertos, já que a ordem de inserção no banco de dados tinha de ser respeitada. Para confiabilidade dos resultados, durante a inserção das medidas da segunda análise das imagens, os expertos não tinham mais acesso ao banco de dados da primeira análise. 


\section{CASUÍSTICA E MÉTODO}

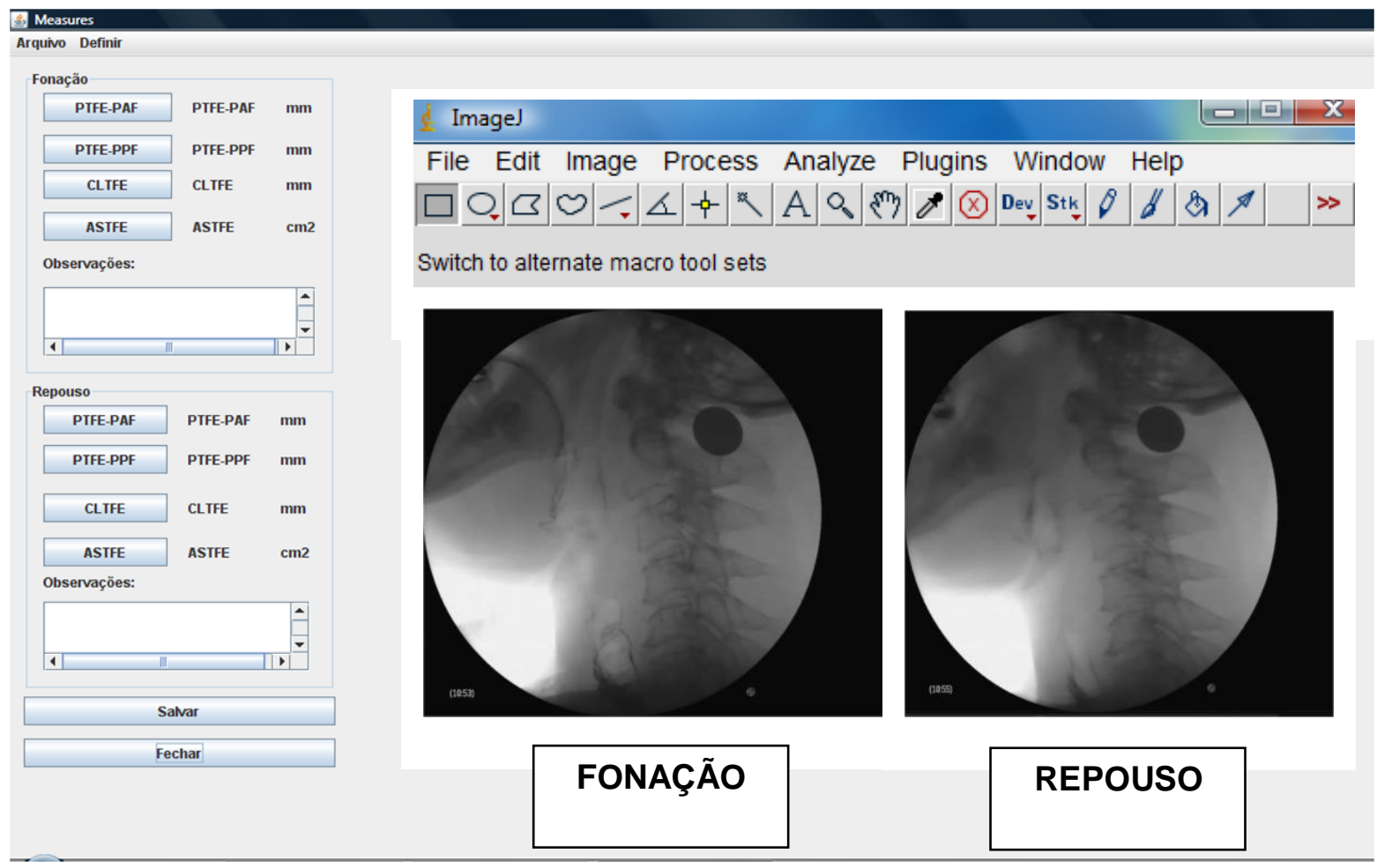

Figura 4 - Modelo do programa computadorizado Measures utilizado para medir as dimensões da TFE durante a fonação e repouso.

Trata-se de um estudo transversal e prospectivo.

\subsection{ANÁLISE ESTATÍSTICA}

\subsubsection{Proficiência da voz e da fala traqueoesofágica}

Para a caracterização da proficiência de voz e de fala traqueoesofágica, realizou-se inicialmente a verificação da confiabilidade entre os expertos quanto as variáveis categóricas do protocolo utilizado, por meio da descrição da porcentagem de julgamentos concordantes (maior ou igual a 50\%) e discordantes (menor que 50\%) de cada parâmetro qualitativo avaliado. Para tanto, o experto mais experiente $(\mathrm{E} 1)$ na área foi considerado o referencial que participou necessariamente de cada cruzamento das análises com os demais expertos, designados como E2, E3 e E4. De acordo com a maior porcentagem de concordância entre os expertos, caracterizou-se a proficiência de voz e de 


\section{CASUÍSTICA E MÉTODO}

fala com PTE, de acordo com a qualidade estabelecida pelo protocolo (boa, moderada ou ruim). Do mesmo modo que o E1 participou de todos os cruzamentos de concordância analisados, a sua resposta prevalecia sobre os demais, em caso de empate das análises de cada parâmetro. O julgamento final da proficiência de voz e de fala traqueoesofágica foi descrito também de acordo com o gênero e com a realização ou não de radioterapia, por meio da utilização de freqüências absoluta e relativa.

Os parâmetros quantitativos do protocolo e sua comparação com 0 gênero foram descritos por meio da média, mediana, mínimo e máximo e desvio padrão. Assim como os parâmetros qualitativos, foram também classificados em bom, moderado ou ruim.

\subsubsection{Exame manométrico}

Para a análise isolada da amplitude de pressão intraluminal da TFE no repouso e durante a fonação propriamente dita e sua relação com o gênero e radioterapia, realizou-se a estatística descritiva, por meio da utilização de média, desvio padrão, máximo, mínimo e mediana. Foi aplicada a transformação logarítmica na amplitude de pressão para verificar se houve diferença significante em seu valor, quando comparadas as condições de repouso e fonação.

\subsubsection{Exame videofluoroscópico}

As dimensões da TFE no repouso e durante a fonação e sua relação com o gênero e radioterapia foram demonstrados descritivamente, considerando os valores de média, desvio padrão, mínimo, máximo, média e mediana. Para medir a concordância entre os avaliadores quanto as dimensões da TFE foi utilizado o coeficiente de correlação intraclasse - ICC (Donner; Wells, 1986), o qual verifica o grau de correlação entre as medidas dentro de cada classe. A partir de uma tabela de Análise de Variância (ANOVA), pôde-se estimar este coeficiente com base nos quadrados médios obtidos. $O$ coeficiente varia de 0 a 1 e quanto mais próximo o coeficiente estiver de 1 , mais correlação haverá entre as medidas dentro de uma mesma classe. Aplicou-se a 
transformação logarítmica nas dimensões da TFE para verificar se houve diferença significante em seu valor, quando comparadas as condições de repouso e fonação.

\subsubsection{Exame manométrico versus exame videofluoroscópico}

Para realizar as comparações de interesse foram propostos modelos lineares de efeitos mistos (McLean et al., 1991). Tais modelos (efeitos aleatórios e fixos) são utilizados na análise de dados em que as respostas de um mesmo indivíduo estão agrupadas e a suposição de independência entre observações num mesmo grupo não é adequada. No modelo de efeitos mistos utilizado, foram considerados como efeito aleatório os indivíduos e como efeitos fixos, as condições de repouso e fonação, e os avaliadores. Esse modelo tem como pressuposto, que o resíduo obtido através da diferença entre os valores preditos pelo modelo e os valores observados tenha distribuição normal com média 0 e variância constante. Nas situações em que tal pressuposto não foi observado, transformações na variável resposta foram utilizadas. O ajuste do modelo foi feito por meio do software SAS versão 9.

\subsubsection{Proficiência de voz e fala traqueoesofágica versus exame manométrico}

\subsubsection{Proficiência de voz e fala traqueoesofágica versus exame videofluoroscópico}

Para tais comparações, foi utilizado o parâmetro julgamento final do protocolo adotado para avaliação da comunicação traqueoesofágica, o qual foi relacionado com as amplitudes de pressão e dimensões da TFE no repouso e durante a fonação, de forma descritiva, por meio da utilização de média, desvio padrão, mediana, mínimo e máximo. 
4. RESULTADOS 


\section{RESULTADOS}

Os resultados respeitarão a seguinte ordem de apresentação: proficiência da voz e da fala traqueoesofágica, caracterização da pressão intraluminal da TFE no repouso e na fonação, caracterização das dimensões da TFE no repouso e durante a fonação, dimensões da TFE versus pressão intraluminal da TFE no repouso e na fonação, pressão intraluminal da TFE no repouso e durante a fonação versus julgamento final da proficiência de voz e de fala, e dimensões da TFE no repouso e na fonação versus julgamento final da proficiência de voz e de fala traqueoesofágica.

\subsection{Proficiência da voz e da fala traqueoesofágica}

Os resultados relacionados à proficiência de voz e de fala traqueoesofágica serão demonstrados de acordo com o caráter quantitativo ou qualitativo apresentado pelos parâmetros pertencentes aos três aspectos globais pré-estabelecidos pelo protocolo adotado.

\subsubsection{Parâmetros quantitativos do aspecto global habilidades fonatórias do protocolo de avaliação da proficiência de voz e de fala traqueoesofágica}

Para todos os participantes, a média geral do tempo máximo de fonação foi moderada, a extensão dinâmica ruim e a intensidade vocal máxima boa (Tabela 1). 


\section{RESULTADOS}

Tabela 1 - Descrição geral da média, mínimo e máximo, e mediana, referente aos parâmetros quantitativos, pertencentes às habilidades fonatórias do protocolo de voz e da fala traqueoesofágica: tempo máximo de fonação (s), extensão dinâmica $(\mathrm{dB})$ e intensidade vocal máxima $(\mathrm{dB})$.

\begin{tabular}{cccc}
\hline Parâmetro & Média & Mín-Máx & Mediana \\
\hline \hline Tempo máximo de fonação & 6,29 & $2,3-17,3$ & 6,05 \\
Extensão dinâmica & 11,78 & $0,46-21,3$ & 11,84 \\
Intensidade vocal máxima & 75,42 & $64,7-86,8$ & 74,2 \\
\hline
\end{tabular}

A maioria dos participantes apresentou tempo máximo de fonação moderado (85\%) e extensão dinâmica ruim (75\%). A intensidade vocal máxima foi categorizada como moderada em $50 \%$ dos participantes (Tabela 2 ).

Tabela 2 - Descrição dos parâmetros quantitativos (tempo máximo de fonação, extensão dinâmica e intensidade vocal máxima), pertencentes às habilidades fonatórias do protocolo de voz e de fala traqueoesofágica, segundo a sua categorização semântica (bom, moderado ou ruim).

\begin{tabular}{lccccccccc}
\hline & \multicolumn{9}{c}{ Categoria semântica } \\
\cline { 2 - 10 } & \multicolumn{2}{c}{ Bom } & \multicolumn{2}{c}{ Moderado } & \multicolumn{2}{c}{ Ruim } & \multicolumn{2}{c}{ Total } \\
\hline Parâmetro & $\mathbf{n}^{*}$ & $(\%)$ & $\mathbf{n}^{*}$ & $(\%)$ & $\mathbf{n}^{*}$ & $(\%)$ & $\mathbf{n}^{*}$ & $(\%)$ \\
\hline $\begin{array}{l}- \text { Tempo máximo de } \\
\text { fonação }\end{array}$ & 1 & 5 & 17 & 85 & 2 & 10 & 20 & 100 \\
\hline- Extensão dinâmica & 0 & 0 & 5 & 25 & 15 & 75 & 20 & 100 \\
\hline $\begin{array}{l}- \text { Intensidade vocal } \\
\text { máxima }\end{array}$ & 9 & 45 & 10 & 50 & 1 & 5 & 20 & 100 \\
\hline *número de indivíduos & & & & & & & &
\end{tabular}

*número de indivíduos

Os valores encontrados para os parâmetros quantitativos, de acordo com a sua categorização semântica (bom, moderado ou ruim), encontram-se na tabela 3. 
Tabela 3 - Descrição da média, mínimo e máximo, e mediana, referente aos parâmetros quantitativos, pertencentes às habilidades fonatórias do protocolo de voz e de fala traqueoesofágica: tempo máximo de fonação (s), extensão dinâmica $(\mathrm{dB})$ e intensidade vocal máxima $(\mathrm{dB})$, segundo a sua categorização semântica (bom, moderado ou ruim).

\begin{tabular}{lccccccccc}
\hline & \multicolumn{7}{c}{ Categoria semântica } \\
\cline { 2 - 8 } & \multicolumn{7}{c}{ Bom } & \multicolumn{7}{c}{ Moderado } \\
\hline Parâmetro & Média & Mín-Máx & Mediana & Média & Mín-Máx & Mediana & $\begin{array}{c}\text { Médi } \\
\text { a }\end{array}$ & Mín-Máx & Mediana \\
\hline \hline $\begin{array}{l}\text { Tempo máximo de } \\
\text { fonação }\end{array}$ & 17,3 & $17,3-17,3$ & 17,3 & 6,11 & $3,2-10,5$ & 6,3 & 2,3 & $2,3-2,3$ & 2,3 \\
$\begin{array}{l}\text { Extensão dinâmica } \\
\text { Intensidade vocal }\end{array}$ & --- & --- & --- & 18 & $16,3-21,3$ & 17,78 & 9,7 & $0,46-15,4$ & 10,4 \\
máxima & 80,33 & $75,7-86,8$ & 79,64 & 72,1 & $68,6-74,4$ & 71,7 & 64,68 & $64,68-64,68$ & 64,68 \\
\hline
\end{tabular}

De acordo com o gênero dos laringectomizados totais falantes com PTE, as mulheres apresentaram tempo máximo de fonação menor e intensidade máxima mais forte do que os homens. Já a extensão dinâmica apresentou-se muito próxima para ambos os gêneros (Tabela 4).

Tabela 4 - Descrição da média, desvio padrão, mínimo e máximo, e mediana, referente aos parâmetros quantitativos tempo máximo de fonação (s), extensão dinâmica $(\mathrm{dB})$ e intensidade vocal máxima $(\mathrm{dB})$, pertencentes às habilidades fonatórias do protocolo de avaliação da proficiência de voz e de fala traqueoesofágica, segundo o gênero dos laringectomizados totais falantes com PTE.

\begin{tabular}{cccccc}
\hline & \multicolumn{5}{c}{ Parâmetro quantitativo } \\
\cline { 2 - 6 } & $\mathbf{n}^{\star}$ & Média & DP $^{\star \star}$ & Min-Máx & Mediana \\
\hline Gênero & 3 & 5,77 & 2,55 & $3,20-8,30$ & 5,80 \\
Feminino & 17 & 6,38 & 3,76 & $2,30-17,30$ & 6,30 \\
\hline Masculino & \multicolumn{5}{c}{ Extensão dinâmica } \\
\hline Feminino & 3 & 11,95 & 4,96 & $6,60-16,40$ & 12,86 \\
\hline Masculino & 17 & 11,75 & 5,13 & $0,46-21,30$ & 11,69 \\
\hline & \multicolumn{5}{c}{ Intensidade vocal maxima } \\
\hline Feminino & 3 & 77,62 & 6,45 & $71,70-84,50$ & 76,66 \\
\hline Masculino & 17 & 75,03 & 5,67 & $64,68-86,80$ & 74,00 \\
\hline${ }^{*}$ número de indivíduos & ${ }^{* *}$ Desvio padrão & \multicolumn{4}{c}{}
\end{tabular}


Os pacientes que necessitaram de tratamento complementar radioterápico apresentaram tempo máximo de fonação maior quando comparados aqueles que não foram submetidos a tal procedimento. No entanto, a intensidade máxima e a extensão dinâmica foram maiores para os pacientes não irradiados (Tabela 5).

Tabela 5 - Descrição da média, desvio padrão, mínimo e máximo, e mediana, referente aos parâmetros quantitativos tempo máximo de fonação (s), extensão dinâmica $(\mathrm{dB})$ e intensidade vocal máxima $(\mathrm{dB})$, pertencentes às habilidades fonatórias do protocolo de avaliação da proficiência de voz e de fala traqueoesofágica, segundo a realização ou não de tratamento complementar radioterápico em laringectomizados totais falantes com PTE.

\begin{tabular}{cccccc}
\hline & \multicolumn{5}{c}{ Parâmetro quantitativo } \\
\cline { 2 - 6 } & $\mathbf{n}^{*}$ & Média & DP $^{* \star}$ & Min-Máx & Mediana \\
\hline Radioterapia & 3 & 5,60 & 2,01 & $3,50-7,50$ & 5,80 \\
\hline Não & 17 & 6,41 & 3,79 & $2,30-17,30$ & 6,30 \\
Sim & 3 & \multicolumn{5}{c}{ Extensão dinâmica } \\
\hline Não & 12,77 & 7,63 & $6,60-21,30$ & 10,40 \\
\hline Sim & 17 & 11,60 & 4,68 & $0,46-18,30$ & 12,00 \\
\hline \multicolumn{5}{c}{ Intensidade vocal maxima } \\
\hline Não & 3 & 78,07 & 7,82 & $71,70-86,80$ & 75,70 \\
\hline Sim & 17 & 74,95 & 5,41 & $64,68-84,50$ & 74,00 \\
\hline *número de indivíduos & \multicolumn{5}{c}{ **Desvio padrão }
\end{tabular}

\subsubsection{Parâmetros qualitativos dos três aspectos globais (habilidades fonatórias, fatores adicionais e julgamento geral) do protocolo de avaliação da proficiência de voz e de fala traqueoesofágica}

A tabela 6 apresenta os resultados gerais obtidos quanto à categorização semântica dos parâmetros qualitativos dos três aspectos globais do protocolo. 
Tabela 6 - Descrição geral do julgamento final e dos parâmetros qualitativos, pertencentes aos três aspectos globais (habilidades fonatórias, fatores adicionais e julgamento geral) do protocolo de voz e de fala traqueoesofágica, segundo a categorização semântica (bom, moderado ou ruim) avaliada pelos expertos.

\begin{tabular}{|c|c|c|c|c|c|c|c|c|c|}
\hline \multirow{3}{*}{ Aspecto Global } & \multirow{3}{*}{ Parâmetro } & \multicolumn{8}{|c|}{ Categoria semântica } \\
\hline & & \multicolumn{2}{|c|}{ Bom } & \multicolumn{2}{|c|}{ Moderado } & \multicolumn{2}{|c|}{ Ruim } & \multicolumn{2}{|c|}{ Total } \\
\hline & & $\mathbf{n}^{*}$ & $(\%)$ & $n^{*}$ & $(\%)$ & $\mathrm{n}^{*}$ & $(\%)$ & $\mathrm{n}^{*}$ & $(\%)$ \\
\hline \multirow{5}{*}{$\begin{array}{l}\text { I. Habilidades } \\
\text { fonatórias }\end{array}$} & - Fluência & 19 & 95 & 1 & 5 & 0 & 0 & 20 & 100 \\
\hline & $\begin{array}{l}\text { - Facilidade para } \\
\text { iniciar fonação }\end{array}$ & 19 & 95 & 1 & 5 & 0 & 0 & 20 & 100 \\
\hline & - Articulação & 11 & 55 & 8 & 40 & 1 & 5 & 20 & 100 \\
\hline & - Modulação da voz & 9 & 45 & 10 & 50 & 1 & 5 & 20 & 100 \\
\hline & - Velocidade de fala & 15 & 75 & 5 & 25 & 0 & 0 & 20 & 100 \\
\hline \multirow[b]{3}{*}{$\begin{array}{l}\text { II. Fatores } \\
\text { adicionais }\end{array}$} & - Ruído do estoma & 18 & 90 & 2 & 10 & 0 & 0 & 20 & 100 \\
\hline & $\begin{array}{l}\text { - Audibilidade da } \\
\text { inspiração }\end{array}$ & 9 & 45 & 11 & 55 & 0 & 0 & 20 & 100 \\
\hline & $\begin{array}{l}\text { - Movimentos } \\
\text { associados de cabeça, } \\
\text { pescoço ou ombros }\end{array}$ & 15 & 75 & 5 & 25 & 0 & 0 & 20 & 100 \\
\hline \multirow[b]{2}{*}{ III. Julgamento geral } & - Qualidade vocal & 7 & 35 & 8 & 40 & 5 & 25 & 20 & 100 \\
\hline & - Inteligibilidade de fala & 14 & 70 & 6 & 30 & 0 & 0 & 20 & 100 \\
\hline \multicolumn{2}{|c|}{ Julgamento final } & 2 & 10 & 13 & 65 & 5 & 25 & 20 & 100 \\
\hline
\end{tabular}

"número de indivíduos

Em relação ao gênero dos laringectomizados totais falantes com PTE e considerando o julgamento final da proficiência de voz e de fala traqueoesofágica, obteve-se que, $50 \%$ dos homens e todas as mulheres foram caracterizadas como falantes moderados (Tabela 7).

Tabela 7 - Descrição, por gênero, do julgamento final da proficiência de voz e de fala traqueoesofágica, segundo a categorização semântica (bom, moderado ou ruim) avaliada pelos expertos

\begin{tabular}{ccccccccc}
\hline \multirow{2}{*}{ Gênero } & \multicolumn{9}{c}{ Julgamento final } \\
\cline { 2 - 10 } & \multicolumn{2}{c}{ Bom } & \multicolumn{2}{c}{ Moderado } & \multicolumn{2}{c}{ Ruim } & \multicolumn{2}{c}{ Total } \\
\cline { 2 - 10 } & $\mathbf{n}^{*}$ & $(\%)$ & $\mathbf{n}^{\star}$ & $(\%)$ & $\mathbf{n}^{*}$ & $(\%)$ & $\mathbf{n}^{*}$ & $(\%)$ \\
\hline \hline Feminino & 0 & 0 & 3 & 15 & 0 & 0 & 3 & 15 \\
Masculino & 2 & 10 & 10 & 50 & 5 & 25 & 17 & 85 \\
Total & 2 & 10 & 13 & 65 & 5 & 25 & 20 & 100 \\
\hline
\end{tabular}

${ }^{*}$ número de indivíduos 
Quanto ao julgamento final da proficiência de voz e de fala traqueoesofágica relacionado à realização ou não de radioterapia complementar, a maioria dos participantes foi julgada como falante moderado (Tabela 8).

Tabela 8 - Descrição do julgamento final da proficiência de voz e de fala traqueoesofágica, segundo a categorização semântica (bom, moderado ou ruim) avaliada pelos expertos e considerando-se a realização ou não de tratamento complementar radioterápico pelos laringectomizados totais falantes com PTE.

\begin{tabular}{ccccccccc}
\hline \multirow{2}{*}{ Radioterapia } & \multicolumn{8}{c}{ Julgamento final } \\
\cline { 2 - 10 } & \multicolumn{2}{c}{ Bom } & \multicolumn{2}{c}{ Moderado } & \multicolumn{2}{c}{ Ruim } & \multicolumn{2}{c}{ Total } \\
\cline { 2 - 10 } & $\mathbf{n}^{\star}$ & $(\%)$ & $\mathbf{n}^{\star}$ & $(\%)$ & $\mathbf{n}^{\star}$ & $(\%)$ & $\mathbf{n}^{*}$ & $(\%)$ \\
\hline \hline Não & 1 & 5 & 12 & 60 & 4 & 20 & 17 & 85 \\
Sim & 1 & 5 & 2 & 10 & 0 & 0 & 3 & 15 \\
Total & 2 & 10 & 14 & 70 & 4 & 20 & 20 & 100 \\
\hline
\end{tabular}

"número de indivíduos

\subsection{Exame manométrico}

\subsubsection{Amplitude de pressão intraluminal da TFE no repouso e durante a fonação}

Considerando a amostra total deste estudo, a amplitude de pressão média obtida na TFE durante a fonação apresentou-se maior quando comparada a situação de repouso, sendo tal diferença estatisticamente significante (Tabela 9). Dos 20 laringectomizados totais participantes, apenas um deles apresentou ausência de resposta durante a fonação.

Tabela 9 - Comparação da média, desvio padrão, mínimo e máximo, e mediana, referente às amplitudes de pressão intraluminal $(\mathrm{mmHg})$ obtidas na TFE, no repouso e durante a fonação, em laringectomizados totais falantes com PTE.

\begin{tabular}{lccccc}
\hline Condição & $\mathbf{n}^{\star}$ & Média & DP $^{\star *}$ & Mín - Máx & Mediana \\
\hline \hline Repouso & 20 & $13,83^{\star * *}$ & 9,64 & $1,70-33,30$ & 14,20 \\
Fonação & 19 & $38,10^{\star * *}$ & 21,53 & $10,80-90,10$ & 36,40 \\
\hline${ }^{*}$ número de indivíduos & & & \\
**Desvio padrão \\
*** p- valor < 0,01
\end{tabular}


A descrição dos achados pressóricos relacionados ao gênero mostrou, durante o repouso, valores médios de amplitude de pressão menores para os homens quando comparados as mulheres (Tabela 10).

Tabela 10 - Descrição da média, desvio padrão, mínimo e máximo, e mediana, referente às amplitudes de pressão intraluminal $(\mathrm{mmHg})$ obtidas na TFE, no repouso e durante a fonação, segundo o gênero de laringectomizados totais falantes com PTE.

\begin{tabular}{lcccccc}
\hline Condição & Gênero & $\mathbf{n}^{\star}$ & Média & DP $^{\star \star}$ & Mín - Máx & Mediana \\
\hline \hline Repouso & $\mathbf{F}$ & 3 & 28,33 & 4,54 & $24,40-33,30$ & 27,30 \\
& $\mathbf{M}$ & 17 & 11,27 & 7,84 & $1,70-26,90$ & 7,5 \\
\hline Fonação & $\mathbf{F}$ & 3 & 33,78 & 13,65 & $10,80-45,50$ & 37,90 \\
& $\mathbf{M}$ & 16 & 36,71 & 22,16 & $10,00-90,10$ & 30,10 \\
\hline
\end{tabular}

*número de indivíduos

**Desvio padrão

Com relação ao tratamento complementar radioterápico, apenas três pacientes não necessitaram de tal procedimento, sendo dois homens e uma mulher, os quais apresentaram valores pressóricos médios maiores que aqueles apresentados pelos indivíduos irradiados, tanto no repouso como durante a fonação (Tabela 11).

Tabela 11 - Descrição da média, desvio padrão, mínimo e máximo, e mediana, referente às amplitudes de pressão intraluminal $(\mathrm{mmHg})$ obtidas na TFE, no repouso e durante a fonação, segundo a realização de tratamento complementar radioterápico em laringectomizados totais falantes com PTE.

\begin{tabular}{lcccccc}
\hline Condição & Radioterapia & $\mathbf{n}^{\star}$ & Média & DP $^{\star \star}$ & Mín - Máx & Mediana \\
\hline \hline Repouso & Não & 3 & 20,27 & 11,84 & $6,60-27,30$ & 26,90 \\
& Sim & 17 & 12,69 & 9,15 & $1,70-33,30$ & 14,10 \\
\hline \multirow{2}{*}{ Fonação } & Não & 3 & 45,52 & 13,84 & $33,00-68,80$ & 42,40 \\
& Sim & 16 & 34,69 & 21,77 & $10,00-90,10$ & 29,10 \\
\hline
\end{tabular}

*número de indivíduos

**Desvio padrão 


\subsection{Exame videofluoroscópico}

Dentre as 40 imagens de videofluoroscopia selecionadas, 24 foram consideradas para análise, considerando-se os momentos de repouso e de fonação. O restante, em função de sua qualidade insatisfatória, não foi avaliado.

\subsubsection{Dimensões da TFE no repouso e durante a fonação}

As dimensões PTFE-PAF e PTFE-PPF aumentaram na condição de fonação quando comparadas ao repouso. No entanto, a CLTFE diminuiu da condição de repouso para a de fonação. Observou-se diferença estatisticamente significante no repouso e durante a fonação para as dimensões PTFE-PPF $(0,01)$ e CLTFE $(0,03)$, atribuindo-se $p<0,05$ (Tabela 12).

Tabela 12 - Descrição da média, desvio padrão, mínimo e máximo, e mediana, referente às dimensões PTFE-PAF, PTFE-PPF e CLTFE da TFE, em milímetro $(\mathrm{mm})$, no repouso e durante a fonação, segundo as análises dos três expertos.

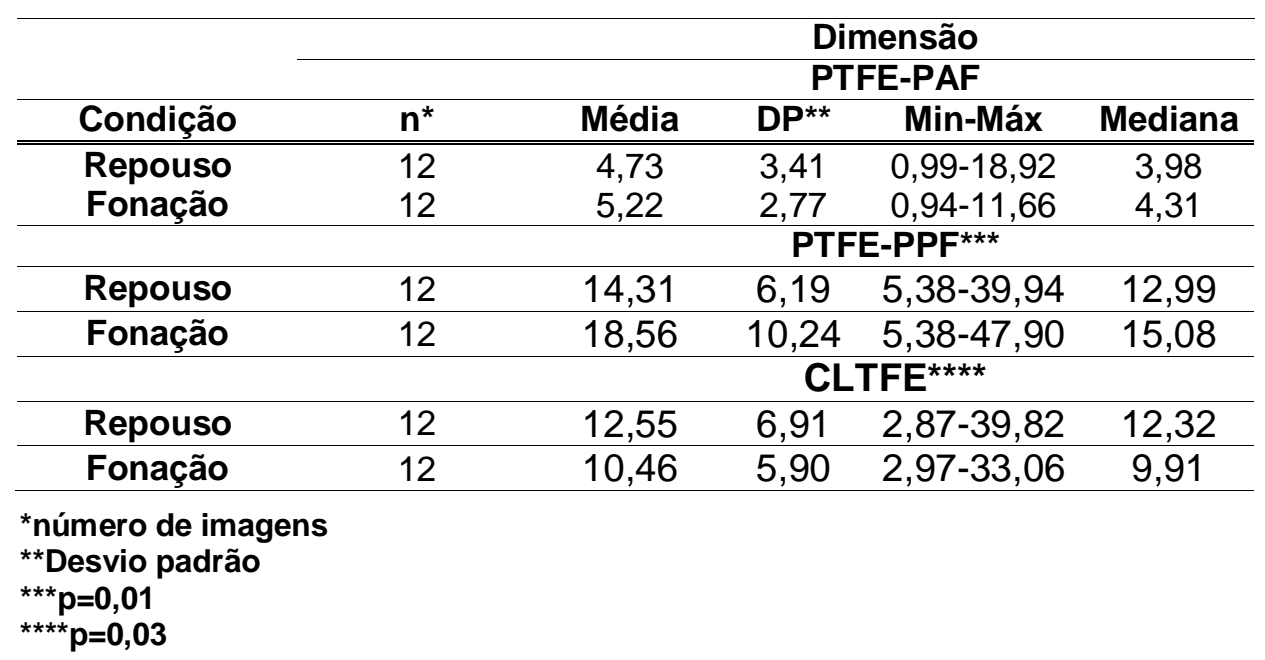

A tabela 13 demonstra os valores observados pelos expertos em cada uma das dimensões avaliadas da TFE, de acordo com o gênero. 
Tabela 13 - Descrição, por gênero, da média, desvio padrão, mínimo e máximo, e mediana, referente às dimensões PTFE-PAF, PTFE-PPF e CLTFE da TFE, em milímetros $(\mathrm{mm})$, no repouso e durante a fonação, em laringectomizados totais falantes com PTE, segundo a avaliação dos expertos.

\begin{tabular}{|c|c|c|c|c|c|c|c|c|c|}
\hline \multicolumn{10}{|c|}{ PTFE-PAF } \\
\hline \multicolumn{7}{|c|}{ Repouso } & \multicolumn{3}{|c|}{ Fonação } \\
\hline Gênero & $n^{*}$ & Média & $\mathbf{D P}^{\star \star *}$ & Min-Máx & Mediana & Média & $\mathrm{DP}^{\star \star \star}$ & Min-Máx & Mediana \\
\hline Feminino & 2 & 4,73 & 2,93 & $0,99-8,72$ & 4,36 & 3,57 & 2,45 & $0,94-7,69$ & 3,26 \\
\hline Masculino & 10 & 4,73 & 3,55 & $1,13-18,92$ & 3,98 & 5,56 & 2,74 & $1,27-11,66$ & 4,91 \\
\hline \multicolumn{10}{|c|}{ PTFE-PPF } \\
\hline Feminino & 2 & 16,30 & 4,26 & $10,55-21,48$ & 15,31 & 22,07 & 6,96 & $16,06-34,18$ & 20,11 \\
\hline Masculino & 10 & 13,92 & 6,49 & $5,38-39,94$ & 12,20 & 17,86 & 10,74 & $5,38-47,90$ & 14,42 \\
\hline \multicolumn{10}{|c|}{ CLTFE } \\
\hline Feminino & 2 & 8,32 & 4,50 & $4,56-16,52$ & 7,03 & 7,31 & 4,73 & $3,90-16,55$ & 6,12 \\
\hline Masculino & 10 & 13,39 & 7,05 & $2,87-39,82$ & 12,85 & 11,09 & 5,98 & $2,97-33,06$ & 10,84 \\
\hline
\end{tabular}

A tabela 14 demonstra os valores observados pelos expertos em cada uma das dimensões avaliadas da TFE, de acordo com a realização ou não de radioterapia complementar.

Tabela 14 - Descrição da média, desvio padrão, mínimo e máximo, e mediana, referente às dimensões PTFE-PAF, PTFE-PPF e CLTFE da TFE, em milímetros $(\mathrm{mm})$, no repouso e durante a fonação, em laringectomizados totais falantes com PTE e submetidos ou não ao tratamento radioterápico complementar, segundo a avaliação dos expertos.

\begin{tabular}{|c|c|c|c|c|c|c|c|c|c|}
\hline \multicolumn{10}{|c|}{ PTFE-PAF } \\
\hline \multicolumn{6}{|c|}{ Repouso } & \multicolumn{4}{|c|}{ Fonação } \\
\hline Radioterapia & $\mathrm{n}^{\star}$ & Média & $\mathrm{DP}^{\star \star \star}$ & Min-Máx & Mediana & Média & $\mathrm{DP}^{* \star}$ & Min-Máx & Mediana \\
\hline Não & 3 & 5,39 & 2,111 & $=3,13-8,72$ & 5,17 & 6,65 & 2,84 & $3,12-10,30$ & $7,7,42$ \\
\hline Sim & 9 & 4,60 & 3,63 & $0,99-18,92$ & 3,72 & 4,94 & 2,71 & $0,94-11,66$ & 4,24 \\
\hline \multicolumn{10}{|c|}{ PTFE-PPF } \\
\hline Não & 3 & 16,09 & 4,16 & $0,99-8,72$ & 4,36 & 19,12 & 4,81 & $13,26-21,48$ & 18,97 \\
\hline Sim & 9 & 13,96 & 6,52 & $1,13-18,92$ & 3,98 & 18,45 & 11,07 & $5,38-39,94$ & 14,65 \\
\hline \multicolumn{10}{|c|}{ CLTFE } \\
\hline Não & 3 & 10,85 & 4,89 & $4,83-17,88$ & 11,42 & 10,93 & 7,78 & $3,90-23,47$ & 8,83 \\
\hline Sim & 9 & 12,89 & 7,27 & 2,87-39,82 & 12,32 & 10,36 & 5,62 & 2,97-33,06 & 9,98 \\
\hline
\end{tabular}

*número de indivíduos

**Desvio padrão

\subsection{Exame videofluoroscópico versus exame manométrico}

Quando consideradas as análises dimensionais da TFE dos expertos, a melhor correlação positiva observada foi moderada e existiu entre PTFE-PAF e amplitude de pressão intraluminal $(0,41)$ da TFE, durante a fonação. Correlações fracas inversas foram constatadas entre CLTFE e amplitude de 
pressão $(-0,27)$ no repouso, e entre PTFE-PPF e amplitude de pressão durante a fonação $(-0,24)$ (Tabela 15).

Tabela 15 - De acordo com a análise dos expertos e a amplitude de pressão intraluminal da TFE, no repouso e na fonação, coeficiente de correlação de Spearman para as dimensões (PTFE-PAF, PTFE-PPF e CLTFE).

\begin{tabular}{clc}
\hline Condição & \multicolumn{1}{c}{ Variáveis } & Coeficiente \\
\hline \hline Repouso & PTFE-PAF x amplitude de pressão & 0,02 \\
& PTFE-PPF x amplitude de pressão & $-0,06$ \\
& CLTFE $\times$ amplitude de pressão & $\mathbf{- 0 , 2 7}$ \\
\hline Fonação & PTFE-PAF x amplitude de pressão & $\mathbf{0 , 4 1}$ \\
& PTFE-PPF x amplitude de pressão & $\mathbf{- 0 , 2 4}$ \\
& CLTFE $\times$ amplitude de pressão & 0,20 \\
\hline
\end{tabular}

\subsection{Proficiência da voz e da fala traqueoesofágica versus exame manométrico}

Os laringectomizados totais caracterizados como bons falantes no julgamento final da caracterização da proficiência de voz e de fala traqueoesofágica apresentaram menor valor de amplitude de pressão no repouso e intermediário durante a fonação, quando comparados aos falantes moderados e ruins (Tabela 16).

Tabela 16 - Descrição da média, desvio padrão, mínimo e máximo, e mediana, referente à amplitude de pressão intraluminal $(\mathrm{mmHg})$ da TFE, no repouso e na fonação, de acordo com a categorização semântica do parâmetro julgamento final da proficiência de voz e de fala traqueoesofágica.

\begin{tabular}{clcccc}
\hline \multicolumn{5}{c}{ Amplitude de pressão } \\
\hline $\begin{array}{c}\text { Julgamento } \\
\text { final }\end{array}$ & Condição & Média & DP* & Mín-Máx & Mediana \\
\hline \hline Bom & Repouso & 13,10 & 11,46 & $5,00-21,20$ & 13,10 \\
& Fonação & 25,50 & 17,25 & $11,30-44,70$ & 20,50 \\
\multirow{2}{*}{ Moderado } & Repouso & 17,55 & 9,08 & $3,30-33,30$ & 17,30 \\
& Fonação & 36,41 & 21,99 & $10,00-90,10$ & 35,40 \\
\multirow{2}{*}{ Ruim } & Repouso & 4,44 & 2,38 & $1,70-6,60$ & 5,90 \\
& Fonação & 40,46 & 19,76 & $24,40-68,80$ & 29,10 \\
\hline${ }^{\star}$ Desvio padrão & & & & &
\end{tabular}




\subsection{Proficiência da voz e da fala traqueoesofágica versus exame videofluoroscópico \\ Constatou-se que, durante o repouso, os melhores laringectomizados} totais falantes com PTE (bons) apresentaram maior PTFE-PAF e menor PTFEPPF. Já na fonação, PTFE-PAF tornou-se menor e PTFE-PPF maior. CLTFE permaneceu com valor intermediário entre os falantes com PTE moderados e ruins. (Tabela 17).

Tabela 17 - Descrição das dimensões PTFE-PAF, PTFE-PPF e CLTFE da TFE, em milímetros $(\mathrm{mm})$, no repouso e na fonação, de acordo com a caracterização do parâmetro julgamento final.

\begin{tabular}{|c|c|c|c|c|c|}
\hline \multirow[b]{2}{*}{$\begin{array}{c}\text { Julgamento } \\
\text { final }\end{array}$} & \multirow[b]{2}{*}{ Condição } & \multicolumn{4}{|c|}{ PTFE-PAF } \\
\hline & & Média & $D P^{*}$ & Mín-Máx & Mediana \\
\hline Bom & $\begin{array}{l}\text { Repouso } \\
\text { Fonação }\end{array}$ & $\begin{array}{l}5,39 \\
3,86\end{array}$ & $\begin{array}{l}1,44 \\
1,76\end{array}$ & $\begin{array}{l}4,19-6,98 \\
2,84-5,89\end{array}$ & $\begin{array}{l}5,00 \\
2,85\end{array}$ \\
\hline Moderado & $\begin{array}{l}\text { Repouso } \\
\text { Fonação }\end{array}$ & $\begin{array}{l}4,64 \\
5,30\end{array}$ & $\begin{array}{l}3,68 \\
2,72\end{array}$ & $\begin{array}{l}0,99-18,92 \\
0,94-11,66\end{array}$ & $\begin{array}{l}3,67 \\
4,36\end{array}$ \\
\hline \multirow[t]{2}{*}{ Ruim } & $\begin{array}{l}\text { Repouso } \\
\text { Fonação }\end{array}$ & $\begin{array}{l}4,81 \\
5,56 \\
\end{array}$ & $\begin{array}{l}3,14 \\
3,54 \\
\end{array}$ & $\begin{array}{c}1,79-9,97 \\
1,27-10,30\end{array}$ & $\begin{array}{l}4,07 \\
5,50 \\
\end{array}$ \\
\hline & & \multicolumn{4}{|c|}{ PTFE-PPF } \\
\hline Bom & $\begin{array}{l}\text { Repouso } \\
\text { Fonação }\end{array}$ & $\begin{array}{l}13,07 \\
24,30\end{array}$ & $\begin{array}{c}3,63 \\
10,68\end{array}$ & $\begin{array}{c}8,90-15,49 \\
12,06-31,71\end{array}$ & $\begin{array}{l}14,82 \\
29,13\end{array}$ \\
\hline Moderado & $\begin{array}{l}\text { Repouso } \\
\text { Fonação }\end{array}$ & $\begin{array}{l}13,84 \\
18,90\end{array}$ & $\begin{array}{c}4,86 \\
10,89\end{array}$ & $\begin{array}{l}5,38-24,10 \\
8,57-47,90\end{array}$ & $\begin{array}{l}12,23 \\
15,46\end{array}$ \\
\hline Ruim & $\begin{array}{l}\text { Repouso } \\
\text { Fonação }\end{array}$ & $\begin{array}{l}17,04 \\
14,16 \\
\end{array}$ & $\begin{array}{c}11,36 \\
5,41\end{array}$ & $\begin{array}{l}9,50-39,94 \\
5,38-22,31 \\
\end{array}$ & $\begin{array}{l}13,21 \\
14,27 \\
\end{array}$ \\
\hline Bom & $\begin{array}{l}\text { Repouso } \\
\text { Fonação }\end{array}$ & $\begin{array}{l}16,31 \\
12,36\end{array}$ & $\begin{array}{l}3,17 \\
1,30\end{array}$ & $\begin{array}{l}\text { FE } \\
14,10-19,94 \\
11,11-13,71\end{array}$ & $\begin{array}{l}14,89 \\
12,27\end{array}$ \\
\hline Moderado & $\begin{array}{l}\text { Repouso } \\
\text { Fonação }\end{array}$ & $\begin{array}{c}10,16 \\
8,62\end{array}$ & $\begin{array}{l}3,92 \\
3,89\end{array}$ & $\begin{array}{l}2,87-16,52 \\
2,97-16,55\end{array}$ & $\begin{array}{l}9,93 \\
7,47\end{array}$ \\
\hline Ruim & $\begin{array}{l}\text { Repouso } \\
\text { Fonação }\end{array}$ & $\begin{array}{l}21,43 \\
17,77\end{array}$ & $\begin{array}{c}10,81 \\
8,96\end{array}$ & $\begin{array}{l}12,91-39,82 \\
10,43-33,06\end{array}$ & $\begin{array}{l}16,63 \\
14,53\end{array}$ \\
\hline
\end{tabular}




\subsubsection{Exame videofluoroscópico versus exame manométrico}

Tabela 18 - Principais coeficientes de correlação de Spearman para as dimensões e amplitude de pressão intraluminal da TFE durante o repouso e a fonação, segundo a avaliação dos expertos.

\begin{tabular}{ccc}
\hline Condição & Variáveis & Coeficiente \\
\hline Repouso & CLTFE x amplitude de pressão & $-0,27$ \\
\hline Fonação & PTFE-PAF x amplitude de pressão & 0,41 \\
& PTFE-PPF x amplitude de pressão & $-0,24$ \\
\hline
\end{tabular}

\subsubsection{Proficiência da voz e da fala traqueoesofágica versus exame manométrico}

Tabela 19 - Descrição das amplitudes de pressão $(\mathrm{mmHg})$ da TFE no repouso e durante a fonação, de acordo com o julgamento final da proficiência de voz e de fala traqueoesofágica.

\begin{tabular}{|c|c|c|c|c|c|c|}
\hline \multirow{3}{*}{$\begin{array}{c}\text { Julgamento } \\
\text { final }\end{array}$} & \multicolumn{6}{|c|}{ Amplitude de pressão da TFE } \\
\hline & \multicolumn{3}{|c|}{ Repouso } & \multicolumn{3}{|c|}{ Fonação } \\
\hline & Menor & Intermediário & Maior & Menor & Intermediário & Maior \\
\hline $\begin{array}{c}\text { Bom } \\
\text { Moderado }\end{array}$ & 141 & 13,10 & 17,55 & 25,50 & 36,41 & 10,16 \\
\hline
\end{tabular}




\section{RESULTADOS}

\subsubsection{Proficiência da voz e da fala traqueoesofágica versus exame videofluoroscópico}

Tabela 20 - Descrição das dimensões da TFE no repouso e durante a fonação, de acordo com o julgamento final da proficiência de voz e da fala traqueoesofágica.

\begin{tabular}{|c|c|c|c|c|c|c|c|c|c|c|c|c|c|c|c|c|c|c|}
\hline \multirow{4}{*}{$\begin{array}{l}\text { Julgamento } \\
\text { final }\end{array}$} & \multicolumn{18}{|c|}{ Dimensão da TFE } \\
\hline & \multicolumn{6}{|c|}{ PTFE-PAF (mm) } & \multicolumn{6}{|c|}{ PTFE-PPF (mm) } & \multicolumn{6}{|c|}{ CLTFE (mm) } \\
\hline & \multicolumn{3}{|c|}{ Repouso } & \multicolumn{3}{|c|}{ Fonação } & \multicolumn{3}{|c|}{ Repouso } & \multicolumn{3}{|c|}{ Fonação } & \multicolumn{3}{|c|}{ Repouso } & \multicolumn{3}{|c|}{ Fonação } \\
\hline & Menor & Intermediário & Maior & Menor & Intermediário & Maior & Menor & Intermediário & Maior & Menor & Intermediário & Maior & Menor & Intermediário & Maior & Menor & Intermediário & Maior \\
\hline Bom & & & 5,39 & 3,86 & & & 13,07 & & & & & 24,30 & & 16,31 & & & 12,36 & \\
\hline Moderado & 4,64 & & & & 5,30 & & & 13,84 & & & 18,90 & & 10,16 & & & 8,62 & & \\
\hline Ruim & & 4,81 & & & & 5,56 & & & 17,04 & 14,16 & & & & & 21,43 & & & 17,77 \\
\hline
\end{tabular}


5. DISCUSSÃO 


\section{DISCUSSÃO}

\section{DISCUSSÃO}

A cirurgia de LT compreende a remoção do osso hióide, do conteúdo do espaço pré-epiglótico, da cartilagem tireóide, do anel cricóide e de um a quatro anéis traqueais, além de músculos constritores que são seccionados da linha oblíqua das cartilagens tireóide e cricoide, alterando a morfofisiologia da TFE (Brok et al., 1998). A possível justificativa para a ocorrência de mudanças no comportamento da TFE é que as fibras do músculo cricofaríngeo são movidas pelo fechamento da sutura, alterando então o seu tamanho e comprimento (Aguiar-Ricz et al., 2007). A interrupção vagal após a LT (van Weissenbrush et al, 2003; Dantas et al., 2005), pelo sacrifício dos nervos laríngeo superior bilateralmente e do inferior (Dantas et al., 2005), não produz apenas prejuízos focais na TFE, mas pode alterar também a peristalse esofágica e a função do esfincter esofágico inferior (Duranceau et al., 1976).

Previamente à cirurgia, já existe preocupação em relação à reabilitação da comunicação alaríngea e especificamente no intra-operatório, há um cuidado especial quanto ao tipo de fechamento faríngeo a fim de se evitar ao máximo problemas com a tonicidade dessa região. Bayles e Deschler (2004) descreveram três tipos de fechamento faríngeo, sendo eles: o fechamento tradicional, que envolve três camadas (mucosa, submucosa e muscular), possibilitando o fornecimento de tecido vascularizado sobre a linha de fechamento e evitando o risco de formação de fístulas; o fechamento não muscular (mucosa e submucosa), que previne a formação do anel cricofaríngeo e, consequentemente, a ocorrência de espasmos; e o fechamento envolvendo a metade da musculatura constritora, com o intuito de fornecer tecido vascularizado e concomitantemente evitar o espasmo. Para a composição da amostra do atual estudo e visando a sua homogeneidade, foram incluídos apenas os pacientes submetidos ao fechamento faríngeo tradicional, partindose do pressuposto que quanto à reabilitação vocal do laringectomizado, não há consenso na literatura acerca do procedimento cirúrgico ótimo, do fechamento faríngeo envolvendo ou não a camada muscular e da exatidão dos músculos responsáveis pela tonicidade (Op de Coul et al., 2003). Clevens et al. (1993) 


\section{DISCUSSÃO}

examinaram a segurança e a eficácia da LT e da punção traqueoesofágica associadas ao não fechamento da musculatura faríngea, não sendo constatados faringoespasmos nos pacientes submetidos a tal procedimento. Independente da técnica cirúrgica empregada. Richardson (1981) destacou a influência do tamanho da ressecção cirúrgica sobre a possibilidade de aquisição da comunicação alaríngea, não havendo influência sobre a qualidade da mesma.

A LT altera profundamente a fonação, a respiração e a sensação de olfato e paladar, considerando-se a perda da voz como a principal responsável pelas consequências econômicas e psicossociais (Gatenby et al., 1985; van Weissenbrush et al., 2000) apresentadas pelo paciente. Especialmente no caso de países subdesenvolvidos, como o Brasil, em que o índice de analfabetismo é evidente, a necessidade pela restauração da comunicação oral torna-se imprescindível (Oliveira et al., 2005). Apesar das dificuldades de emprego e de proximidade aos serviços médicos especializados, os resultados da voz traqueoesofágica obtidos nos países de 3 mundo foram comparáveis com centros de excelência de $1^{\circ}$ mundo (Fagan et al., 2002). Diante dessa similaridade, confirma-se que os critérios de sucesso e insucesso da comunicação traqueoesofágica são universais, porém faltam dados consensuais e normativos para tais caracterizações. Diante disso, uma vantagem é observada no fato de que os pacientes do presente estudo pertencem à rede pública de saúde, cujo centro hospitalar está vinculado a uma universidade, que preconiza o ensino, a pesquisa e a assistência, os quais favorecem o entendimento da ciência aplicada à prática.

Após a LT, a nova conformação anatômica adquirida não elimina completamente as possibilidades de reabilitação da comunicação (Brown et al., 2003), já que aspectos como fluxo aéreo pulmonar e mecanismos de ressonância continuam presentes, necessitando assim, apenas da substituição da fonte sonora (Pou, 2004). O trato digestório passa então a responder pela produção vocal alaríngea de forma secundária e compensatória. Em decorrência dessa adaptação funcional, a exigência por condições ótimas e específicas para o cumprimento da função fonatória é maior, assim como a 
sensibilidade para falhas, necessitando, portanto, de dedicação especial por parte da equipe multiprofissional na detecção e prevenção de fatores prejudiciais. Inúmeros problemas são associados ao insucesso da comunicação alaríngea, porém não há consenso na literatura a este respeito.

Kazi et al. (2009a) referiram que aspectos de reconstrução cirúrgica da faringe, modalidades de tratamento adjuvantes para o câncer laríngeo, e complicações de tratamento ou toxicidades podem afetar as propriedades aerodinâmicas e mioelásticas da fístula traqueoesofágica e da TFE, influenciando a produção vocal alaríngea. Somado a isso, Aguiar-Ricz et al. (2007) destacaram alguns fatores pós-cirúrgicos que podem impedir a aquisição da voz esofágica, tais como, estenose, fibrose cicatricial e invaginações de mucosa, que associados a mudanças neurológicas, podem causar espasticidade da musculatura, não permitindo a passagem do fluxo aéreo da faringe para o esôfago. Tal entendimento pode também ser aplicado à voz traqueoesofágica, porém considerando o fluxo aéreo de forma inversa, ou seja, esôfago-faringe. Em decorrência da existência de diversos aspectos que podem influenciar a reabilitação vocal alaríngea, a amostra do presente estudo foi selecionada visando o máximo de uniformidade possível, a fim de se obterem resultados mais confiáveis. Desse modo, justifica-se o fato de que apesar do montante inicial de 258 prontuários, selecionaram-se apenas 20 , que cumpriram absolutamente com os critérios de inclusão e exclusão préestabelecidos. Optou-se pela cirurgia mais tradicional, associada ao fechamento clássico da faringe, sem associação a tratamentos complementares para hipertonicidade e espasticidade da musculatura, a fim de se evitar qualquer influência advinda desses procedimentos, já que estes merecem atenção individual, possibilitando outros estudos. No entanto, aceitou-se para composição da amostra, indivíduos submetidos a radioterapia complementar, considerando-se que tal procedimento foi muito comum entre os pacientes.

À parte dos aspectos biológicos, fatores emocionais e sociais apresentam também importante papel na área de reabilitação do laringectomizado total, havendo inúmeros instrumentos para suas 


\section{DISCUSSÃO}

caracterizações (Schuster et al., 2004). Carmo et al. (2006) referiram que os aspectos intrafamiliar (Shames et al., 1963) e social são importantes também para aquisição de uma melhor e mais rápida reabilitação da comunicação dos laringectomizados totais.

Conforme consagrada na literatura (St Guily et al.,1992; Culton; Gerwin 1996; Clements et al., 1997; Barros, 2002; Op de Coul et al., 2003; Bunting, 2004; Singer, 2004; Chone et al., 2005; Gerwin; Culton, 2005; Albirmawy et al., 2006; Boscolo-Rizzo et al., 2008; Bellandese (2009), a voz com PTE, proposta por Singer e Blom (1980), tem sido o método preferencial de reabilitação da comunicação alaríngea, em função da qualidade dos resultados de voz e de fala alcançados e do seu rápido aprendizado (Bunting, 2004). Em longo prazo, no estudo de Geraghty et al. (1996), observou-se que $70 \%$ dos laringectomizados totais usuários de PTE apresentaram sucesso inicial com tal método de comunicação, diminuindo para $66 \%$ no decorrer do seguimento. Ferrer Ramírez et al. (2001) constataram que a voz traqueoesofágica foi alcançada a longo-prazo por aproximadamente $70 \%$ dos pacientes, sendo que $80 \%$ apresentaram uma boa voz. Em 2002, Mendenhall et al. constataram que, dos pacientes que adquiriram a voz traqueoesofágica, aproximadamente metade permanecerão com tal método de comunicação com o decorrer do tempo.

Apesar das altas taxas de sucesso apresentadas, a comunicação traqueoesofágica não está imune de complicações e falhas, porém, os benefícios alcançados com tal método compensam os seus riscos (Bozec et al., 2009). Dentre os diversos problemas atribuídos como possíveis causas do insucesso da voz traqueoesofágica, especial atenção é dedicada ao estudo da morfofisiologia da TFE, por meio da utilização de diferentes instrumentos para sua análise, tais como a manometria esofágica com o emprego de provas vocais específicas (Morgan et al., 1992; Aguiar-Ricz, 2005; Aguiar-Ricz et al., 2007; Chone et al., 2008a) e a videofluoroscopia visual ou quantitativa (Damsté; Lerman, 1969; Perry et al., 1987; Isman; O’Brien, 1992; van As, 2001; van As et al., 2001; van As et al., 2003; Kazi et al., 2006; Lundström et al., 2008; Fouquet et al., 2009). Medidas objetivas podem apresentar valor 
potencial considerável quanto à avaliação das características da TFE, podendo preencher uma lacuna entre forma e qualidade vocal, contribuindo assim em pesquisas e na tomada de decisões (Kazi et al., 2006). Cantu et al. (1998) acrescentam que falta uma documentação forte, composta por variáveis que contribuam para o julgamento de sucesso ou falha no procedimento de punção traqueoesofágica. Outros pesquisadores dedicaram-se ao estudo da motilidade e pressão esofágica (Dantas et al., 2001; Dantas et al., 2002, Allan et al., 2009), como forma de somar conhecimentos quanto ao entendimento fisiológico da produção vocal alaríngea.

Em relação às amplitudes de pressão obtidas na TFE em falantes traqueoesofágicos, independente da qualidade de voz e de fala, foram obtidos valores superiores durante a fonação quando comparada à situação de repouso, em que a diferença pressórica foi significante no presente estudo. Com base nos valores pressóricos obtidos durante o repouso, nota-se que há uma força de contração presente na TFE (Costa, 2003), sendo que justificativas técnicas e morfofisiológicas parecem contribuir para o entendimento disso e precisam ser consideradas durante a avaliação. Murray et al. (2003) destacaram que a própria presença e movimento do catéter na região da TFE durante o exame manométrico padrão podem contribuir com a elevação pressórica reflexa. Além disso, a falta de vantagem mecânica da camada estrutural das pregas vocais verdadeiras pode oferecer maior resistência à TFE, sendo que a presença de fibrose cicatricial pode contribuir também com o fornecimento de resistência a essa região durante o repouso (Kotby et al., 2009).

O sacrifício neural decorrente da LT pode favorecer a ocorrência de espasmos da musculatura remanescente, interferindo possivelmente na medição pressórica, mesmo que na condição de repouso. Dados os fatores já descritos e considerando a constituição muscular da TFE, é aceitável relacionar a pressão manométrica obtida no repouso com a resistência oferecida pelo fascículo transverso do cricofaríngeo, considerando-se a sua função em indivíduos laríngeos saudáveis. A simples presença e características morfológicas da proeminência faringoesofágica no repouso poderiam também 


\section{DISCUSSÃO}

contribuir com o fornecimento de alguma resistência, considerando-se que a TFE difere entre os laringectomizados totais em relação ao seu formato, rigidez cicatricial entre a hipofaringe e esôfago, localização do tumor, extensão da mucosa e submissão a diferentes cirurgias e outros procedimentos, proporcionando respostas finais distintas (Schuster et al., 2005).

Quanto ao aumento de pressão da TFE durante a fonação constatado neste estudo, pode-se considerar que seja decorrente da resistência já existente na condição de repouso associada ao comportamento da TFE e ao fluxo aéreo pulmonar necessário para a produção vocal. Kotby et al. (2009) acrescentaram que a simples vibração redundante da mucosa remanescente pode aumentar a resistência da TFE.

Previamente à compreensão do patológico, é imprescindível o entendimento da normalidade, seja em âmbito anatômico ou fisiológico. Assim, para estudar a pressão intraluminal da TFE em laringectomizados totais, o conhecimento pressórico na população normal é essencial. De forma geral, o laringectomizado total apresenta uma redução no comportamento funcional da TFE (Sandberg, 1970; Welch et al., 1979) em nível pressórico após a realização da LT. Dantas et al. (1999) observaram que a pressão da TFE durante a deglutição foi menor nos pacientes laringectomizados $(34,9 \mathrm{mmHg})$ em relação aos indivíduos normais $(61,2 \mathrm{mmHg})$, sendo que a explicação para essa diminuição da amplitude de contrações foi relacionada ao prejuízo funcional da inervação esofágica em decorrência da manipulação cirúrgica. Considerando as pressões em repouso da TFE, Winans et al. (1974) obtiveram valores pressóricos menores $(20,6 \mathrm{mmHg})$ nos laringectomizados totais do que nos indivíduos normais $(29,4 \mathrm{mmHg})$. Hanks et al. (1981) referiram também que a cirurgia de LT altera as pressões de repouso e picos de pressão da TFE, apresentando em seu estudo uma diminuição significativa durante o repouso, passando de $24,5 \mathrm{mmHg}$ para $13,5 \mathrm{mmHg}$ duas semanas após a cirurgia, não havendo alterações nos seis meses subsequentes. Do mesmo modo, o pico de pressão pós-deglutição diminuiu significativamente, passando de $37,5 \mathrm{mmHg}$ para $21,7 \mathrm{mmHg}$ na condição pós-operatória, não se modificando também ao longo de seis meses. Considerando-se um período de observação de seis a 12 


\section{DISCUSSÃO}

meses, Dantas et al. (2000) não encontraram modificações na motilidade esofágica em pacientes laringectomizados, indicando que, uma vez comprometida, ela permanece sem mais alterações. Na presente pesquisa, os valores pressóricos durante 0 repouso foram menores que aqueles encontrados na população normal, concordando com a literatura apresentada anteriormente.

Em 1974, Winans et al. compararam o grupo de falantes esofágicos bons e ruins, constatando menores valores de pressão $(13,1 \mathrm{mmHg})$ para os bons falantes em comparação aos ruins $(29,6 \mathrm{mmHg})$, durante o repouso. Mais recentemente, Aguiar-Ricz (2005) obteve em seu estudo pressão em repouso da TFE de $17,2 \mathrm{mmHg}$ para os falantes e de $25,1 \mathrm{mmHg}$ para os não falantes traqueoesofágicos, não constatando diferença pressórica durante a emissão da vogal prolongada, cujos valores encontrados foram de $43,6 \mathrm{mmHg}$ para 0 primeiro grupo e de 55,3mmHg para o segundo. Em 2007, Aguiar-Ricz et al. encontraram valor médio de pressão da TFE de $11,83 \mathrm{mmHg}$ no repouso em falantes esofágicos com sucesso, e de $9,92 \mathrm{mmHg}$ para os sem sucesso, não havendo diferença significante entre eles. Chone et al. (2008a) constataram média de pressão na TFE de $11,76 \mathrm{mmHg}$ para os laringectomizados totais sem espasmos, e maiores de $16 \mathrm{mmHg}$ para todos aqueles com espasmos. No trabalho de Morgan et al. (1992), os pacientes laringectomizados totais foram classificados de acordo com a tonicidade da TFE, sendo estabelecido que pressão acima de $20 \mathrm{mmHg}$ estava associada a falhas na voz. Com base nas pesquisas citadas anteriormente e posto que todos os participantes da presente pesquisa são falantes traqueoesofágicos, o valor encontrado na TFE durante o repouso respeitou os achados da literatura, assim como os valores apresentados pelos bons falantes. Quanto à amplitude de pressão obtida durante a fonação, é notável a sua inconsistência entre os trabalhos desenvolvidos na área, provavelmente atribuída à falta de uniformidade metodológica para realização da manometria.

Considerando-se que para deglutir, a TFE se comporta de acordo com a consistência e volume do bolo alimentar, espera-se que, em analogia a deglutição, tal região atue de forma distinta durante a fala, conforme a prova 


\section{DISCUSSÃO}

vocal utilizada, no exame manométrico do laringectomizado total. Tal conhecimento é importante a mérito de comparação dos achados pressóricos e por contribuir com a busca de valores referenciais específicos do comportamento da TFE durante a fonação. Assim, empregou-se neste estudo a mesma prova vocal para avaliação pressórica e dimensional da TFE, assegurando-se uma análise morfofisiológica inter-instrumentos mais confiável. $\mathrm{Na}$ tentativa de propor limiares pressóricos de predição, Chone et al. (2008a) estudaram a sensibilidade, especificidade e acurácia de limiar pressórico para o diagnóstico de espasmo em falantes traqueoesofágicos, revelando-se valores acima de $16 \mathrm{mmHg}$.

Estudos na área de limiares pressóricos de predição são de grande valia para determinação dos indivíduos que terão sucesso ou insucesso na comunicação traqueoesofágica, de forma a evitarem determinadas condições, tais como procedimentos cirúrgicos desnecessários, possíveis frustrações emocionais diante da grande expectativa gerada com a apresentação de tal método de comunicação alaríngea, além do tempo e custos envolvidos.

Apesar de não ter sido objetivo do presente estudo e de seus resultados não apresentarem significância estatística, a exploração dos achados entre gênero e amplitude de pressão ainda é válida, observando-se menores valores para os homens na condição de repouso $(11,27 \mathrm{mmHg})$ quando comparada às mulheres $(28,33 \mathrm{mmHg})$, sendo que tal situação pode estar relacionada à diferença anatômica entre homens e mulheres, considerando-se que o trato digestório do gênero feminino é naturalmente menor e, quando associada a ressecções de estruturas e fibrose cicatricial, espera-se que a resistência oferecida pela TFE seja maior. Porém, quando se trata de comportamento funcional compensatório de estruturas remanescentes, outros fatores devem interagir nesse processo, cada qual influenciando de uma determinada forma, tais como aspectos cirúrgicos e resposta anatômica de cada indivíduo. No entanto, a amplitude de pressão média durante a fonação mostrou-se maior nos homens, sugerindo a participação de um maior componente aéreo para tal gênero, o que, somado às outras características já citadas anteriormente pode ter contribuído para esse aumento pressórico. 
Com base na existência de correlação positiva entre pressão subpseudoglótica e fluxo aéreo (Kotby et al., 2009), e considerando-se os achados do presente estudo, provavelmente os homens apresentariam maiores valores pressóricos no esôfago, os quais, caso fossem mensurados, segundo Aguiar-Ricz et al. (2007) atuariam como uma bomba ejetora de ar para a faringe, proporcionado a sua vibração. No estudo de Mohri et al. (1998), observou-se em laringectomizados totais falantes com fístula traqueoesofágica, a formação de uma câmara de ar subneoglótica durante a fonação. Dantas et al. (1998) estudaram a motilidade esofágica em 20 homens e 20 mulheres saudáveis, por meio da deglutição, não sendo observada diferença na amplitude de contração esofágica entre os gêneros. No entanto, no estudo de Perera et al. (2008) envolvendo também indivíduos laríngeos saudáveis, observou-se aumento significativo na pressão da TFE induzido pela fonação, sugerindo a existência de uma contração reflexa. Tal pressão gerada foi influenciada pelo sexo, sendo maiores no gênero masculino.

Dentre as formas de tratamento para o câncer de laringe, destaca-se a cirurgia realizada isoladamente ou associada a tratamentos complementares como a radioterapia e a quimioterapia. Singer (2004) investigou as formas de tratamento em nível mundial, citando também a existência do protocolo de preservação de órgãos, o qual é estritamente direcionado a casos específicos. Além das modificações morfofisiológicas decorrentes da $L T$, a radioterapia pode causar a perda da elasticidade dos tecidos irradiados (Kazi et al, 2006), comprometendo ou não o comportamento da TFE para a fonação.

Com base nos resultados do presente estudo, verificou-se que o índice de LT isoladamente para tratamento do câncer laríngeo foi reduzido, necessitando na grande maioria dos casos de radioterapia complementar. Apesar de não pertencer aos propósitos deste estudo e do número de indivíduos com e sem radioterapia ter sido reduzido para extração de conclusões analíticas confiáveis, os achados possibilitaram a criação de hipóteses que poderão contribuir futuramente com outras pesquisas na área. Os reduzidos valores pressóricos obtidos no repouso e na fonação para os indivíduos irradiados podem sugerir que o possível enrijecimento tecidual 
causado pela radioterapia comprometeu a morfologia da TFE, dificultando o comportamento funcional das estruturas remanescentes para a fonação, do qual dependeria o resultado pressórico capturado pela manometria. Parece que a possível hipertonicidade decorrente da rigidez muscular advinda dos efeitos tardios da radioterapia não produz necessariamente comportamento hiperfuncional da TFE, conforme constatado no presente estudo. Pelo contrário, talvez a dose média de radiação (6105,3cGy) recebida pelos pacientes foi o suficiente para causar a hipertonicidade da musculatura, dificultando a movimentação das estruturas remanescentes da TFE, já que se trata de um valor muito elevado quando comparado à dose de radiação diagnóstica (Mclvor et al., 1990). De acordo com Richardson (1981), a radioterapia não foi considerada em seu estudo como um fator determinante para os resultados da comunicação esofágica. Dantas et al. (2005) constataram em seu estudo que os pacientes submetidos à radioterapia apresentaram a mesma amplitude nos $2 \mathrm{~cm}$ abaixo da TFE daqueles que não foram submetidos $(36,7 \mathrm{mmHg}$ e $34,7 \mathrm{mmHg}$, respectivamente).

A inexistência da relação entre hipertonicidade e hiperfunção pode favorecer o entendimento que o papel da manometria esofágica é capturar a amplitude de pressão gerada pela somatória de características morfológicas e comportamentais da TFE, e não especificamente da sua tonicidade muscular. Para melhor compreensão dessa atividade muscular da TFE, exame como a eletromiografia (Pruszewicz et al., 1992; Omori et al., 1994; Nishizawa et al., 2001) poderá contribuir no acréscimo de conhecimentos a respeito da influência da radioterapia na musculatura da TFE, porém tais estudos focados na LT são escassos na literatura. Por meio da investigação sobre o efeito da fonação na pressão intraluminal do trato gastrointestinal superior em indivíduos laríngeos saudáveis, Perera et al. (2008) acrescentaram que o aumento pressórico da TFE não determina as contribuições específicas dos componentes musculares da mesma, necessitando para isso, de estudos eletromiográficos. Não limitante a manometria que mensura a força radial esofágica, Gravesen et al. (2009) destacaram a importância do estudo da força axial para melhor compreensão da função esofágica, já que trata-se de uma 


\section{DISCUSSÃO}

atividade complexa e dependente de músculos longitudinais e circulares. Talvez, a realização do estudo de forças esofágicas longitudinais associadas as radiais possam contribuir para o melhor entendimento da morfofisiologia da nova fonte sonora alaríngea, considerando-se o movimento contrário ao do alimento, apresentado pelo fluxo aéreo. Convém ressaltar que, apesar do pequeno número amostral para favorecer a comparação entre os gêneros e entre os pacientes submetidos ou não ao tratamento radioterápico, os resultados observados foram interessantes, porém sem conclusões analíticas, necessitando aumentar o número de sujeitos, por meio de pesquisas multicêntricas.

Conforme a literatura já mencionada anteriormente, é interessante observar que os melhores falantes alaríngeos apresentaram os menores valores pressóricos na TFE durante a manometria, sustentando-se a hipótese de que falhas na comunicação são dependentes da amplitude de pressão nessa região. Tal condição incentiva pesquisadores a se dedicarem no estudo da tonicidade da TFE para a reabilitação alaríngea (Mclvor et al., 1990; van As, 2001; van As et al., 2001; van Weissenbrush et al., 2003; Chone et al., 2008b; Chone et al., 2009), empregando-se diferentes instrumentos para a sua caracterização em hipotônica, hipertônica ou espástica. De acordo com o estudo de Mclvor et al. (1990), dos 134 falantes esofágicos ruins, 14\% foram classificados radiologicamente como hipotônicos, 30\% como hipertônicos, $46 \%$ espásticos e 10\% como casos de estenose faringoesofágica. Por meio da avaliação videofluoroscópica visual e quantitativa da neoglote junto a análises perceptual e acústica da voz, van As (2001) constatou que uma boa voz traqueoesofágica se relacionou com a presença de uma barra cricofaríngea durante a fonação e com as condições de normotonia e discreta hipertonia da TFE, diferenciando-se dos casos de extrema hipertonicidade que necessitam de tratamento apropriado. Nesse mesmo estudo, a hipotonicidade foi considerada como uma condição desfavorável para a qualidade vocal, sendo associada a ausência de uma proeminência faringoesofágica, ou quase nula (Artazkoz Del Toro e Martínez, 1997). Além das investigações por imagem a respeito da tonicidade da TFE, Chone et al. (2008a) utilizaram também a 
manometria para a identificação de espasmos da musculatura faringoesofágica na produção vocal traqueoesofágica. É relevante considerar que a existência de diferentes desenhos metodológicos influencia os resultados obtidos quanto à caracterização da tonicidade da musculatura da TFE, dificultando a padronização dos achados pressóricos em laringectomizados totais.

Partindo-se do pressuposto que a hipotonicidade é considerada um fator prejudicial para a aquisição da voz traqueoesofágica com sucesso e por isso necessita ser tratada, há poucas alternativas para sua solução, como a orientação ao paciente quanto a necessidade de oclusão mais intensificada do estoma, que possibilitará a aproximação da proeminência faringoesofágica, quando presente, e a parede faríngea anterior, promovendo a geração de pressão esofágica e favorecendo o melhor aproveitamento do fluxo aéreo. Além disso, proporciona melhor equilíbrio entre as resistências apresentadas no repouso e durante a fonação. Caso tal alternativa não seja efetiva, há possibilidade de utilização de uma banda externa no pescoço do paciente visando oferecer maior compressão na região da TFE e vencer a falta de resistência, porém é uma alternativa pouco confortável em função da pressão constante. Além desses procedimentos foi proposta uma solução cirúrgica para casos de hipotonicidade, sendo demonstrada em um estudo de caso com resultados satisfatórios (Hilgers et al., 2006).

Quanto a hipertonicidade e ao espasmo da musculatura faringoesofágica, Gress (2004) referiu que tais condições de tonicidade da TFE não devem ser consideradas contra-indicações a punção traqueoesofágica, pois a produção vocal com sucesso pode ser alcançada com meios apropriados de intervenção. Diferente dos casos de hipotonicidade, há várias opções de tratamento disponíveis, incluindo-se terapia de fala, dilatação da TFE, neurectomia faríngea (Koybasioglu et al., 2003), miotomia (Horowitz; Sasaki, 1993; Op de Coul et al., 2003) e injeção de toxina botulínica (Blitzer et al., 1995; Zormeier et al., 1999; Lewin et al., 2001; Hamaker e Blom, 2003; Chone et al., 2008a; Chone et al., 2008b; Chone et al., 2009). Na década de 70, Winans et al. (1974) já ressaltavam a importância dos cirurgiões em modificar cuidadosamente a técnica de LT em favor de uma reconstrução mais 


\section{DISCUSSÃO}

frouxa do músculo cricofaríngeo ou utilizar técnicas alternativas. Outros trabalhos envolveram a associação da miotomia com a neurectomia do plexo faríngeo (Blom et al., 1995; van Weissenbrush et al., 2000) ou ainda a miotomia com implante da cartilagem traqueal na parede anterior do esôfago, cuja técnica foi empregada por Hirano et al. (1999) em falantes esofágicos e com shunt traqueoesofágico, visando a não ocorrência de espasmos do cricofaríngeo e formação de espaço subneoglótico amplo.

É interessante observar que todos os estudos realizados e focados na tonicidade da musculatura utilizaram diferentes instrumentos para a sua caracterização, sendo que os estudos com imagem foram baseados no comportamento funcional qualitativamente e/ou quantitativamente da TFE para a definição da tonicidade. Já aqueles que caracterizaram a tonicidade, por meio do estudo pressórico, atribuíram a amplitude encontrada, exclusivamente a musculatura. Com base nessas pesquisas e na busca pelo melhor instrumento de análise, há muitas incertezas quanto a denominação de tonicidade, já que quando a estudamos, remetemos necessariamente a musculatura e não a sua atividade funcional, apesar desta estar sob influência da tonicidade muscular. Acredita-se que a manometria esofágica seja o melhor instrumento para quantificar o resultado comportamental da TFE em hiperfuncional, hipofuncional ou funcional, mas não em hipertonia e hipotonia. Está claro que achados manométricos de estudos já realizados revelaram casos denominados de hipertonicidade com correta resolução muscular posteriormente, porém ter feito parte desses estudos pacientes com espasmos da musculatura que geraram valores elevados de pressão capturados pela manometria ou ainda, a coincidência de casos de real hipertonicidade da TFE com comportamento hiperfuncional, os quais justificam o sucesso aos tratamentos específicos para a tonicidade. Enquanto que a porcentagem que não respondeu ao tratamento possivelmente faz parte do grupo de pacientes que não apresentaram hipertonicidade ou espasmo muscular, mas apresentaram elevado valor pressórico decorrente da atividade hiperfuncional, talvez relacionada a uma hipotonia que necessitou de uma atuação muscular compensatória para o cumprimento da determinada função. Diante dessa inferência, não se observou 
nenhum estudo relacionando a manometria esofágica com o comportamento funcional da TFE, cujo propósito foi um dos interesses do presente trabalho.

Para este estudo, decidiu-se pela utilização da manometria para caracterização da resposta funcional da TFE, por acreditar que é o instrumento mais indicado para esse fim, já que o fornecimento de resultados quantitativos fortalece a confiabilidade de seus achados, diferenciando-se de conclusões meramente visuais. Para tanto, há necessidade de experiência por parte do profissional responsável pelas análises manométricas. Além disso, para maior fidedignidade e consistência dos achados relacionados a TFE, aconselha-se a associação desses tipos de instrumentos objetivos e mensuráveis com a avaliação perceptivo-auditiva (Kazi et al., 2009b), que continua sendo a melhor forma de caracterização da qualidade vocal. No entanto, van As et al. (2001) citaram o tempo consumido para análise, a necessidade de um grupo de juízes e o caráter subjetivo de avaliação como algumas das desvantagens que a avaliação perceptual pode apresentar.

Em relação ao grupo de juízes, devem ser considerados o nível de experiência com a categoria de vozes selecionadas e o cálculo da confiabilidade desses julgamentos, incluindo-se o número de repetições e intervalos de análise. O emprego de juízes leigos para avaliação da voz traqueoesofágica (Williams; Watson, 1985; Isman; O'Brien, 1992; Most et al., 2000; van As et al., 2001; Bellandese, 2009) não é incomum e apresentam diferentes objetivos para o seu emprego, ou seja, podem ser incluídos para análise da aceitabilidade da voz alaríngea ou mesmo da qualidade vocal propriamente dita. De acordo com van As et al. (2001), juízes leigos tendem a atribuir menores valores para o tipo de voz com PTE do que juízes experientes, considerando-se que o padrão interno daqueles sem experiência seja de vozes normais para posterior comparação. Ao contrário disso, o conhecimento de aspectos anatomofisiológicos referentes à produção vocal traqueoesofágica proporciona aos avaliadores experientes, mais informações específicas para serem consideradas em seu julgamento.

Atualmente, há vários instrumentos disponíveis para a avaliação da voz traqueoesofágica, ficando a critério do terapeuta/pesquisador a adotar o mais 


\section{DISCUSSÃO}

adequado dentro daquilo que fora proposto para investigação. No caso de vozes alaríngeas, em função da participação de outras estruturas para a fonação, recomenda-se que a avaliação seja mais abrangente, envolvendo maior número de parâmetros de $\mathrm{vOz} e$ de fala visando enriquecer $\mathrm{o}$ entendimento a respeito da produção vocal resultante. Atendendo a isso, adotou-se para a presente pesquisa um protocolo validado que dispõe de diversos parâmetros quantitativos e qualitativos para caracterização da proficiência da comunicação traqueoesofágica. Somado a isso, a presente pesquisa foi criteriosa quanto aos procedimentos para seleção dos expertos e avaliação da comunicação dos falantes com PTE, a fim de obter o máximo de confiabilidade dos achados.

Considerando os parâmetros quantitativos, tempo máximo de fonação, extensão dinâmica e intensidade vocal máxima, as médias obtidas junto as suas caracterizações, segundo o protocolo, foram 6,29s (moderado), 11,78dB (ruim) e 75,42dB (bom), respectivamente. Apesar da impossibilidade de análise significante dos dados, mas considerando a descrição por gênero, os homens apresentaram o maior tempo máximo de fonação e a menor intensidade vocal máxima. A extensão dinâmica para ambos os sexos apresentou-se muito semelhante. Atentando-se na literatura, Globlek et al. (2004) encontraram tempo máximo de fonação médio de 6,85s e intensidade vocal de $70,75 \mathrm{~dB}$ para os falantes traqueoesofágicos. Most et al. (2000) observaram média de tempo máximo de fonação traqueoesofágica de $65,98 \mathrm{~ms}$ e para os indivíduos laríngeos de 67,39ms. Max et al. (1996) encontraram diferença significante quanto ao tempo máximo de fonação entre falantes esofágicos $(1,33 \mathrm{~s})$ e traqueoesofágicos (8,19s), o nível de intensidade vocal máxima obtido para os falantes traqueoesofágicos foi de $70,70 \mathrm{~dB}$ e para os esofágicos de $61,90 \mathrm{~dB}$, e a extensão dinâmica não apresentou diferença entre os dois grupos de falantes (esofágicos: $12,80 \mathrm{~dB}$ e traqueoesofágicos: 19,10dB). Finizia et al. (1999) obtiveram para 0 grupo de laringectomizados totais $e$ falantes traqueoesofágicos, o tempo máximo de fonação de $14,7 \mathrm{~s}$. No trabalho desenvolvido por Ceccon et al. (1998) envolvendo falantes com PTE, a média encontrada para a emissão prolongada da vogal/a/ foi de 12,36s e para a 


\section{DISCUSSÃO}

intensidade máxima foi de $76,55 \mathrm{~dB}$. Considerando-se os critérios para a caracterização dos falantes traqueoesofágicos, segundo o protocolo adotado no presente estudo, constata-se que a minoria dos estudos realizados apresentou tempo máximo de fonação médio maior que 10s para assim serem caracterizados como bons falantes. Desse modo, os achados do presente estudo apresentaram equilíbrio junto a literatura a respeito desse parâmetro. A dificuldade em obter valores de tempo máximo de fonação superior a 10s pode estar relacionada à dificuldade de controle e aproveitamento do fluxo aéreo disponível para a fonação pelo falante traqueoesofágico, já que as estruturas que cumprem com a fonação alaríngea não dispõem dos ajustes peculiares apresentados pelos falantes laríngeos. Além disso, o escape aéreo pela prótese pode favorecer a diminuição desse fluxo aéreo que já se apresenta sob reduzido controle.

A intensidade vocal máxima foi o melhor parâmetro quantitativo avaliado neste estudo, podendo o mesmo ser observado na literatura, considerando-se os critérios de caracterização do protocolo adotado. De acordo com Kotby et al.(2009), não há correlação positiva entre nível de pressão sonora e fluxo aéreo, ou seja, a intensidade vocal forte não significa que o fluxo aéreo é elevado. Motta et al. (2001) observaram nos falantes com PTE uma positiva relação entre volume e fluxo fonatório, que representou o pré-requisito da fala sem pausas freqüentes. Porém, ressalta-se a importância do controle desse volume aéreo, de modo que todo o ar disponível seja aproveitado da forma mais adequada possível, independente da sua quantidade. Estudos com imagem podem contribuir com a comparação do volume aéreo disponível para a produção vocal e a qualidade da fonação resultante, tal como a ultrasonografia e a videofluoroscopia, sendo que esta última fornece apenas dados superficiais de área, ao contrário do primeiro exame que possibilita a análise tridimensional da câmara de ar no esôfago proximal.

De forma descritiva apenas, quanto à extensão vocal, verificou-se que não houve diferença significativa entre os gêneros, sugerindo que os falantes traqueoesofágicos apresentam, de modo geral, dificuldade no controle da intensidade vocal. Tais achados precisam ser mais bem explorados para 


\section{DISCUSSÃO}

proporcionar melhor confiabilidade. Ceccon et al. (1998) constataram em seu estudo pequena capacidade da voz traqueoesofágica em alcançar intensidades maiores do que a habitual durante a fonação, cuja provável explicação para isso seja resultado da estabilidade do fluxo aéreo através da prótese a TFE, ou ainda, da incapacidade de adaptação da pressão do fluxo aéreo conforme a necessidade de emissão em intensidade mais forte. Tal capacidade de variação da intensidade do mais fraco ao mais forte reflete a habilidade do indivíduo em modular o som emitido. Somado a isso, Deschler et al. (1999) comparando as características de voz e fala alaríngea, por meio do coeficiente de correlação, constatou-se que o conhecimento do nível de pressão sonora foi um fator significante na predição da frequência fundamental, porém ressaltaram que a causa do controle do pitch em falantes traqueoesofágicos não está claramente definida. Segundo esses autores, tais informações fortalecem a teoria que a voz traqueoesofágica é um ativo processo associado as propriedades mioelásticas e aerodinâmicas da TFE. De acordo com Grolman et al. (2008), a prótese vocal diminui a força aerodinâmica efetiva durante a fonação, porém, sozinha não contribui com a produção sonora traqueoesofágica, já que pode ser considerada como um processo de transformação de forças, caracterizando a sua eficiência vocal.

No âmbito terapêutico, Oliveira et al. (2005) compararam a qualidade da comunicação oral de falantes traqueoesofágicos pré e pós o treinamento fonoaudiológico, constatando-se que a maioria dos participantes apresentaram melhora nos parâmetros melodia frasal e canto, contribuindo com a redução da monotonia da comunicação. Tal conhecimento torna-se importante por incentivar $O$ trabalho terapêutico envolvendo tais parâmetros e consequêntemente contribuir com a melhora da extensão dinâmica dos falantes traqueoesofágicos. Além disso, Hilgers et al. (1997) enfatizaram que o trabalho respiratório abdominal, a coordenação fonorrespiratória, a oclusão completa do estoma, postura e relaxamento corporal devem ser focados no processo terapêutico a fim de se obter adequada produção vocal.

No estudo de Blom et al. (1995), a freqüência fundamental foi significativamente maior para os neurectomizados que apresentaram uma TFE 
maior, sugerindo que a tensão residual nessa região após a neurectomia foi responsável pela maior freqüência fundamental, não sendo suficientemente excessiva de modo a produzir faringoespasmos. Tal relação inversamente proporcional entre freqüência e massa difere da encontrada em falantes laríngeos.

É importante salientar que as provas vocais utilizadas para avaliação da comunicação devem ser selecionadas cuidadosamente, respeitando-se os parâmetros de interesse para análise, assim como as orientações para a sua realização, que devem ser conduzidas de maneira apropriada pelos terapeutas. Provas vocais sem sentido específico favorecem o aumento da velocidade e maior gasto de ar durante a fonação (Ceccon et al., 1998).

Em se tratando da radioterapia relacionada aos parâmetros quantitativos do protocolo do presente estudo, os pacientes que necessitaram de tal procedimento adjuvante apresentaram maior tempo máximo de fonação (6,4s - moderado) e menores valores médios de intensidade máxima $(74,9 \mathrm{~dB}$ moderada) e extensão dinâmica (11,6dB - ruim) quando comparados descritivamente aos não irradiados, porém tal diferença não foi tão marcante, sugerindo talvez a não influência da radioterapia para tais parâmetros. Porém, é preciso considerar o tamanho amostral do estudo, que dificulta a representatividade dos achados. De acordo com Richardson (1981), a radioterapia não foi um fator determinante para os resultados de comunicação. van As et al. (2001) observaram que a voz foi julgada como menos expressiva, monótona no grupo de paciente submetido a radioterapia pós-operatória do que naquele submetido na condição pré-cirúrgica. No estudo de Finizia et al. (1999), ressaltou-se que a qualidade vocal de pacientes submetidos ao tratamento radioterápico exclusivo poderia ter sido melhor, caso a terapia fonoaudiológica tivesse sido oferecida após a finalização da radioterapia.

No atual estudo, os parâmetros que mais se destacaram quanto a maior porcentagem de caracterização como bom foram: fluência (95\%), facilidade para iniciar a fonação $(95 \%)$ e ruído do estoma $(90 \%)$. Porém, o julgamento final apresentou-se como bom para apenas $10 \%$ da amostra e a qualidade vocal para $35 \%$, sendo que tais parâmetros foram os que apresentaram o 
maior número de indivíduos na categoria ruim. Apesar da qualidade da voz traqueoesofágica ser soberana a outras formas de reabilitação alaríngea, percebe-se que ainda está aquém da voz laríngea (Williams; Watson, 1987). $\mathrm{Na}$ pesquisa de Ceccon et al. (1998), 66,7\% dos falantes traqueoesofágicos apresentaram qualidade vocal boa e $33,3 \%$ foram julgados como moderado. Most et al, (2000) evidenciaram que falantes laríngeos diferiram significativamente de falantes esofágicos e traqueoesofágicos quanto a entonação e a freqüência fundamental, e os traqueoesofágicos foram mais aceitáveis, porém menos inteligível que os bons falantes esofágicos. Medidas perceptuais de inteligibilidade de fala são afetadas por inúmeros fatores, tais como, nível de esforço, intensidade vocal e a própria qualidade vocal, somadas a precisão articulatória. A produção de palavra isolada é mais fácil para o falante traqueoesofágico quando comparada a fala encadeada, pois neste caso há necessidade de coordenação do fluxo aéreo junto a vibração contínua do sinal, visando a preservação de aspectos sintáticos e semânticos da expressão, o que facilita a compreensão do ouvinte (McAuliffe et al., 2000). Winans et al. (1974) também destacaram que a habilidade na articulação é um dos fatores determinante para a inteligibilidade de fala. Com base na literatura, van As et al. (2001) ainda acrescenta que em falantes traqueoesofágicos, não somente a qualidade da voz é afetada, mas também a sua inteligibilidade. Especialmente em casos de falantes alaríngeos, a ênfase terapêutica para a reabilitação da comunicação deve considerar o máximo de parâmetros de voz e de fala, já que se trata de uma fonação produzida por uma nova fonte sonora, cujas maiores exigências e sensibilidade são esperadas para cumprimento efetivo da função.

Comparando-se os resultados pré e pós-treino fonoaudiológico para a comunicação com PTE, Oliveira et al. (2005) constataram que a melodia frasal e canto apresentaram o maior número de sujeitos com melhora, sugerindo que a ênfase terapêutica em variação melódica pode melhorar a qualidade da comunicação de indivíduos laringectomizados com PTE. No estudo de Williams e Watson (1985), os juízes experientes consideraram os usuários de PTE como melhores que os demais grupos alaríngeos quanto a apresentação visual 


\section{DISCUSSÃO}

durante a fala, velocidade de fala, ruído de fala, inteligibilidade e efetividade geral da comunicação. Entre outros objetivos pesquisados, Stajner-Katusic et al. (2006) encontraram para falantes traqueoesofágicos: tempo total de leitura de $31,4 \mathrm{~s}$, taxa de fala de 2,77 silabas/s e duração do bloqueio fonético de $2,07 \mathrm{~s}$, considerando a vantagem da prótese vocal sobre os outros tipos de comunicação alaríngea.

A ausência de ruído do estoma em $90 \%$ dos pacientes do presente estudo sugere que houve perfeita oclusão do estoma durante a produção vocal (Motta et al., 2001). Ao contrário disso, o escape de ar durante a fonação produz um ruído expiratório que gera distração no ouvinte e dificuldades de compreensão (Ceccon et al., 1998). Blom et al. (1995) cita a utilização de uma válvula de traqueostoma para prevenir o escape de ar observado algumas vezes com a oclusão digital, permitindo também que as mãos fiquem livres (Karlen; Maisel, 2001). O tamanho exageradamente grande do estoma pode influenciar a oclusão hermética digital, necessitando de outros dispositivos para sua resolução, como a utilização de bolas para a oclusão. Além disso, Lewin (2004) descreveu técnicas como cânulas fenestradas de laringectomia para diminuir o diâmetro do estoma e permitir a oclusão digital, sendo variáveis os níveis de sucesso e aceitação pelos pacientes. O estoma pequeno foi apresentado como mais freqüente em pacientes submetidos à radioterapia, dificultando a colocação da PTE e os cuidados com ela, sendo a solução mais comum para este caso a dilatação seriada do estoma com tubos de laringectomia de silicone progressivamente mais largos, sendo destacado que a posição e o formato do estoma são intrínsecos a cada paciente, tamanho e localização do tumor laríngeo, além da técnica cirúrgica utilizada. Em relação ao estoma e visando a diminuição de secreção e proteção pulmonar, no estudo de Masson et al. (2008), a utilização do HME diminuiu a tosse e a expectoração dos pacientes, porém a qualidade vocal não apresentou diferença. Na presente pesquisa, nenhum paciente fez uso de qualquer dispositivo a nível do estoma.

Apesar de não ter sido objetivo do presente estudo, a caracterização do julgamento final como falantes moderados prevaleceu sobre todas as mulheres, assim como a maioria dos homens. Na presente pesquisa, um dos 


\section{DISCUSSÃO}

dois falantes do gênero masculino caracterizados no julgamento final como bons, foi submetido a tratamento radioterápico complementar, demonstrando talvez a não influência desse procedimento em sua comunicação. Novamente, reforça-se a necessidade de um maior número de indivíduos para inferir seguramente a respeito. Chone et al. (2005) constataram que o uso da radioterapia não influenciou a taxa de sucesso da prótese vocal, seja inserida primariamente ou secundariamente. Mais recentemente, Casso et al. (2008) observaram que após a $L T$, a radioterapia realizada, como tratamento inicial ou em situação pós-operatória, afetou os resultados da deglutição, mas não o desenvolvimento da fala. De acordo com o estudo de Kazi et al. (2005) que objetivou adquirir informações sobre a experiência do paciente com a prótese traqueoesofágica, por meio de um questionário auto-administrado, constataram que as mulheres foram menos satisfeitas com a qualidade da voz alaríngea do que os homens, provavelmente em função do pitch mais grave apresentado por essa população.

Em relação aos dados de videofluoroscopia obtidos neste estudo, a dimensão PTFE-PPF aumentou do repouso $(14,31 \mathrm{~mm})$ para fonação $(18,56 \mathrm{~mm})$ e CLTFE diminuiu, apresentando-se no repouso com $12,55 \mathrm{~mm}$ e $10,46 \mathrm{~mm}$ durante a fonação, cujas diferenças foram significantes. Tais achados permitem a inferência de que tais medidas são as responsáveis pela morfofisiologia da TFE, das quais dependerá o resultado da PTFE-PAF durante a fonação, a qual é considerada pela literatura (van As et al., 2001) como o mais importante fator relacionado a qualidade da comunicação, considerandose que quanto menor esse valor, melhor a qualidade vocal resultante. Diante disso, verificamos que a medida de PTFE-PAF não apresentou diferença estatisticamente significante no repouso e durante a fonação, porém há uma grande implicância clínica agregada a essa dimensão, já que seu valor reduzido pode favorecer a formação pressórica abaixo da TFE, que poderá proporcionar um fluxo aéreo suficiente o bastante para gerar vibração das paredes faríngeas e conseqüente produção vocal alaríngea. Porém, tal aproximação das estruturas para a produção vocal não deve ocorrer com 
tensão, de maneira excessiva que provavelmente repercutirá em uma qualidade vocal insatisfatória.

Omori e Kojima (1999) constataram em seu estudo que as vozes julgadas como severas ou moderadamente tensas pertenceram aos pacientes que apresentaram fechamento excessivo da TFE, ressaltando-se importância de se distinguir a aproximação da proeminência faringoesofágica com a parede anterior da faringe com e sem tensão durante a fonação. Dando continuidade as medidas da TFE relacionadas a proficiência da $\operatorname{voz} e$ da fala traqueoesofágica, no estudo de van As et al. (2001) observou-se também que os indivíduos caracterizados como melhores falantes apresentaram maior aumento na distância máxima subneoglótica durante a fonação, quando comparada ao repouso, a qual está relacionada com a tensão de fechamento da TFE, porém, sendo esta muito alta, pode resultar em uma qualidade vocal pior ou até mesmo ausência de voz. Tal situação pode ser atribuída as condições de hiperfunção e/ou espasmo da musculatura remanescente da TFE, fortalecendo mais uma vez a importância da manometria para a sua caracterização.

Kazi et al. (2006) avaliaram a TFE em laringectomizados totais, por meio da videofluoroscopia visual e quantitativa, além de caracterizarem a qualidade vocal desses indivíduos, constatando-se correlação significante, durante a fonação, entre a menor distância mínima da TFE com a parede anterior da faringe e a ausência de regurgitação de bário, e a presença de uma proeminência faringoesofágica regular e normotônica. Além disso, observou-se também correlação entre grau geral discreto da voz e a menor distância mínima da TFE durante a fonação. Assim como observado no presente estudo, tais autores identificaram também diferença significante entre o comprimento da TFE no repouso $(23 \mathrm{~mm})$ e na fonação $(22 \mathrm{~mm})$, além da máxima distância subneoglótica no repouso $(7 \mathrm{~mm})$ e na fonação $(8 \mathrm{~mm})$.

De acordo com o estudo de Fouquet et al. (2009) envolvendo a videofluoroscopia visual e quantitativa e a qualidade vocal esofágica, a presença da proeminência faringoesofágica foi mais frequênte nos grupos de bons e moderados falantes, apresentando-se mais curto para o primeiro grupo. 


\section{DISCUSSÃO}

Proeminência faringoesofágica marcadamente presente e curta foi também relacionada a boa qualidade de vozes esofágicas no estudo de Daou et al. (1984), já na década de 80. Isman e O'Brien (1992) estudaram radiologicamente a TFE em laringectomizados totais proficientes tanto para a voz esofágica como para a traqueoesofágica, constatando-se comprimentos similares da TFE durante a fonação com PTE (12 a 50mm) e na esofágica (8 a $48 \mathrm{~mm}$ ). Do mesmo modo, Wetmore et al. (1985) concluíram que as características quanto a localização e formato da TFE em falantes esofágicos e traqueoesofágicos apresentaram-se semelhantes. Dentre outros objetivos, Lundström et al. (2008) investigaram as possíveis diferenças na aparência e localização da TFE entre falantes esofágicos e traqueoesofágicos, constatando-se correlação, durante a fonação, entre a distância da proeminência faringoesofágica e a parede anterior da faringe com a distância máxima abaixo da TFE, sendo que cada uma delas se relacionou também com a área superficial da TFE. Iwai et al. (2006) constataram em seu estudo a contribuição significativa da fonação traqueoesofágica para acelerar a aquisição imediata da voz esofágica.

Apesar da não significância estatística, quando as dimensões da TFE foram avaliadas descritivamente quanto ao gênero, não foi observada diferença entre homens e mulheres para PTFE-PAF $(4,73 \mathrm{~mm})$ durante o repouso, porém, na fonação, tal valor diminuiu para as mulheres $(3,57 \mathrm{~mm})$ e aumentou para os homens $(5,56 \mathrm{~mm})$. Para a dimensão PTFE-PPF, as mulheres passaram de $16,30 \mathrm{~mm}$ no repouso para $22,07 \mathrm{~mm}$ na fonação, sendo ambos os valores superiores aos dos homens $(13,92 \mathrm{~mm}$ para $17,86 \mathrm{~mm})$. Por outro lado, o CLTFE apresentou-se menor para as mulheres nas duas condições avaliadas. Partindo-se da uniformidade de PTFE-PAF durante o repouso entre os gêneros e tentando justificar tal condição durante a fonação, é necessário primeiramente considerar a anatomofisiologia das outras dimensões, já que a PTFE-PAF resulta dessa interação. O CLTFE durante a fonação é encurtado de forma a contribuir com a aproximação anterior da proeminência faringoesofágica a parede anterior da faringe PTFE-PPF, aumentando desse modo com o comprimento transversal dessa dimensão. Como nas mulheres o 


\section{DISCUSSÃO}

CLTFE apresentou-se menor nas condições de repouso e fonação, restou provavelmente ao PTFE-PPF a responsabilidade de ser maior, a fim de se justificar a diminuição de PTFE-PAF para esse gênero.

Apesar de não serem contemplados nos objetivos do estudo e de não apresentarem significância comprovada, a exploração descritiva dos achados relacionados a radioterapia é interessante, observando-se que os indivíduos não submetidos a tal procedimento complementar apresentaram os maiores valores de PTFE-PAF e PTFE-PPF, tanto no repouso como na fonação. O CLTFE por sua vez foi maior para os indivíduos que necessitaram da radioterapia, diminuindo seu valor do repouso $(12,89 \mathrm{~mm})$ para a fonação $(10,36 \mathrm{~mm})$. A perda da elasticidade tecidual da TFE pode ter dificultado a movimentação das estruturas remanescentes para a fonação, apresentando-se menor para os falantes irradiados. Durante o repouso, o enrijecimento gerado nessa área provavelmente contribuiu com a diminuição do comprimento transversal da TFE, decorrente de uma maior compressão ou ainda fibrose tecidual, o que justifica o valor mais elevado de PTFE-PAF dos pacientes não irradiados. Tal compressão tecidual parece afetar apenas a morfologia da medida transversal, exigindo-se um trabalho compensatório do CLTFE que, forçadamente tenta compensar a dificuldade morfofisiológica de PTFE-PPF durante a fonação traqueoesofágica.

Unindo-se os achados da manometria com as dimensões da TFE no repouso e durante a fonação obtidos na presente pesquisa, a melhor correlação positiva observada foi moderada e existiu entre PTFE-PAF e amplitude de pressão $(0,41)$ durante a fonação, ou seja, quanto maior a distância entre a proeminência faringoesofágica e a parede anterior da faringe, maior a amplitude de pressão durante a fonação. Tal correlação pode sugerir a influência do volume do fluxo aéreo na captação da pressão associado ao resultado das características morfofuncionais das estruturas que participam da fonação. Relacionando-se tal achado a qualidade vocal traqueoesofágica deste estudo, constata-se que os melhores falantes apresentaram menor média pressórica na TFE durante a fonação, confirmando-se que quanto menor PTFE-PAF, menor a pressão intraluminal durante a fonação, cuja situação 
parece favorecer a qualidade da proficiência de voz e de fala traqueoesofágica. Ressalta-se também que o oposto é verdadeiro e foi também confirmado neste estudo, ou seja, os piores falantes apresentaram os maiores valores de pressão e de PTFE-PAF durante a fonação, estando nestes casos associadas provavelmente ao comportamento hiperfuncional compensatório das estruturas responsáveis por PTFE-PPF e CLTF, considerando-se a importância dessas dimensões para o resultado final de PTFE-PAF. Tal comportamento compensatório decorre do reduzido comprimento longitudinal e transversal dessas medidas, visando atingir o máximo de equilíbrio das estruturas da TFE para a produção vocal, proporcionado uma atividade pressórica inversamente proporcional ao tamanho dessas dimensões, o que concorda com as correlações inversas observadas neste estudo.

\subsection{Considerações finais}

Do ponto de vista metodológico, buscou-se preconizar neste trabalho a objetividade e o caráter quantitativo de seus instrumentos, como a manometria e a videofluoroscopia, relacionadas à proficiência da comunicação traqueoesofágica, cujos objetivos são inéditos na literatura até o presente momento e por isso poderá contribuir com a pesquisa e a clínica fonoaudiológica, a fim de se beneficiar a população de laringectomizados totais, por meio da compreensão morfofisiológica da TFE e adequada intervenção terapêutica.

Além da clara importância da reabilitação vocal para o laringectomizado total, há grande exigência científica quanto à compreensão das características morfofuncionais da TFE, que permitam a caracterização anatomofisiológica de sucesso e insucesso da comunicação traqueoesofágica, por meio do estabelecimento de critérios refinados que permitam a sua reprodução metodológica e simultaneamente contribuam na seleção prévia dos candidatos a PTE. Tal condição favorece o estabelecimento de estratégias mais seguras e específicas à reabilitação vocal alaríngea, permitindo a tomada de decisões pertinentes e imediatas ao caso. Somado a isso, os resultados deste trabalho 
podem ser considerados como o ponto de partida para o desenvolvimento de estudos longitudinais envolvendo as condições pré e pós-inserção da PTE.

Convém ressaltar que em função da seleção dos participantes deste trabalho ter sido criteriosamente realizada, não foi possível obter um tamanho amostral maior. Como resolução do exposto, aconselha-se o desenvolvimento de estudos posteriores de forma multicêntrica.

A ferramenta de medição computadorizada desenvolvida para este estudo permite ser empregada a âmbito clínico e de pesquisa, já que é de fácil manuseio e pode complementar a avaliação clínica fonoaudiológica do laringectomizado total. Ressalta-se que além de mensurar as dimensões da TFE, pode também ser utilizada a outros propósitos de investigação anatômica. 
6. CONCLUSÕES 


\section{CONCLUSÕES}

\section{Caracterização da proficiência de voz e de fala}

A maioria dos laringectomizados totais com PTE foi caracterizada semanticamente como falante moderado.

\section{Pressão intraluminal da TFE durante o repouso e a fonação}

Houve aumento significante da amplitude de pressão durante a fonação quando comparada a situação de repouso.

\section{Dimensões da TFE durante o repouso e a fonação}

Houve aumento significante na dimensão PTFE-PPF e diminuição também significante de CLTFE durante a fonação quando comparadas a situação de repouso.

Relação entre as dimensões e as amplitudes de pressão intraluminal da TFE, no repouso e durante a fonação, e a caracterização da proficiência de voz e de fala traqueoesofágica

A dimensão PTFE-PAF da TFE apresentou correlação positiva com a amplitude de pressão intraluminal durante a fonação. Já PTFE-PAF, no repouso, e CLTFE, durante a fonação, demonstraram correlação inversa com a pressão intraluminal da TFE.

Os bons falantes traqueoesofágicos apresentaram valor intermediário de amplitude de pressão intraluminal na condição de repouso e o menor valor durante a fonação, quando comparados aos falantes moderados e ruins.

Comparando-se com os falantes moderados e ruins, os bons falantes traqueoesofágicos apresentaram maior PTFE-PAF e menor PTFE-PPF durante o repouso. Já na fonação, PTFE-PAF tornou-se menor e PTFE-PPF maior para os melhores falantes. Os valores dimensionais de CLTFE foram intermediários, ou seja, entre os falantes moderados e ruins, tanto no repouso como na fonação. 
7. REFEREATCIAS BIBLIOGRÁFICAS 


\section{REFERÊNCIAS}

1. Aguiar-Ricz L, Dantas RO, Ricz H, Gielow I, Mamede RC, Perdoná GC. Behavior of the cricopharyngeal segment during esophageal phonation in laryngectomized patients. J Voice. 2007 Mar; 21(2): 248-56.

2. Aguiar-Ricz, LN. Pressões intraluminares na faringe, transição faringoesofágica e esôfago, em laringectomizados falantes com prótese traqueoesofágica e não falantes sem prótese. [tese]. Ribeirão Preto: Universidade de São Paulo, Faculdade de Medicina; 2005.

3. Albirmawy OA, Elsheikh MN, Saafan ME, Elsheikh E. Managing problems with tracheoesophageal puncture for alaryngeal voice rehabilitation. Laryngol Otol. 2006 Jun; 120(6): 470-7.

4. Allan W, Burgess L, Hurren A, Marsh R, Samuel PR, Small PK. Oesophageal function in tracheoesophageal fistula speakers after laryngectomy. J Laryngol Otol. 2009 Jun; 123(6): 666-72.

5. Artazkoz del Toro JJ, López Martínez R. Videofluoroscopy of the pharyngoesophageal segment after total phonatory laryngectomy. Acta Otorrinolaringol Esp. 1997 Jan-Feb; 48(1): 51-6.

6. Barros APB. Efetividade da comunicação oral, qualidade de vida e depressão pós-faringolaringectomia e laringectomia total. [dissertação]. São Paulo: Universidade de São Paulo, Faculdade de Medicina; 2002.

7. Bayles SW, Deschler DG. Operative prevention and management of voicelimiting pharyngoesophageal spasm. Otolaryngol Clin North Am. 2004 Jun; 37(3): 547-58.

8. Bellandese MH. Fundamental frequency and gender identification in standard esophageal and tracheoesophageal speakers. J Commun Disord. 2009 MarApr; 42(2): 89-99.

9. Blitzer A, Komisar A, Baredes S, Brin MF, Stewart C. Voice failure after tracheoesophageal puncture: management with botulinum toxin. Otolaryngol Head Neck Surg. 1995 Dec;113(6): 668-70. 
10. Blom ED, Pauloski BR, Hamaker RC. Functional outcome after surgery for prevention of pharyngospasms in tracheoesophageal speakers. Part I: Speech characteristics. Laryngoscope. 1995 Oct; 105(10): 1093-103.

11. Boscolo-Rizzo P, Zanetti F, Carpené S, Da Mosto MC. Long-term results with tracheoesophageal voice prosthesis: primary versus secondary TEP. Eur Arch Otorhinolaryngol. 2008 Jan; 265(1): 73-7.

12. Bozec A, Poissonnet G, Chamorey E, Demard F, Santini J, Peyrade F, Ortholan C, Benezery K, Thariat J, Sudaka A, Anselme K, Adrey B, Giacchero $P$, Dassonville $O$. Results of vocal rehabilitation using tracheoesophageal voice prosthesis after total laryngectomy and their predictive factors. Eur Arch Otorhinolaryngol. 2009 Nov 5; [Epub ahead of print]

13. Brok HA, Stroeve RJ, Copper MP, Schouwenburg PF. The treatment of hypertonicity of the pharyngo-oesophageal segment after laryngectomy. Clin Otolaryngol Allied Sci. 1998 Aug; 23(4): 302-7.

14. Brown DH, Hilgers FJ, Irish JC, Balm AJ. Postlaryngectomy voice rehabilitation: state of the art at the millennium. World J Surg. $2003 \mathrm{Jul}$; 27(7): 824-31.

15. Bunting GW. Voice following laryngeal cancer surgery: troubleshooting common problems after tracheoesophageal voice restoration. Otolaryngol Clin North Am. 2004 Jun; 37(3): 597-612.

16. Cantu E, Ryan WJ, Tansey S, Johnson CS Jr. Tracheoesophageal speech: predictors of success and social validity ratings. Am J Otolaryngol. 1998; 19(1): 12-7.

17. Carmo RD, Camargo Z, Nemr K. Relação entre qualidade de vida e autopercepção da qualidade vocal e pacientes laringectomizados totais. Rev Cefac. 2006 Out-Dez; 8(4): 518-28.

18. Casso C, Slevin NJ, Homer JJ. The impact of radiotherapy on swallowing and speech in patients who undergo total laryngectomy. Otolaryngol Head Neck Surg. 2008 Dec; 139(6):792-7. 
19. Ceccon FP, Abrahão M, Cervantes O, Carrara de Angelis E. Contribuição ao estudo da voz alaríngea: análise acústica, temporal e perceptiva da voz traqueoesofágica. Rev Bras Cir Cabeça e Pescoço. 1998 Jan-Abr; 22 (4): 21-8.

20. Chone CT, Gripp FM, Spina AL, Crespo AN. Primary versus secondary tracheoesophageal puncture for speech rehabilitation in total laryngectomy: long-term results with indwelling voice prosthesis. Otolaryngol Head Neck Surg. 2005 Jul; 133(1): 89-93.

21. Chone CT, Seixas VO, Andreollo NA, Quagliato E, Barcelos IH, Spina AL, Crespo AN. Computerized manometry use to evaluate spasm in pharyngoesophageal segment in patients with poor tracheoesophageal speech before and after treatment with botulinum toxin. Braz $\mathrm{J}$ Otorhinolaryngol. 2009 Mar-Apr; 75(2): 182-7.

22. Chone CT, Seixas VO, Paes LA, Gripp FM, Teixeira C, Andreollo NA, Spina AL, Quagliato E, Barcelos IK, Crespo AN. Use of computerized manometry for the detection of pharyngoesophageal spasm in tracheoesophageal speech. Otolaryngol Head Neck Surg. 2008 Sep; 139(3): 449-52.

23. Chone CT, Teixeira C, Andreollo NA, Spina AL, Barcellos HK, Quagliato E, Crespo AN. Reabilitação fonatória do laringectomizado total: utilização de toxina botulínica na voz traqueoesofágica com prótese fonatória. Rev Bras Otorrinolaringol. 2008 Mar-Abr; 74(2): 230-4.

24. Clements KS, Rassekh $\mathrm{CH}$, Seikaly $\mathrm{H}$, Hokanson JA, Calhoun $\mathrm{KH}$. Communication after laryngectomy. An assessment of patient satisfaction. Arch Otolaryngol Head Neck Surg. 1997; 123(5): 493-6.

25. Clevens RA, Esclamado RM, Hartshorn DO, Lewin JS. Voice rehabilitation after total laryngectomy and tracheoesophageal puncture using nonmuscle closure. Ann Otol Rhinol Laryngol. 1993 Oct; 102(10): 792-6.

26. Costa MMB. Análise estrutural da laringofaringe e suas implicações na miotomia do cricofaríngeo, na injeção de toxina botulínica e na dilatação por balão. Arq Gastroenterol. 2003 Abr-Jun; 40 (2): 63-72. 
27. Culton GL, Gerwin JM. Current trends in laryngectomy rehabilitation: a survey of speech-language pathologists. Otolaryngol Head Neck Surg. 1998 Apr; 118(4): 458-63.

28. Damsté PH, Lerman JW. Configuration of the neoglottis: an x-ray study. Folia Phoniatr. 1969; 21(5):347-58.

29. Dantas RO, Aguiar LN, Ramos FS, Mamede RC, Silva AK, Gonçalves AS, Mello Filho FV. Evaluation of esophageal motility in laryngectomized patients. Arq Gastroenterol. 1999 Jul-Sep; 36(3): 112-6.

30. Dantas RO, Aguiar-Ricz LN, Gielow I, Mello-Filho FV, Mamede RC. Proximal esophageal contractions in laryngectomized patients. Dysphagia. 2005 Spring; 20(2): 101-4.

31. Dantas RO, Aguiar-Ricz LN, Oliveira EC, Mello-Filho FV, Mamede RC. Influence of esophageal motility on esophageal speech of laryngectomized patients. Dysphagia. 2002 Spring: 17(2): 121-5.

32. Dantas RO, Aguiar-Ricz LN, Ramos FC, Oliveira, EC, Mello-Filho, FV, Mamede, RC. Evolução das alterações motoras do esôfago de pacientes laringectomizados. GED. 2000 19: 113-16.

33. Dantas RO, Ferriolli E, Souza MA. Gender effects on esophageal motility. Braz J Med Biol Res. 1998 Apr; 31(4): 539-44.

34. Dantas RO, Ricz LNA, Oliveira EC, Mello -Filho FV, Mamede, RCM. Pressão intr-esofágica durante a produção da voz esofágica em pacientes laringectomizados com e sem recuperação da capacidade de comunicação oral. Arq Gastroenterol. 2001 38: 158-61.

35. Daou RA, Shultz JR, Remy H, Chan NT, Attia EL. Laryngectomee study: clinical and radiologic correlates of esophageal voice. Otolaryngol Head Neck Surg. 1984 Dec; 92(6): 628-34.

36. Deschler DG, Doherty ET, Reed CG, Singer MI. Effects of sound pressure levels on fundamental frequency in tracheoesophageal speakers. Otolaryngol Head Neck Surg. 1999 Jul; 121(1): 23-6.

37. Duranceau A, Jamieson G, Hurwitz AL, Jones RS, Postlethwait RW. Alteration in esophageal motility after laryngectomy. Am J Surg. 1976 Jan; 131(1): 30-5. 
38. Fagan JJ, Lentin R, Oyarzabal MF, Isaacs S, Sellars SL. Tracheoesophageal speech in a developing world community. Arch Otolaryngol Head Neck Surg. 2002 Jan; 128(1): 50-3.

39. Ferrer Ramírez MJ, Guallart Doménech F, Brotons Durbán S, Carrasco Llatas M, Estellés Ferriol E, López Martínez R. Surgical voice restoration after total laryngectomy: long-term results. Eur Arch Otorhinolaryngol. 2001 Nov; 258(9): 463-6.

40. Finizia C, Dotevall H, Lundström E, Lindström J. Acoustic and perceptual evaluation of voice and speech quality: a study of patients with laryngeal cancer treated with laryngectomy vs irradiation. Arch Otolaryngol Head Neck Surg. 1999 Feb; 125(2): 157-63.

41. Fouquet ML, Gonçalves AJ, Behlau M. Relation between videofluoroscopy of the esophagus and the quality of esophageal speech. Folia Phoniatr Logop. 2009; 61(1): 29-36.

42. Gatenby RA, Rosenblum JS, Leonard CM, Moldofsky PJ. Broder GJ. Esophageal speech: double-contrast evaluation of the pharyngoesophageal segment. Radiology. 1985 Oct; 157(1): 127-31.

43. Geraghty JA, Wenig BL, Smith BE, Portugal LG. Long-term follow-up of tracheoesophageal puncture results. Ann Otol Rhinol Laryngol. $1996 \mathrm{Jul}$; 105(7): 501-3.

44. Gerwin JM, Culton GL. Quality of life in prosthetic voice users. Otolaryngol Head Neck Surg. 2005 Nov; 133(5): 685-8.

45. Globlek D, Stajner-Katusic S, Musura M, Horga D, Liker M. Comparison of alaryngeal voice and speech. Logoped Phoniatr Vocol. 2004; 29(2): 87-91.

46. Gravesen FH, Funch-Jensen P, Gregersen H, Drewes AM. Axial force measurement for esophageal function testing. World J Gastroenterol. 2009 Jan $14 ; 15(2):$ 139-43.

47. Gress CD. Preoperative evaluation for tracheoesophageal voice restoration. Otolaryngol Clin North Am. 2004 Jun; 37(3): 519-30. 
48. Grolman W, Eerenstein SE, Tange RA, Canu G, Bogaardt H, Dijkhuis JP, Dreschler WA, Schouwenburg PF. Vocal efficiency in tracheoesophageal phonation. Auris Nasus Larynx. 2008 Mar; 35(1): 83-8.

49. Hamaker RC, Blom ED. Botulinum neurotoxin for pharyngeal constrictor muscle spasm in tracheoesophageal voice restoration. Laryngoscope. 2003 Sep; 113(9): 1479-82.

50. Hanks JB, Fisher SR, Meyers WC, Christian KC, Postlethwait RW, Jones RS. Effect of total laryngectomy on esophageal motility. Ann Otol Rhinol Laryngol. 1981 Jul-Aug; 90: 331-4.

51. Hilgers FJ, Balm AJM, Gregor RT, Scholtens BEGM, Ackerstaff AH. A practical guide to post-laryngectomy vocal and pulmonary rehabilitation. Amsterdam: Thesis publishers; 1997. Capítulo 6, Speech therapy; p. 68-77.

52. Hilgers FJ, van As-Brooks CJ, Polak RM, Bing TI. Surgical improvement of hypotonicity in tracheoesophageal speech. Laryngoscope. 2006 Feb; 116(2): 345-8.

53. Hirano S, Kojima H, Shoji K, Kaneko K, Tateya I, Asato R, Omori K. Vibratory analysis of the neoglottis after surgical intervention of cricopharyngeal myotomy and implantation of tracheal cartilage. Arch Otolaryngol Head Neck Surg. 1999 Dec; 125(12): 1335-40.

54. Horowitz JB, Sasaki CT. Effect of cricopharyngeus myotomy on postlaryngectomy pharyngeal contraction pressures. Laryngoscope. 1993 Feb; 103(2): 138-40.

55. Isman KA, O'Brien CJ. Videofluoroscopy of the pharyngoesophageal segment during tracheoesophageal and esophageal speech. Head Neck. 1992 Sep-Oct; 14(5): 352-8.

56. Iwai H, Shimano T, Omae M, Kaneko T, Yamashita T. Early acquisition of esophageal phonation following tracheoesophageal phonation. Acta Otolaryngol. 2006 Jul; 126(7): 764-8. 
57. Karlen RG, Maisel RH. Does primary tracheoesophageal puncture reduce complications after laryngectomy and improve patient communication? Am J Otolaryngol. 2001 Sep-Oct; 22(5): 324-8.

58. Kazi R, Kanagalingam J, Venkitaraman R, Prasad V, Clarke P, Nutting CM, Rhys-Evans P, Harrington KJ. Electroglottographic and perceptual evaluation of tracheoesophageal speech. J Voice. 2009 Mar; 23(2): 247-54.

59. Kazi R, Singh A, De Cordova J, Clarke P, Harrington K, Rhys-Evans P. A new self-administered questionnaire to determine patient experience with voice prostheses (Blom-Singer valves). J Postgrad Med. 2005 Oct-Dec; 51(4): 253-8.

60. Kazi R, Singh A, Mullan GP, Venkitaraman R, Nutting CM, Clarke P, RhysEvans $\mathrm{P}$, Harrington KJ. Can objective parameters derived from videofluoroscopic assessment of post-laryngectomy valved speech replace current subjective measures? An e-tool-based analysis. Clin Otolaryngol. 2006 Dec; 31(6): 518-24.

61. Kazi RA, Singh A, Venkitaraman R, Sayed SI, Rhys-Evans P, Harrington $\mathrm{KJ}$. Is electroglottography-based videostroboscopic assessment of postlaryngectomy prosthetic speech useful? J Cancer Res Ther. 2009 Apr-Jun; 5(2): 85-92.

62. Köybaşioğlu A; Oz O; Uslu S; lleri F; Inal E; Unal S. Comparison of pharyngoesophageal segment pressure in total laryngectomy patients with and without pharyngeal neurectomy. Head Neck. 2003 Aug; 25(8):617-23.

63. Kotby MN, Hegazi MA, Kamal I, Gamal El Dien N, Nassar J. Aerodynamics of the pseudo-glottis. Folia Phoniatr Logop. 2009; 61(1): 24-8.

64. Lewin JS, Bishop-Leone JK, Forman AD, Diaz EM Jr. Further experience with Botox injection for tracheoesophageal speech failure. Head Neck. 2001 Jun; 23(6): 456-60.

65. Lewin JS. Nonsurgical management of the stoma to maximize tracheoesophageal speech. Otolaryngol Clin North Am. 2004 Jun; 37(3): 585-96.

66. Lundström E, Hammarberg B, Munck-Wikland E, Edsborg N. The pharyngoesophageal segment in laryngectomees--videoradiographic, acoustic, and voice quality perceptual data. Logoped Phoniatr Vocol. 2008; 33(3): 115-25. 
67. Masson ACC, Fouquet MLF, Gonçalves AJ. Umidificador de traqueoestoma: influência na secreção e voz de laringectomizados. 2008 jul-set; 20(3): 183-8.

68. Max L, Steurs W, de Bruyn W. Vocal capacities in esophageal and tracheoesophageal speakers. Laryngoscope. 1996 Jan; 106(1 Pt 1): 93-6.

69. McAuliffe MJ, Ward EC, Bassett L, Perkins K. Functional speech outcomes after laryngectomy and pharyngolaryngectomy. Arch Otolaryngol Head Neck Surg. 2000 Jun; 126(6): 705-9.

70. Mclvor J, Evans PF, Perry A, Cheesman AD. Radiological assessment of post laryngectomy speech. Clin Radiol. 1990 May; 41(5): 312-6.

71. Mendenhall WM, Morris CG, Stringer SP, Amdur RJ, Hinerman RW, Villaret DB, Robbins KT. Voice rehabilitation after total laryngectomy and postoperative radiation therapy. J Clin Oncol. 2002 May 15; 20(10): 2500-5.

72. Mohri M, Kinishi M, Amatsu M. Dynamics of subneoglottic lumen in tracheoesophageal phonation. Ann Otol Rhinol Laryngol. 1998 Nov;107 (11 Pt 1): 974-6.

73. Morgan DW, Hadley J, Willis G, Cheesman AD. Use of a portable manometer as a screening procedure in voice rehabilitation. J Laryngol Otol. 1992 Apr; 106(4): 353-5.

74. Most T, Tobin Y, Mimran RC. Acoustic and perceptual characteristics of esophageal and tracheoesophageal speech production. J Commun Disord. 2000 Mar-Apr; 33(2): 165-80.

75. Motta S, Galli I, Di Rienzo L. Aerodynamic findings in esophageal voice. Arch Otolaryngol Head Neck Surg. 2001 Jun; 127(6): 700-4.

76. Murray JA, Clouse RE, Conklin JL. Components of the standard oesophageal manometry. Neurogastroenterol Motil. 2003 Dec; 15(6): 591606. 
77. Nishizawa N, Mesuda Y, Kobashi M, Takahashi M, Inuyama Y. Identification of the opener and closer of the pharyngoesophagus in laryngectomees. Auris Nasus Larynx. 2001 May; 28 Suppl: S63-9.

78. Oliveira IB, Costa CC, Chagas JFS, Rochetti ECG, Oliveira LO. Comunicação oral de laringectomizados com prótese traqueoesofágica: análise comparativa pré e pós-treino. Pró-Fono. 2005 Maio-Ago; 17(2): $165-74$.

79. Omori K, Kojima H. Neoglottic vibration in tracheoesophageal shunt phonation. Eur Arch Otorhinolaryngol. 1999; 256(10): 501-5.

80. Omori K, Kojima H, Nonomura M, Fukushima H. Mechanism of tracheoesophageal shunt phonation. Arch Otolaryngol Head Neck Surg. 1994 Jun; 120(6): 648-52.

81. Op de Coul BM, van den Hoogen FJ, van As CJ, Marres HA, Joosten FB, Manni JJ, Hilgers FJ. Evaluation of the effects of primary myotomy in total laryngectomy on the neoglottis with the use of quantitative videofluoroscopy.Arch Otolaryngol Head Neck Surg. 2003 Sep; 129(9):1000-5.

82. Perera L, Kern M, Hofmann C, Tatro L, Chai K, Kuribayashi S, Lawal A, Shaker R. Manometric evidence for a phonation-induced UES contractile reflex. Am J Physiol Gastrointest Liver Physiol. 2008 Apr; 294(4): G885-91.

83. Perry A, Cheesman AD, Mclvor J, Chalton R. A British experience of surgical voice restoration techniques as a secondary procedure following total laryngectomy. J Laryngol Otol. 1987 Feb; 101(2): 155-63.

84. Pou AM. Tracheoesophageal voice restoration with total laryngectomy. Otolaryngol Clin North Am. 2004 Jun; 37(3): 531-45.

85. Pruszewicz A, Woźnica B, Kruk-Zagajewska A, Obrebowski A. Electromyography of cricopharyngeal muscles in patients with oesophageal speech. Acta Oto-Laryngol. 1992; 112(2): 366-9. 
86. Richardson JL. Surgical and radiological effects upon the development of speech after total laryngectomy. Ann Otol Rhinol Laryngol. 1981 May-Jun; 90(3 Pt 1): 294-7.

87. Sandberg N. Motility of the pharynx and oesophagus after laryngectomy. Acta Otolaryngol Suppl. 1970; 263: 124-7.

88. Schuster M, Lohscheller J, Hoppe U, Kummer P, Eysholdt U, Rosanowski F. Voice handicap of laryngectomees with tracheoesophageal speech. Folia Phoniatr Logop. 2004 Jan-Feb; 56(1): 62-7.

89. Schuster M, Rosanowski F, Schwarz R, Eysholdt U, Lohscheller J. Quantitative detection of substitute voice generator during phonation in patients undergoing laryngectomy. Arch Otolaryngol Head Neck Surg. 2005 Nov; 131(11): 945-52.

90. Shames GH, Font J, Matthews J. Factors related to speech proficiency of the laryngectomized. J Speech Hear Disord. 1963 Aug; 28: 273-87.

91. Singer MI. The development of successful tracheoesophageal voice restoration. Otolaryngol Clin North Am. 2004 Jun; 37(3): 507-17.

92. Singer MI, Blom ED. An endoscopic technique for restoration of voice after laryngectomy. Ann Otol Rhinol Laryngol. 1980 Nov-Dec; 89(6 Pt 1):529-33.

93. St Guily JL, Angelard B, el-Bez M, Julien N, Debry C, Fichaux P, Gondret R. Postlaryngectomy voice restoration. A prospective study in 83 patients. Arch Otolaryngol Head Neck Surg. 1992 Mar; 118(3): 252-5.

94. Stajner-Katusić S, Horga D, Musura M, Globlek D. Voice and speech after laryngectomy. Clin Linguist Phon. 2006 Apr-May; 20(2-3): 195-203.

95. van As CJ, Op de Coul BM, van den Hoogen FJ, Koopmans-van Beinum FJ, Hilgers FJ. Quantitative videofluoroscopy: a new evaluation tool for tracheoesophageal voice production. Arch Otolaryngol Head Neck Surg. 2001 Feb; 127(2): 161-9.

96. van As CJ, Op De Coul BM, Eysholdt U, Hilgers FJ. Value of digital highspeed endoscopy in addition to videofluoroscopic imaging of the neoglottis in tracheoesophageal speech. Acta Otolaryngol. 2004 Jan; 124(1): 82-9. 
97. van As CJ. A multidimensional assessment of voice quality. 2001. Capítulo 7, Videofluoroscopy related to perceptual evaluations, acoustic analyses and clinical factores; p. 122-38.

98. van As CJ, Koopmans-van Beinum FJ, Pols LC, Hilgers FJ. Perceptual evaluation of tracheoesophageal speech by naive and experienced judges through the use of semantic differential scales. J Speech Lang Hear Res. 2003 Aug; 46(4): 947-59.

99. van Weissenbrush R, Kunnen M, Albers FWJ, Van Cauwenberge PB, Sulter AM. Cineradiography of the pharyngoesophageal segment em post laryngectomy total. Ann Otol Rihinol laryngol. 2000 Mar; 109(3): 311-9.

100. Welch RW, Gates GA, Luckmann KF, Ricks PM, Drake ST. Change in the force-summed pressure measurements of the upper esophageal sphincter prelaryngectomy and postlaryngectomy. Ann Otol Rhinol Laryngol. 1979 Nov-Dec; 88(Pt 1): 804-8.

101. Wetmore SJ, Ryan SP, Montague JC, Krueger K, Wesson K, Tirman R, Diner $W$. Location of the vibratory segment in tracheoesophageal speakers. Otolaryngol Head Neck Surg. 1985 Jun; 93(3): 355-61.

102. Williams SE, Watson JB. Differences in speaking proficiencies in three laryngectomee groups. Arch Otolaryngol. 1985 Apr; 111(4): 216-9.

103. Williams SE, Watson JB. Speaking proficiency variations according to method of alaryngeal voicing. Laryngoscope. 1987 Jun; 97(6): 737-9.

104. Winans CS, Reichbach EJ, Waldrop WF. Esophageal determinants of alaryngeal speech. Arch Otolaryngol. 1974 Jan; 99(1): 10-4.

105. Zormeier MM, Meleca RJ, Simpson ML, Dworkin JP, Klein R, Gross M, Mathog RH. Botulinum toxin injection to improve tracheoesophageal speech after total laryngectomy. Otolaryngol Head Neck Surg. 1999 Mar; 120(3): 314-9. 
8. APA $\mathcal{E} \mathcal{N D C E S}$ 


\section{APÊNDICE A}

\section{TERMO DE CONSENTIMENTO LIVRE E ESCLARECIDO UTILIZADO PARA OS PACIENTES (PARTE I).}

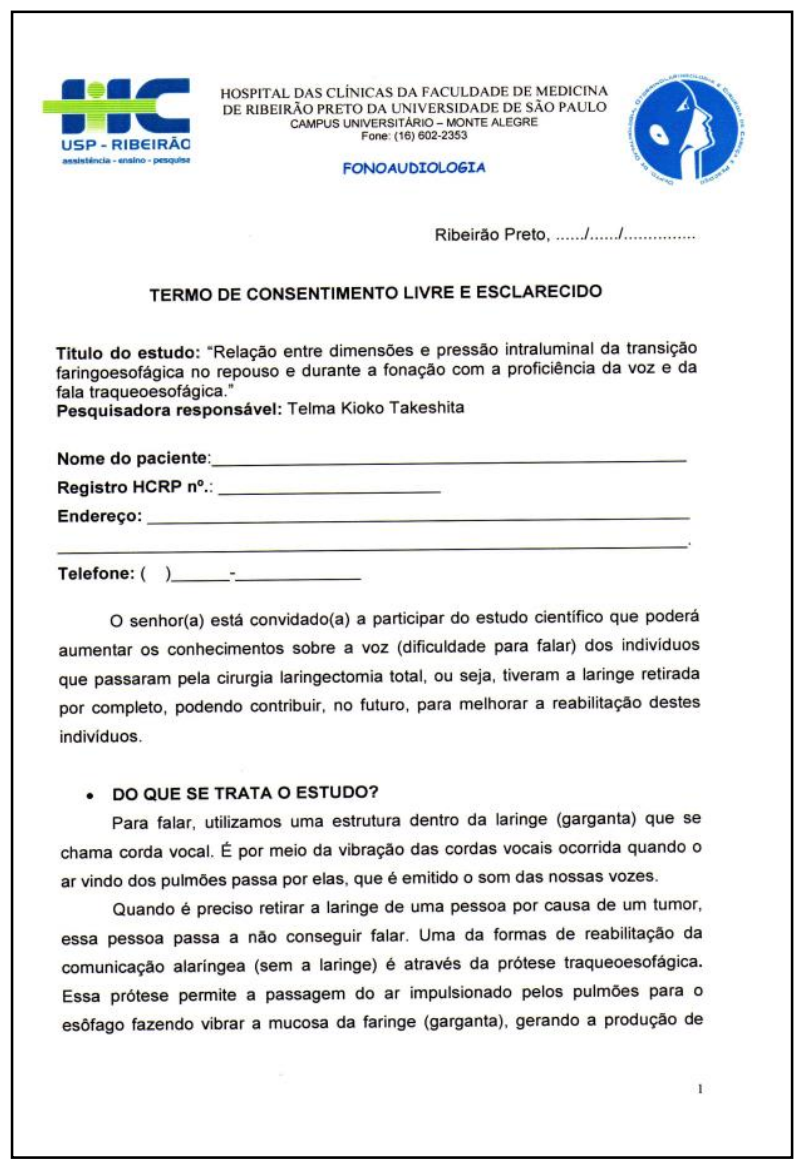

voz. No entanto, após a colocação da prótese alguns pacientes não conseguem desenvolver a voz traqueoesofágica.

O objetivo desse estudo é avaliar e comparar a qualidade vocal traqueoesofágica com dados obtidos pelos exames de manometria e videofluoroscopia da transiçăo faringoesofágica (região que separa a garganta e o esôfago) em pacientes laringectomizados totais usuários de prótese fonatória traqueoesofágica, verificando o comportamento funcional dessa regiāo durante a fala e o repouso e se esses achados contribuem para a não aquisiçăo e desenvolvimento da voz traqueoesofágica.

\section{- como será Realizado o estudo?}

Primeiramente, será feita a gravação de sua voz e fala por meio de uma câmera de vídeo em local silencioso. $O(A)$ senhor(a) ficará sentado(a) a um metro de distância da câmera filmadora para que a produção do som seja registrada sem perda da qualidade. Para isso serâo realizadas medidas do volume da sua voz, utilizando-se um aparelho chamado decibelimetro, que ficará também a um metro de distância do(a) senhor(a) para captar o som. Também será medido, por meio de um cronômetro, o tempo que o(a) senhor(a) manterá a emissão do som. $O(A)$ senhor(a) será instruido(a) para que fale normalmente, ou seja, como está acostumado, as seguintes provas vocais: emitir o mais longo possivel as vogais "a", "i", "u", após a inspiraçẫo; contar de um a vinte, após a inspiração; cantar "Parabéns a você" e dizer quais as vantagens e desvantagens do uso da prótese vocal?".

Para avaliar o comportamento do trânsito faringoesofágico durante a fala e o repouso é preciso realizar três exames, a manometria, a videofluroscopia e a eletromiografia. Na manometria o(a) senhor(a) ficará sentado confortavelmente e será anestesiada a cavidade nasal com lidocaina gel $2 \%$ para a passagem de uma sonda pela narina (nariz) que será posicionada no esôfago e depois na faringe. Após a acomodaçăo da sonda será pedido que o (a) senhor(a) fale a vogal "a" de forma prolongada.

Para o exame da videofluroscopia o(a) senhor(a) ficará sentado em uma cadeira para a realização da avaliaçăo radiológica (videofluoroscópica) durante a 


\section{TERMO DE CONSENTIMENTO LIVRE E ESCLARECIDO UTILIZADO PARA OS PACIENTES (PARTE II).}

fala e o repouso. Será pedido que o(a) senhor(a) fale a vogal "a" de forma prolongada.

Os dados coletados serão avaliados, relacionando os achados do exame radiológico com a manometria.

- o Estudo traRÁ ALgum BENEFício no SEU tRATAMENTO?

Não. Este estudo tem o objetivo de tentar esclarecer o porque que alguns laringectomizados não conseguem falar. Portanto, será possível apenas beneficiar, no futuro, outros pacientes que passaram pela mesma cirurgia.

- gravação de voz e fala, manometria e a videofluorocopia OFERECEM ALGUM DESCONFORTO, PREJUizo OU DANO?

A gravação de voz e fala implicará apenas em registro com câmera filmadora, com microfone conectado a um computador, com aparelho decibelimetro e com cronômetro, năo acarretando ao(à) senhor(a) qualquer desconforto, dano ou prejuizo

A sonda, que entrará pela narina e será posicionada no esôfago durante o exame manométrico, promove discreto incômodo, no entanto se este for intenso ou se o (a) senhor (a) sentir dor e solicitar que pare o exame, o mesmo será suspenso imediatamente. Para a realização da manometria é exigido jejum.

$\mathrm{Na}$ videofluoroscopia o exame é como um raio $\mathrm{X}$ e o contaste oferecido não traz nenhum prejuizo a sua saúde. $O$ tempo esperado de sua exposiçăo à radiação será minimo e controlado para que não haja danos a sua saúde ( máximo de 8 minutos). Não é exigido jejum para realizaçấo do exame.

Dessa forma, ambos procedimentos não oferecem riscos ou prejuizos ao paciente.

- O QUE ACONTECE COM QUEM NÃO PARTICIPA DO ESTUDO?

Nada. O seguimento e os retornos do(a) senhor(a) serão realizados independentemente da participação na Pesquisa Cientifica e este fato não influenciará de modo algum no tipo de tratamento ao qual o senhor(a) tem direito. o acompanhamento ambulatorial ocorrerá das maneiras corriqueiras no
Ambulatório de Cirurgia de Cabeça e Pescoço do Hospital das Clinicas da Faculdade de Medicina de Ribeirão Preto, independentemente da participação ou năo na pesquisa.

- uMA Vez PARTICIPANDO do ESTUdo É POSSIVEL DESISTIR?

Sim. Será mantido total sigilo sobre a identidade dos participantes e em qualquer momento os mesmos poderão desistir da participação, e conseqüentemente seus dados não serão utilizados na presente pesquisa, sem quaisquer despesas ou interferência no tratamento da doença deste participante.

Por fim, caso se sinta lesado(a), o(a) senhor(a) tem o direito de solicitar indenizaçăo, conforme legislaçăo vigente, embora não estejam previstas indenizaçōes. Qualquer questionamento a respeito do estudo, antes ou durante a realizaçăo do mesmo, será esclarecido ao participante. Em caso de dúvidas ou problemas com a pesquisa, você pode procurar a pesquisadora responsável Telma Kioko Takeshita, no Ambulatório de Cirurgia Cabeça e Pescoço do Hospital das Clinicas da Faculdade de Medicina da Universidade de São Paulo, pelo telefone (16) 3602-2353.

PARTICIPANTE DA PESQUISA OU RESPONSAVEL

TELMA KIOKO TAKESHITA PESQUISADORA RESPONSAVE 


\section{APÊNDICE B}

\section{PROTOCOLO UTILIZADO PARA SELEÇÃO DOS PARTICIPANTES DA PESQUISA DE ACORDO COM OS CRITÉRIOS DE INCLUSÃO PREVIAMENTE ESTABELECIDOS}

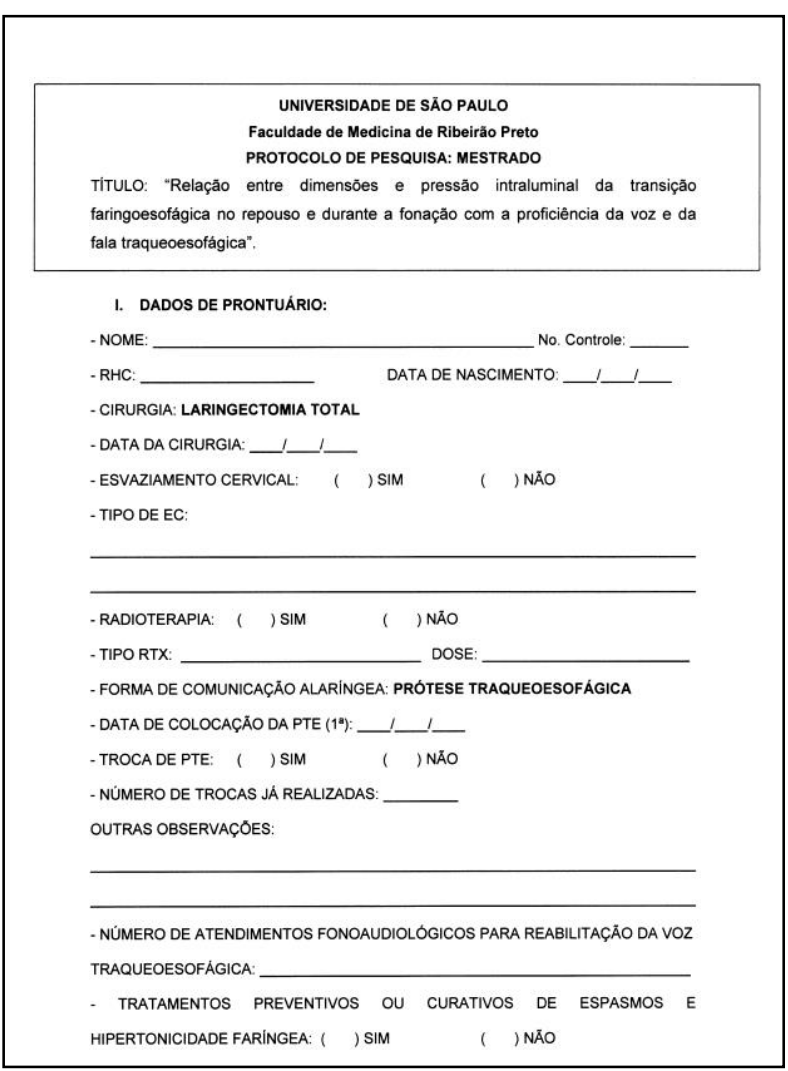

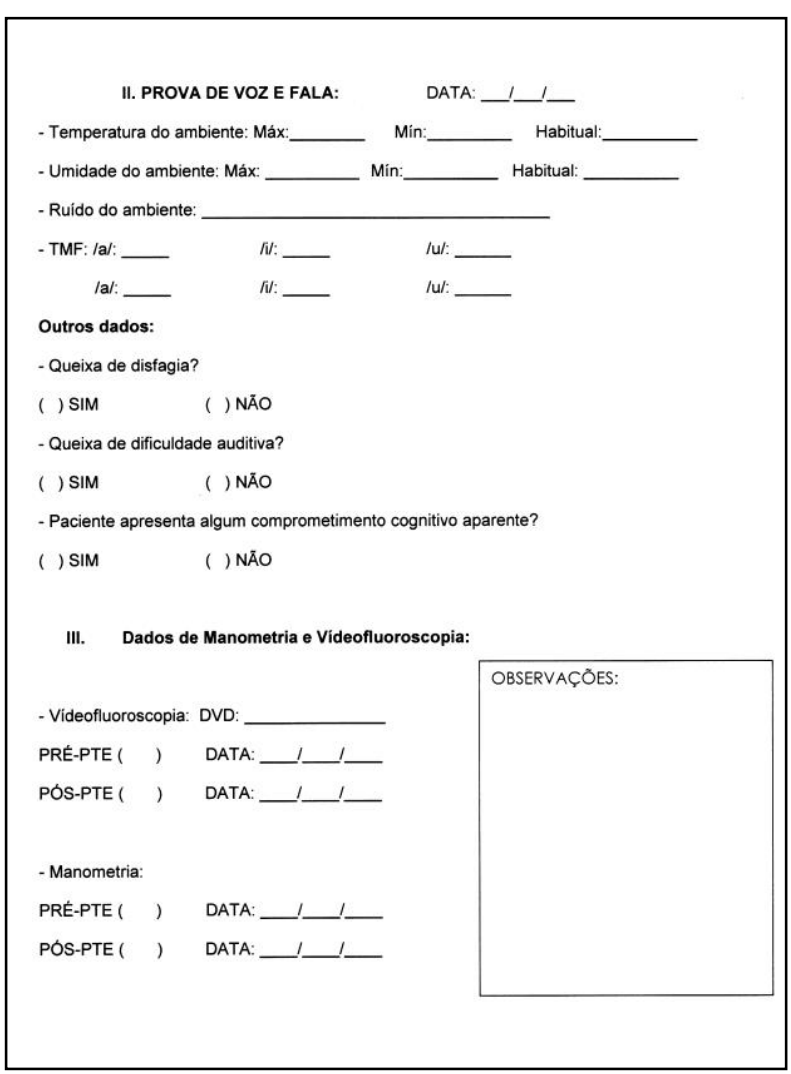




\section{APÊNDICE C}

\section{TERMO DE CONSENTIMENTO LIVRE E ESCLARECIDO UTILIZADO PARA OS EXPERTOS QUE PARTICIPARAM DA AVALIAÇÃO DA VOZ E DA FALA TRAQUEOESOFÁGICA.}
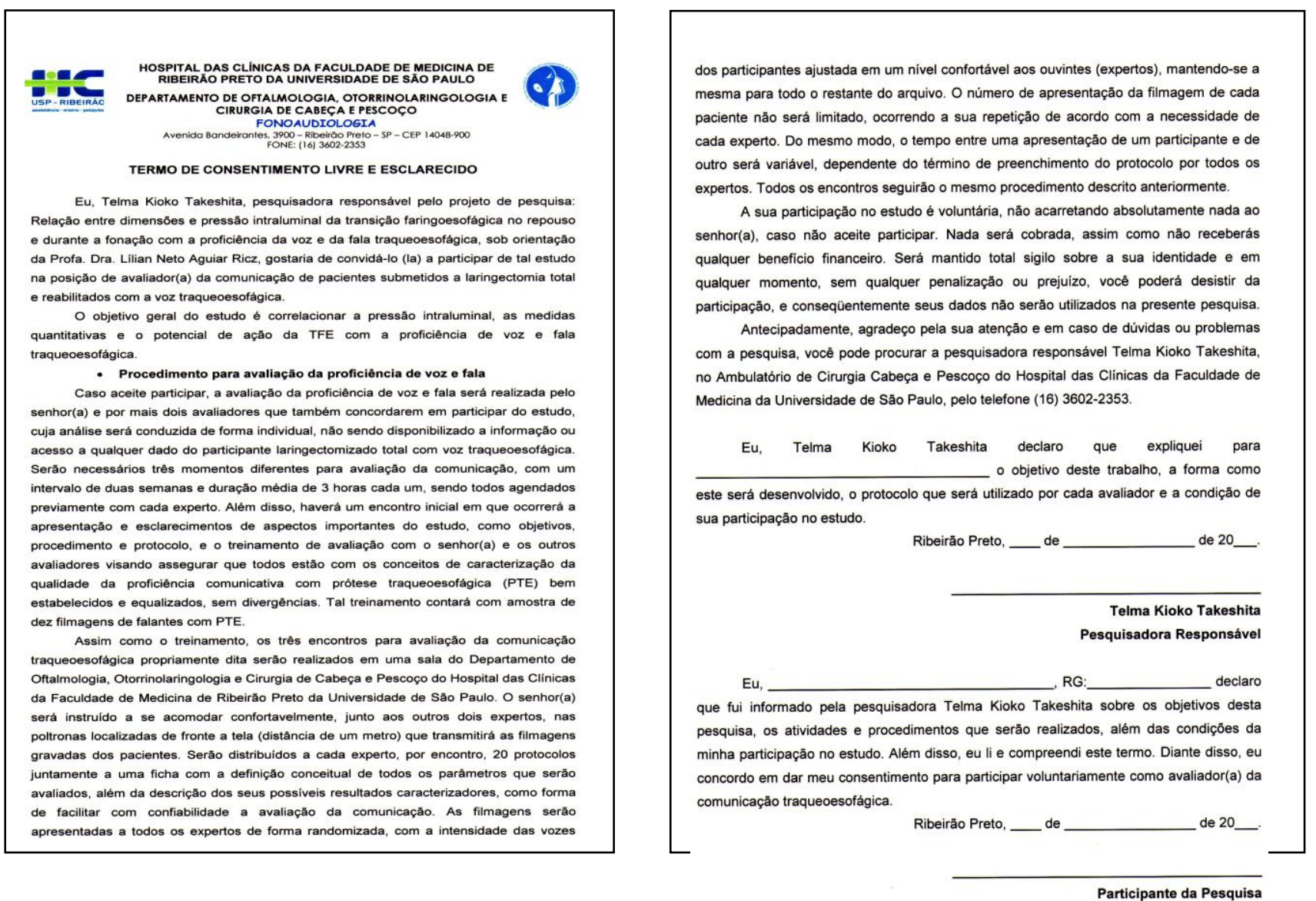


\section{APÊNDICE D}

\section{TERMO DE CONSENTIMENTO LIVRE E ESCLARECIDO UTILIZADO PARA OS EXPERTOS QUE PARTICIPARAM DA AVALIAÇÃO DAS IMAGENS DE VIDEOFLUOROSCOPIA NO REPOUSO E DURANTE A FONAÇÃO.}

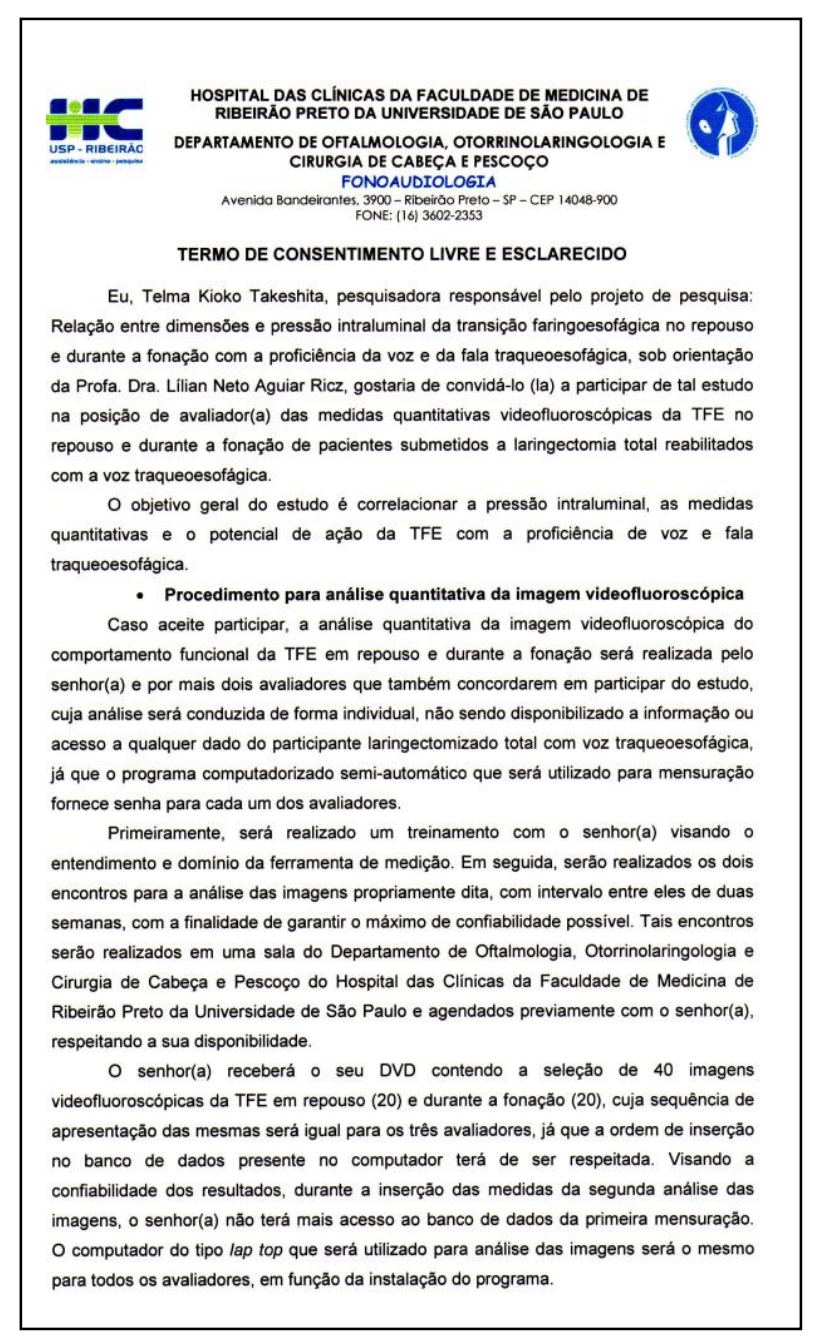

A sua participação no estudo é voluntária, não acarretando absolutamente nada ao senhor(a), caso não aceite participar. Nada será cobrada, assim como não receberás qualquer beneficio financeiro. Será mantido total sigilo sobre a sua identidade e em qualquer momento, sem qualquer penalização ou prejuizo, você poderá desistir da participação, e conseqüentemente seus dados não serão utilizados na presente pesquisa.

Antecipadamente, agradeço pela sua atenção e em caso de dúvidas ou problemas com a pesquisa, você pode procurar a pesquisadora responsável Telma Kioko Takeshita, no Ambulatório de Cirurgia Cabeça e Pescoço do Hospital das Clínicas da Faculdade de Medicina da Universidade de São Paulo, pelo telefone (16) 3602-2353.

Eu, Telma Kioko Takeshita declaro que expliquei para este será desenvolvido, o protocolo que será utilizado por cada avaliador e a condição de sua participação no estudo.

Ribeirão Preto, de de 20

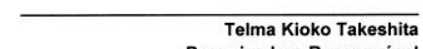
Pesquisadora

Eu, $\begin{gathered}\text { Eu, } \\ \text { declaro que fui informado pela pesquisadora Telma Kioko Takeshita sobre os objetivos }\end{gathered}$ RG: desta pesquisa, os atividades e procedimentos que serão realizados, além das condiçōes da minha participação no estudo. Além disso, eu li e compreendi este termo. Diante disso, eu concordo em dar meu consentimento para participar voluntariamente como avaliador(a) da comunicaçăo traqueoesofágica.

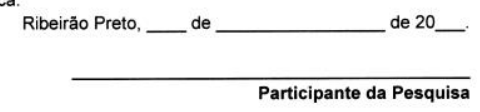


9. ANEXOS 


\section{ANEXO A}

\section{APROVAÇÃO DO COMITÊ DE ÉTICA EM PESQUISA DO HCFMRP-USP}

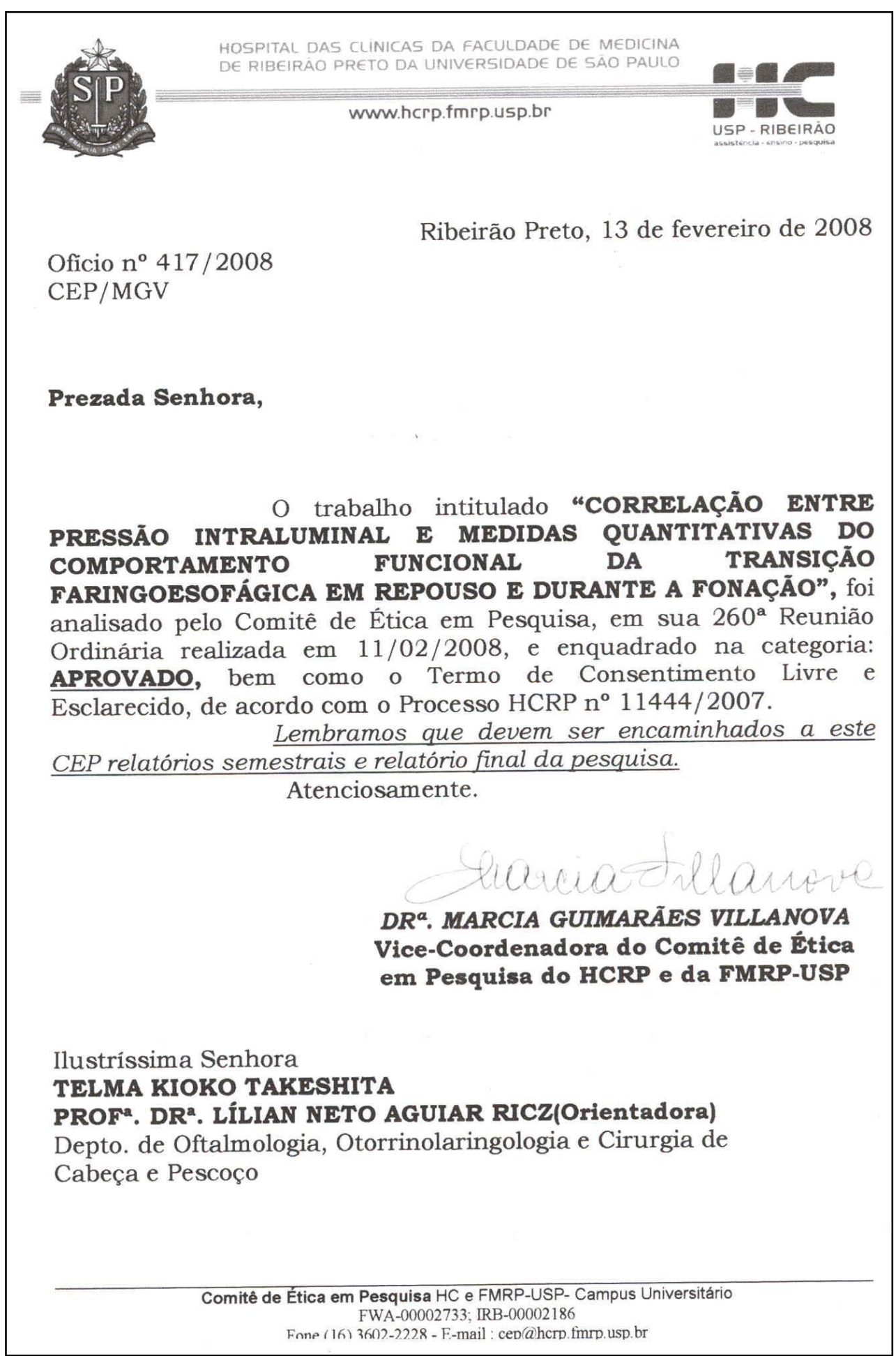




\section{ANEXO B}

\section{PROTOCOLO UTILIZADO PELOS EXPERTOS PARA AVALIAÇÃO DA VOZ E FALA TRAQUEOESOFÁGICA}

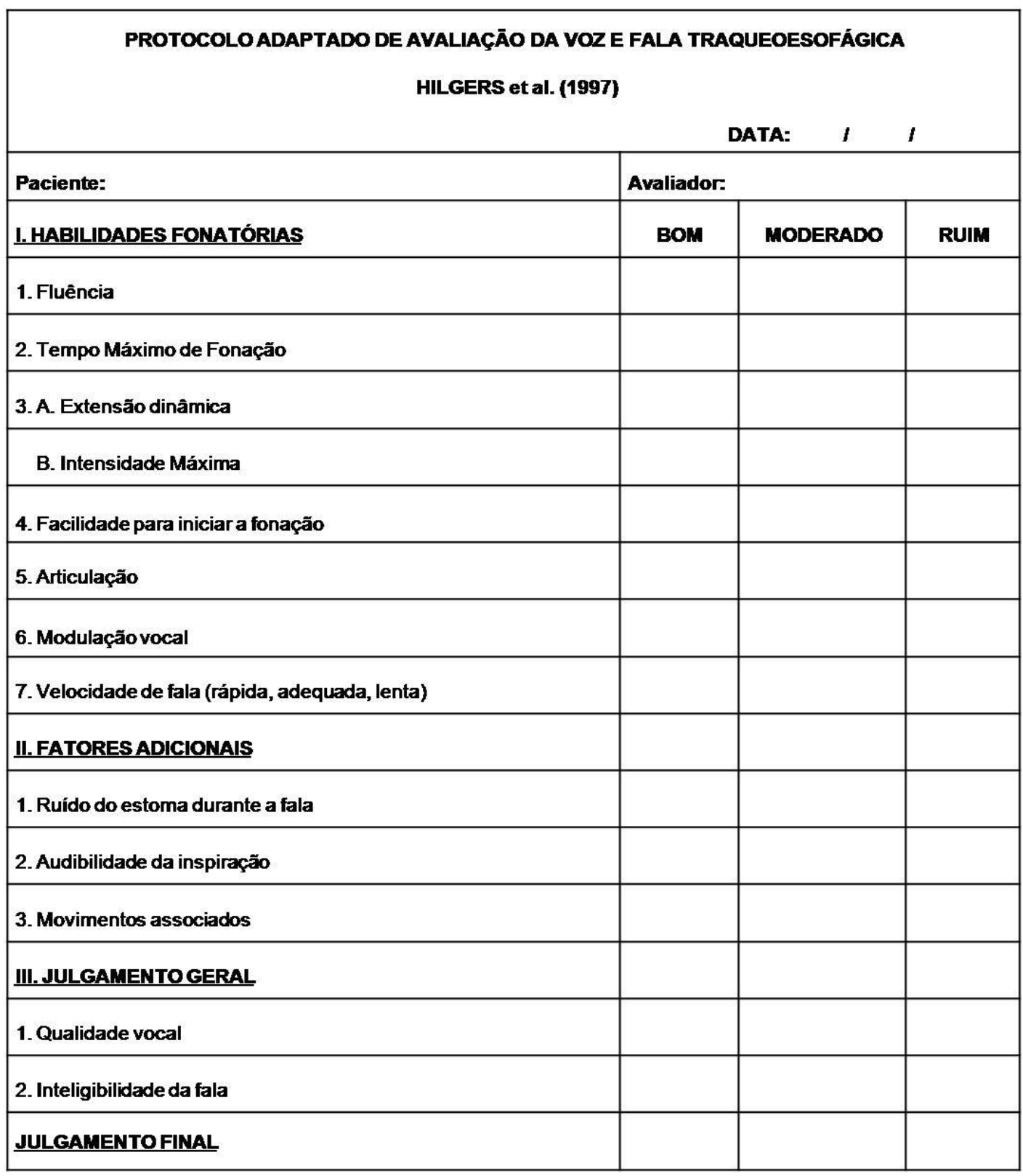




\section{FONTES CONSULTADAS}




\section{FONTES CONSULTADAS}

1. Behlau M, Madazio G, Feijó D, Pontes P. Avaliação de voz. In: Behlau, M. Voz: O livro do especialista I. São Paulo: Revinter; 2001. p. 85- 246.

2. Donner A, Wells G. A comparison of confidence interval methods for the Intraclass Correlation Coefficient. Biometrics. 1986; 42(2): 401-412.

3. Fehring R. The Fehring model. In: Carroll-Johnson, RM. Classification of the nursing diagnosis: proceedins of the tenth conference. Philadelphia: Lippicott; 1994. p. 55-62.

4. Funaro VMBO (coordenador). Diretrizes para apresentação de dissertações e teses da USP: documento eletrônico e impresso. São Paulo: SIBI/USP, 2009.

5. Jesus CAC. Raciocínio clinico de graduandos e enfermeiros na construção de diagnóstico de enfermagem. [tese]. Ribeirão Preto: Universidade de São Paulo, Escola de Enfermagem; 2000.

6. Littell RC, Milliken GA, Stroup WW, Wolfinger RD. SAS System for mixed models. Cary, NC, USA: SAS Institute Inc; 1996. 633p.

7. MCLean RA, Sanders WL, Stroup WW. A Unified Approach to Mixed linear Models. The American Statistician. 1991; 45: 54-64.

8. Pagano M, Gauvreau K. Princípios de Bioestatística. São Paulo: Editora Thomson; 2004. 506p.

9. Rother ET, Braga MER. Como elaborar a sua tese: estrutura e referências. São Paulo: Projeto gráfico e editoração eletrônica Amélia Oraci Gasparini; 2001. 85p.

10. SAS/STAT® User's Guide, Version 9. Cary, NC, USA: SAS Institute Inc; 2002-2003. 
11. Wright RE, Boyd CS, Workman A. Radiation doses to patients during pharyngeal videofluoroscopy. Dysphagia. 1998 Spring; 13(2): 113-5. 